\title{
Tumor-targeted delivery of childhood vaccine recall antigens by attenuated Listeria reduces pancreatic cancer
}

Benson Chellakkan Selvanesan ${ }^{1 \$}$, Dinesh Chandra ${ }^{1 \$}$, Wilber Quispe-Tintaya ${ }^{1 \$}$, Arthee Jahangir $^{1}$, Ankur Patel ${ }^{1}$, Kiran Meena ${ }^{1}$, Rodrigo Alberto Alves Da Silva ${ }^{1}$, Steven K Libutti ${ }^{2}$, Ziqiang Yuan ${ }^{2}$, Jenny $\mathrm{Li}^{1}$, Sarah Siddiqui ${ }^{1}$, Amanda Beck ${ }^{3}$, Lydia Tesfa ${ }^{4}$, Wade Koba $^{5}$, Jennifer Chuy $^{6}$, John C. McAuliffe ${ }^{7}$, Rojin Jafari ${ }^{8}$, David Entenberg ${ }^{8,9,10}$, Yarong Wang $^{8,9,10}$, John Condeelis ${ }^{8,9,10,11}$, and Claudia Gravekamp ${ }^{1^{*}}$.

${ }^{\$}$ These authors contributed equally to this manuscript.

Running title: Cancer treatment through childhood vaccine recall antigens

Department of Microbiology and Immunology, ${ }^{1}$ Albert Einstein College of Medicine, 1300 Morris Park Avenue, Bronx, NY 10461, USA

${ }^{2}$ Rutgers University, Cancer Institute of New Jersey, 195 Little Albany St, New Brunswick, New Jersey 08901, USA

${ }^{3}$ Department of Pathology, Albert Einstein College of Medicine, Michael F. Price Center, 1301 Morris Park Avenue, Room 158, Bronx, NY 10461

${ }^{4}$ Department of Microbiology and Immunology, Albert Einstein College of Medicine, Jack and Pearl Resnick Campus, 1300 Morris Park Avenue, Chanin Building, Room 309, Bronx, NY 10461

${ }^{5}$ Department of Radiology, Albert Einstein College of Medicine, MRRC, 1300 Morris Park Avenue, Bronx, NY 10461, USA

${ }^{6}$ Department of Medical Oncology, Montefiore/Einstein Center for Cancer Care, Department of Medical Oncology, 1695 Eastchester Road, 2nd Floor, Bronx, NY 10461, USA 
${ }^{7}$ Department of Surgery, Montefiore Medical Center, 1521 Jarrett Place, $2^{\text {nd }}$ Floor, Bronx, NY 10461, USA

${ }^{8}$ Department of Anatomy and Structural Biology, Albert Einstein College of Medicine, Michael F. Price Center, 1301 Morris Park Avenue.

${ }^{9}$ Gruss-Lipper Biophotonics Center,Albert Einstein College of Medicine, Michael F. Price Center, 1301 Morris Park Avenue.

${ }^{10}$ Integrated Imaging Program, Albert Einstein College of Medicine, Michael F. Price Center, 1301 Morris Park Avenue.

${ }^{11}$ Department of Surgery,Albert Einstein College of Medicine, Michael F. Price Center, 1301 Morris Park Avenue.

* To whom correspondence should be addressed:

Claudia Gravekamp

Albert Einstein College of Medicine

Department of Microbiology and Immunology

1300 Morris Park Avenue

Forchheimer Bldg., Room 407A

Bronx, NY 10461

Email: claudia.gravekamp@einstein.yu.edu

Phone: 718-430-4048(office)/4067 (lab)/Fax: 718-430-8711 


\section{ABSTRACT}

Pancreatic ductal adenocarcinoma is highly metastatic, poorly immunogenic, and immune suppression prevents $\mathrm{T}$ cell activation. We developed a microbial-based immunotherapeutic concept for selective delivery of a highly immunogenic tetanus toxoid protein $\left(\mathrm{TT}_{856-1313}\right)$ as an alternative for neoantigens, into tumor cells by attenuated Listeria monocytogenes, and reactivation of pre-existing TT-specific memory $\mathrm{T}$ cells (generated during childhood) to kill infected tumor cells. Thus, TT here functions as the tumor antigen. Treatment of KPC mice with Listeria-TT resulted in TT accumulation inside tumor cells, and attraction of the reactivated TT-specific memory CD4 T cells. Gemcitabine (GEM) combined with Listeria-TT significantly improved the migration of CD4 T cells into tumors and the production of perforin and granzyme $\mathrm{B}$, turning cold into immunological hot tumors. The number of CD8 T cells in the KPC tumors was 3-fold lower than that of CD4 T cells. Moreover, lymph node like structures (LNS) were observed in close contact with the pancreatic tumors exhibiting CD4 T cells (and less abundantly CD8 T cells) of all treatment groups, but most frequently in KPC mice treated with Listeria-TT or Listeria-TT+GEM. Notably, the production of granzyme B (and less of perforin) was observed in the LNS of Listeria-TT+GEM only. The Listeria-TT+GEM treatment significantly reduced pancreatic tumors and metastases by $80 \%$ in Panc-02 and KPC mouse models, with minimal side effects. Our results unveil new mechanisms of Listeria and GEM improving immunotherapy for PDAC.

Keywords: Listeria monocytogenes, childhood vaccine recall antigens, Tetanus toxoid, pancreatic cancer, pre-existing memory $\mathrm{T}$ cells 


\section{INTRODUCTION}

Pancreatic ductal adenocarcinoma (PDAC) is extremely difficult to cure. Modern systemic therapies, such as gemcitabine, provide some survival benefits ${ }^{1-4}$, while gemcitabine and abraxane or FOLFIRINOX further modestly improve survival ${ }^{5,6}$. This underscores the need for additional and innovative approaches. Cancer immunotherapy with checkpoint inhibitors has shown promising results, however, less so for PDAC $^{7}$. PDAC is poorly immunogenic because of the low mutational load and the few effective neoantigens present ${ }^{8,9}$, and because immune suppression, particularly by myeloidderived suppressor cells (MDSC) and tumor-associated macrophages (TAM), prevents T cell activation in the tumor microenvironment $(\mathrm{TME})^{10-12}$. Moreover, evidence suggests that naïve T cells are more prone to undergo apoptosis or are less efficiently activated than memory T cells in the TME of cancer patients and tumor-bearing mice ${ }^{13,14}$.

To address these problems we have developed a novel treatment modality using an attenuated bacterium Listeria monocytogenes ${ }^{15}$ (Listeria) to deliver a highly immunogenic recall antigen such as tetanus toxoid (TT)(as an alternative to neoantigens) selectively into tumor cells, and to reactivate pre-existing memory $\mathrm{T}$ cells against TT (generated during childhood vaccinations) (Fig. 1A). These TT-specific memory cells are in turn attracted to the Listeria-TT in the TME, where they destroy the infected now highly immunogenic tumor cells. These memory $T$ cells circulate in the blood for life, and can be reactivated at any age. This has been shown even in patients with cancer, including pancreatic cancer ${ }^{16-18}$. Such an approach overcomes the need for participation of naïve $\mathrm{T}$ cells during cancer treatment. To further improve $\mathrm{T}$ cell responses against TT, Listeria-TT was combined with low doses of gemcitabine (GEM) to reduce immune suppressive MDSC and TAM populations.

In previous studies we have shown that, most likely through C3bi and C1q receptors $^{19-21}$, Listeria attracts and infects MDSC $^{10}$. These MDSC are present in large 
numbers in patients and mice with cancer ${ }^{11,22}$. However, the primary tumor also selectively attracts MDSC through the production of cytokines and factors ${ }^{11,23}$, where MDSC deliver Listeria to the TME as a Trojan horse ${ }^{10,22}$. Once at the tumor site, Listeria spreads from MDSC into tumor cells through a cell-to-cell mechanism unique to Listeria $^{24}$. Listeria can also infect tumor cells directly ${ }^{25}$. Listeria would be rapidly killed in healthy tissues, but is protected from immune clearance in the TME through strong immune suppression. Because of this combination of selective attraction of MDSC by bacteria and cancer with the strong immune suppression occurring in the TME but not in normal tissues, Listeria can selectively enter, multiply, and survive in the TME but not in normal tissues ${ }^{10,22,26,27}$. Based on these results we now use Listeria as a platform for the selective delivery of anticancer agents to the $\mathrm{TME}^{22,26,28}$. Of note is that this approach is completely different from the clinical trials, in which Listeria has been used to infect antigen-presenting cells to stimulate $\mathrm{T}$ cells against naturally expressed tumor antigens $^{29}$, while in our approach Listeria colonizes and changes the tumor microenvironment, and delivers childhood vaccine recall antigens into tumor cells.

In the current study, we tested the combination of Listeria-TT+GEM (Fig. 1B) in two mouse models of pancreatic cancer, a syngeneic Panc-02 model ${ }^{30}$ and a transgenic KPC model ${ }^{31,32}$. Listeria-TT was administered intraperitoneally, and the biodistribution of Listeria-TT, as well as the production of TT in tumor cells was monitored in vivo. We demonstrate that the combination of Listeria-TT+GEM robustly attracted CD4 T cells to the TME, and improved $\mathrm{T}$ cell responses in correlation with a significant reduction in pancreatic cancer at early and advanced stages of both Panc-02 and KPC mouse models. This study provides insight into mechanisms of improving immunotherapy for pancreatic cancer. 


\section{RESULTS}

\section{Development and characterization of Listeria-TT}

The Listeria construct used to develop Listeria-TT includes pGG34 ${ }^{33}$, a truncated non-cytolytic Listeriolysin $\mathrm{O}$ (LLO) fused to a non-toxic $\mathrm{TT}_{856-1313}$ fragment, and a myc sequence for detection as outlined in Fig. 2A. Secretion of LLO-TT ${ }_{856-1313}$ protein into the culture medium by the bacteria was detected by western blotting (Fig. 2B). Infection of Panc-02 tumor cells with Listeria- $\mathrm{TT}_{856-1313}$ resulted in the expression of TT protein in the tumor cells (Fig. 2C).

\section{Listeria-TT infection of tumor cells in vitro and in vivo}

We previously showed that Listeria can be used as a delivery platform for anticancer agents $^{22,26}$, however TT fusion to LLO could potentially alter LLO function (LLO is required to escape the vacuole after phagocytosis ${ }^{34}$ ). To test Listeria-TT delivery function, we determined the infection rate of pancreatic tumor cells cultured with ListeriaTT in comparison to Listeria alone. Panc-02 tumor cells were abundantly infected in both cases (Fig. 2D). We also determined that Listeria-TT effectively killed the Panc-02 cells (Fig. 2E).

TT is highly immunogenic, and might lead to faster elimination of Listeria-TT in vivo than Listeria alone, consequently preventing accumulation in the TME. To assess this, a single high dose of Listeria-TT was injected intraperitoneally (ip) into Panc-02 mice, and numbers of Listeria-TT were quantified in all tissues (tumors, metastases, and normal tissues) at different time points. As shown in Fig. 2F, Listeria-TT accumulated robustly in tumors and metastases, but could hardly be detected in normal tissues. Interestingly, the same dose of Listeria injected intravenously was nearly undetectable in tumors and metastases (Fig. S1A and B). This was true not only for metastases in the liver and pancreas, but also for metastases in the lungs (Fig. S1C). 
To confirm that Listeria-TT was taken up in vivo by tumor cells within the TME of live mice, we injected Alexa-680-labeled Listeria-TT into the peritoneal cavity of transgenic mice whose macrophages expressed cyan fluorescent protein (CFP) ${ }^{35}$, and which had orthotopic, Dendra-2 labeled pancreatic tumors (Panc-02-Dendra). High-resolution intravital multiphoton microscopy (IVMI) of these tumors showed individual Listeria-TT bacteria inside tumor cells and macrophages (Fig. 2G). Finally, presence of TT protein was demonstrated immunohistochemically inside tumor cells of the pancreatic ducts, and secreted in the TME of KPC mice that received Listeria-TT or Listeria-TT+GEM (Fig. 2H). Notably, detection of TT was much stronger in the tumors of Listeria-TT+GEMtreated mice than of Listeria-TT-treated mice. While GEM kills Listeria in vitro, more Listeria bacteria were detected in the tumors of Listeria+GEM-treated mice compared to Listeria alone (Fig. 2I and J). Since GEM reduces immune suppression, the extracellular Listeria will be more exposed to immune clearance which may drive Listeria to a safer place to escape GEM and the immune system, i.e. to the TME and inside tumor cells were Listeria could survive and multiply.

\section{Listeria-TT reactivates memory $\mathrm{T}$ cells to TT in tumor-bearing mice}

Our concept is to generate pre-existing memory T cells specific for TT prior to tumor development, to avoid the necessity of activating naïve T cells in a TME. Therefore, we generated TT-specific memory CD4 and CD8 T cells in mice through two injections of Tetanus vaccine (TTvac) prior to tumor development (Fig. 3A). One week after the second immunization, Panc-02 tumor cells were injected into the mammary fat pad. When tumors were $10 \mathrm{~mm}$ in diameter, the Listeria TT+GEM treatment was initiated as in Fig. 1B. After the complete treatment cycle, spleen cells were isolated from the Panc02 tumor-bearing mice, restimulated with TT protein in vitro, and analyzed for memory T cell responses producing IFNy (Fig. 3B). We found that CD4 and CD8 T cells of mice 
that received Listeria -TT or Listeria -TT+GEM were strongly activated by TT, but not of mice that received saline or GEM alone (Mann-Whitney $p<0.05$ and $p<0.001$ ), indicating the high specificity of CD4 and CD8 memory T cells responsive to the TT protein. Similar results were obtained for memory cells isolated from tumors in KPC mice (Fig. 3C).

To evaluate whether Listeria-TT+GEM could overcome immune suppression in the tumor-bearing Panc-02 mice, we also analyzed "in vivo" T cell responses, i.e., without in vitro restimulation with TT. At the end of the treatment cycle, CD4 and CD8 T cell responses (CD69, Granzyme B, Perforin, and IFNy) were strongly improved in spleen cell populations (pooled) of mice treated with Listeria-TT+GEM compared to all control groups (Table 1A, Fig. S2A and B). Both CD4 and CD8 T cells produced high levels of granzyme B, perforin, and/or IFNy. These responses were even stronger for CD4 T cells than for CD8 T cells. Moreover, Listeria-TT or GEM alone also increased the production of perforin in CD4 and CD8 T cells compared to the saline treatments. Similar results were found in KPC mice, i.e., Listeria-TT+GEM improved T cell responses compared to all other groups (Table 1B). In sum, therefore, the analysis showed that $\mathrm{T}$ cells were activated by TT, Listeria, and GEM in the tumor-bearing mice.

\section{Listeria-TT+GEM turns "cold" tumors into immunological "hot" tumors}

To confirm that Listeria-TT+GEM was able to overcome immune suppression in the TME, we performed RNAseq analyses of pancreatic tumors from KPC mice that had been treated with Listeria-TT+GEM, or untreated. As shown in Fig. 3D, CD4 and CD8 T cells were strongly represented in the tumors of Listeria-TT+GEM-treated KPC mice but not in the untreated group. Moreover, multiple granzymes as well as perforin were highly expressed in the Listeria-TT+GEM-treated mice, as were factors involved in tumor cell 
apoptotic pathways, including multiple caspases, TNF and Fas, most likely activated by perforin and granzyme B.

We also analyzed whether T cells in orthotopic Panc-02 tumors, of mice treated with Listeria-TT or Listeria-TT+GEM were specific for TT, by ELISPOT (Fig. 2K) and flow cytometry (Fig. 2L). The numbers of TT-specific T cells producing IFN $\gamma$ were 10 -fold higher in the tumors of Listeria-TT-treated mice compared to the saline or GEM control groups, and 3 times higher than Listeria-TT+GEM (Fig. 2L).

Based on the fact that Listeria causes TT accumulation in the TME (Fig. 2H) and TTspecific memory $\mathrm{T}$ cells have been generated (Fig. 3A-C), we expect these memory $\mathrm{T}$ cells to be attracted to the TME. To visualize the TME and T cells in more detail, the $\mathrm{KPC}$ tumors were analyzed by immunohistochemistry (IHC). As shown in Fig. 4A and E, CD4 T cells were present in the tumors of KPC mice treated with LM-TT, but hardly at all in the tumors of saline- or GEM-treated mice. More detail about the CD4 T cells in the KPC tumors of all four treatment groups is shown in Fig. S3A-D. Most remarkable was that addition of GEM to the Listeria-TT treatment significantly enhanced the migration of CD4 T cells to the tumors of KPC mice compared to all other groups, even compared to the Listeria-TT group. These CD4 T cells were found in the tumor areas that expressed TT protein and CD31-positive vessels (Fig. S4A-C). Of note is, that CD8 T cells were sparsely present in the tumor areas (Fig. S3E-H).

Notably, lymph node-like structures (LNS) were frequently observed in close contact with the KPC tumors of mice treated with Listeria-TT or Listeria-TT+GEM, and less frequently in KPC mice treated with saline or GEM (Fig. 4A). Higher magnification images of a LNS are shown in Fig. S4D. To determine whether T cells present in the LNS were functional and exhibited memory phenotype, we isolated the CD45+ lymphocytes (81.2\%) from the LNS of Listeria-TT-treated mice, and then gated the CD4 (40.4\%) or CD8 (52.0\%) T cells by flow cytometry, followed by gating of the IFN $\gamma+$ CD4 
(3.28\%) or CD8 (2.91\%) T cells (Fig. 4B). Within these IFN $\gamma+$ CD4 and IFN $\gamma+$ CD8 T cell populations, $54 \%$ and 55\%, respectively, exhibited a memory phenotype (CD44+CD62L-).

Of clinical relevance is that perforin and granzyme $B$, both involved in $T$ cellmediated tumor cell cytolysis, were detected in both pancreatic tumors and LNS of Listeria-TT+GEM-treated mice, and less abundantly in Listeria-TT-treated mice, but not at all in tumors or LNS of saline or GEM-treated mice (Fig 4C,D and E, Fig. S4E). We observed that perforin was less abundantly produced than granzyme B in general. Also, L-selectin as well as $\mathrm{Cxc} 3$ and chemokines $\mathrm{Cxcl} 9$ and $\mathrm{Cxcl} 10$ were highly upregulated in KPC tumors of mice treated with Listeria-TT+GEM compared to untreated mice (Fig. S5A). These genes are known to be involved in T cell trafficking ${ }^{36,37}$. Also, CD40 and CD40L was highly upregulated in KPC tumors by Listeria-TT+GEM (Fig. S5A). It has been reported that CD40 engagement activates $\mathrm{T}$ cells and correlates with antitumor activity $^{38}$. Together, the results indicated that Listeria-TT+GEM treatment altered "cold" tumors to "hot" tumors, promoting a strong influx of CD4 T cells into the KPC tumors, as well as production of perforin and granzyme B. These results are supported by the RNAseq data as discussed above, showing that immune responses in the KPC tumors were strongly activated by Listeria-TT+GEM (Fig. 3D).

\section{Listeria-TT and GEM alter the TME}

In Panc-02 tumor bearing mice, GEM reduced the blood MDSC population by 80$90 \%$, and in primary tumors by $50 \%$, compared to the saline group (Fig. $3 E$ ), and the TAM population by $67 \%$ in primary tumors compared to the saline group (Fig. 3E). Moreover, for the residual MDSC and TAM cells, the production in pancreatic metastases of factors involved in immune suppression, including IL-10, IL-6 and the transcription factor MARCO, was reduced in mice treated with Listeria-TT+GEM (Table 
1CD, Fig. S6AB), while there was increased production by these cells of TNFa, involved in tumor cell killing, and expression of CD80, involved in T cell activation. These findings indicated that Listeria TT+GEM altered the TME.

\section{Listeria-TT+GEM reduces advanced and early pancreatic cancer in KPC and Panc- 02 mice}

We evaluated Listeria-TT+GEM treatment of 3.5-5 months old KPC mice with advanced pancreatic cancer by PET scan analysis. SUVmax, a measure of the metabolic activity of tumors and metastases, provided an indicator of tumor growth. Significant reductions in SUVmax for PDAC tumors from 1.9 to 0.4 , and for liver metastases from 2.1 to 0.3 , were observed in the mice receiving Listeria TT+GEM treatment (Fig. 5A). The PDAC tumors were reduced by $80 \%(p<0.01)$ and the liver metastases by $87 \%(p<0.01)$. Small changes in the SUVmax of tumors and metastases in the saline and GEM control groups were not statistically significant, nor was the $50 \%$ decrease in the LM-TT group (Fig. 5A). A representative example of a pancreatic KPC tumor in each group is shown in Fig 5B.

We also tested Listeria-TT+GEM therapeutically in Panc-02 mice with early and advanced pancreatic cancer. We found nearly complete elimination of early stage pancreatic cancer (Fig. S5B and E), and a significant reduction in primary $(85 \%$; $p<0.001)$ and metastatic tumor burdens $(89 \% ; p<0.0001)$ of advanced pancreatic cancer (Fig. S5Cfor mice treated as outlined in Fig. 1B, compared to the saline group (Fig. S5C and F).

Finally, we tested Listeria-TT+GEM in mice with advanced orthotopically generated Panc-02 tumors and metastases. Fourteen days after injection of Panc-02 tumor cells into the pancreas, when tumors and metastases were developed, treatment with Listeria-TT+GEM and control groups were started as in Fig. 1B and continued for two 
weeks. Two days after the last treatment, mice were euthanized and analyzed for tumor weight and number of metastases. A significant reduction was observed in the weight of the primary tumors $(68 \% ; p<0.05)$ and in the number of liver metastases $(95 \% ; p<0.01)$ compared to the saline group (Fig S5D and G).

\section{TT contributes to eradication of pancreatic cancer}

An important question is to what extent TT contributes to eradication of the pancreatic cancer. This question has been analyzed from different angels. First, we compared the effect of Listeria-TT with Listeria on advanced pancreatic cancer in different mouse tumor models (Panc-02 and KPC). Those mice that received Listeria-TT also received the TT vaccine prior tumor development (according Fig. 1B). As shown in Fig 5C, the number of metastases in Listeria-TT-treated mice was significantly lower compared to the number of metastases in mice treated with Listeria alone $(p<0.05)$. Also the tumor weight of Listeria-TT-treated mice was significantly lower than of Listeriatreated mice $(p<0.05)$, although this was less robust. A similar trend was observed in the transgenic KPC mice. Listeria-TT robustly reduced the SUVmax of tumors and metastases (50\%) while hardly an effect was observed by Listeria alone (Fig 5D).

Second, we evaluated the importance of the TTvac, administered prior tumor development, in efficacy (effect on tumors and metastases), and compared the effect of TT vaccinations followed by Listeria-TT to Listeria-TT without prior TT vaccinations in the Panc-02 model. As shown in Fig 5E, the number of metastases and tumor weight was significantly less in the TTVac+Listeria-TT-treated mice compared to the mice treated with Listeria-TT alone $(\mathrm{p}<0.05)$. 


\section{Safety of Listeria-TT}

A dose-limiting toxicity study (DLT) for Listeria-TT showed that the $\mathrm{LD}_{50}$ of ListeriaTT was $2 \times 10^{8} \mathrm{CFU}$ (Fig. S5H). Our treatment studies used a dosage of $10^{7} \mathrm{CFU}$ of Listeria-TT, well below the $\mathrm{LD}_{50}$.

We also analyzed potential toxicity by pathological examination, 2 days after treatment of C57BI6 mice with Listeria-TT+GEM. Though a mild increase in leukocytes was observed in the spleen, liver, and lungs, no significant pathological effects of Listeria-TT+GEM were observed. (Table S1). In addition, we compared liver functions of the treated $\mathrm{C} 57 \mathrm{BI} / 6$ mice. A small increase in the aminotransferase (AST) level was observed in plasma from Listeria-TT+GEM-treated mice compared to the saline group, while alanine aminotransferase (ALT) levels were similar between the two groups (Table S2).

\section{DISCUSSION}

The success of cancer immunotherapies such as checkpoint inhibitors and CAR T cells in PDAC has been underwhelming, due to low immunogenicity of the tumor, strong immune suppression at multiple levels, and inefficient activation of naïve $T$ cells in the $\mathrm{TME}^{8,9,11-14}$. Moreover, low neoantigen expression levels result in poor attraction of

neoantigen-specific $\mathrm{T}$ cells ${ }^{39,40}$. In this study, we demonstrated the effectiveness of a tumor-targeting attenuated Listeria, in combination with GEM, in treating animal models of early and advanced pancreatic cancer. Our treatment strategy offers the advantages of selective delivery of immunogenic TT protein, at high concentrations, to the TME and into tumor cells, and altering the function of macrophages and MDSC in the TME in favor of immune stimulation. TT now used as tumor antigen, could be an alternative for those patients that lack neoantigen expression. Moreover, we showed the contribution of TT to 
eradicating pancreatic cancer from different angels, i.e. Listeria-TT was significantly more effective than Listeria alone, and omitting the TT vaccine prior Listeria-TT treatments resulted in a significant less effect on metastases and tumors compared to TTvac+Listeria-TT, although the effect on tumors was less robust.

We found novel effects of GEM, i.e. GEM significantly improved the migration of CD4 T cells to the KPC tumor, when added to the Listeria-TT treatment, which may have been the result of more Listeria-TT bacteria in the tumors and thus more TT protein in the tumors of mice treated with Listeria-TT+GEM compared to Listeria-TT alone. Also, GEM reduced the MDSC population which down regulates L-selectin on T cells, a gene involved in T cell trafficking. L-selectin was strongly upregulated in tumors of KPC mice treated with Listeria-TT+GEM.

While ELISPOT data both showed that both CD4 and CD8 T cells were activated by $\mathrm{TT}$ in vitro, in the tumors of KPC mice treated with Listeria-TT+GEM CD4 T cells were predominantly detected by IHC. Also, the LNS contained both CD4 and CD8 T cells, but apparently only the CD4 T cells were abundantly detected in the tumor areas. The TT vaccine is considered as an exogenous protein, activating MHC class I CD4 T cells, while Listeria-TT secretes TT inside and outside cells, and is therefore considered as endogenous and exogenous proteins, activating class I and II CD8 and CD4 T cells, respectively. Indeed, in humans the TT vaccine predominantly activated CD4 T cells.

A notable finding was the appearance of well-developed LNS in close contact with the tumors in KPC mice treated with Listeria-TT or Listeria-TT+GEM. While it is unclear whether or not these may have been the source of $\mathrm{T}$ cells trafficking to the tumors, perforin and granzyme B were detected in both LNS and tumors of Listeria-TT+GEMand Listeria-TT-treated mice. The Cxcr3 receptor and chemokines Cxcl9 and Cxcl10 (interacts with Cxcr3) were also highly upregulated by Listeria-TT+GEM in KPC tumors, 
possibly participating in T cell trafficking to the KPC tumors. Detailed studies will be required to identify the pathways of $\mathrm{T}$ cell migration into these tumors.

Tertiary lymph node structures in proximity to pancreatic tumors have been correlated with increased patient survival in $\mathrm{PDAC}^{42}$. Conversely, tumor draining lymph nodes were found to correlate with immune suppression, a more metastatic character, and poor outcome in PDAC patients ${ }^{43}$. Our study showed that Listeria-TT+GEM overcame immune suppression in the TME, as demonstrated by the RNAseq data and $\mathrm{IHC}$ of the KPC tumors and the functional T cells in the LNS and tumor areas producing perforin, granzyme, and IFN $\gamma$, and this correlated with a strong decrease in the number of metastases and tumor growth in mice.

Listeria-based immunotherapies for pancreatic cancer have also been reported by others. KPC mice in the early stage of PDAC that were immunized with Listeria $\triangle \mathrm{ActA}$ $\Delta$ InIB (LADD) engineered to express the Kras12GD mutation, combined with anti-CD25 Abs and cyclophosphamide, demonstrated delayed PanIN progression and moderately but significantly improved survival ${ }^{44}$. In another interesting study using the flank model, 4T1 and CT26 mice were immunized with LADD expressing $A H 1$, also expressed by the tumors. This stimulated migration of tumor-specific CD8 T cells into tumors, reducing Tregs and converting M2 macrophages to $\mathrm{M}^{45}$. In addition, mouse models of cervical, breast, and skin cancer have been successfully treated with Listeria expressing E7, Her2/neu, Flk-1, CD105, Mage-b, ISG15, and HMW-MAA ${ }^{46}$.

Listeria has also been tested in clinical trials in patients with various cancers, including pancreatic cancer, showing safety and tumor-specific $\mathrm{T}$ cell responses, however, modestly improved survival (for a review see Forbes et al) ${ }^{29}$. As mentioned earlier, the concept of Listeria in clinical trials is completely different from our concept. Listeria used in the clinical trials is based on a "classical concept", i.e. the delivery of tumor-specific antigens into dendritic cells to stimulate naïve and memory $T$ cells to 
these antigens which are naturally expressed by the tumors, while our concept is based on colonizing and changing the TME by Listeria, and delivery of a highly immunogenic childhood vaccine antigen TT into tumor cells by Listeria, and reactivating pre-existing memory T cells to TT. This "classical concept" in clinical trials is partly the result of altering the Listeria (deletion of $A c t A$ and $I n I B$ ) to improve safety and consequently cannot spread and/or multiply in vivo, and partly the result of administering Listeria intravenously (iv). We administer the Listeria in our mouse models intraperitoneally (ip). As demonstrated in this study, Listeria administered iv hardly reach tumors and metastases (pancreatic and breast cancer), but when administered ip Listeria colonizes the TME abundantly, delivers antigens in high concentration to the TME and inside tumor cells, and infects/alters MDSC and TAM. In multiple biodistribution studies in mice with pancreatic and breast cancer we found that Listeria was rapidly eliminated most likely by the immune system in blood ${ }^{10,22,26}$, because the blood lacks immune suppression, while the TME is heavily immune suppressed.

Elderly cancer patients react less efficiently to vaccines than young adults ${ }^{47,48}$, which is also true for cancer immunotherapy ${ }^{49,50}$, mainly due to lack of naïve $T$ cells later in life $^{51}$. We believe that our approach of reactivating memory $T$ cells generated during childhood overcomes the need for naïve $T$ cells, potentially making this therapeutic strategy more effective for older patients. This may lead to new treatment modalities against pancreatic cancer where other types of therapies fail.

\section{MATERIALS AND METHODS}

\section{Animal care}

C57BL/6 male and female mice aged 3 months were obtained from Charles River. KPC mice ${ }^{31}$ were generated in the laboratories of Drs. Gravekamp and Libutti, as described 
previously $^{26}$. C57BI/6N-Tg(Cfms-gal4-vp16)-(UAS-eCFP) ${ }^{35}$ were maintained in the laboratory of Dr. Condeelis. All mice were housed in the animal husbandry facility at Albert Einstein College of Medicine according to the Association and Accreditation of Laboratory Animal Care guidelines, and kept under BSL-2 conditions as required for Listeria treatments. All KPC mice were genotyped by Transnetyx (Cordova, TN).

\section{Cell lines}

The Panc-02 cell line with the Kras-G12D mutant allele was derived from a methylcholanthrene-induced ductal adenocarcinoma growing in a C57BL/6 female mouse ${ }^{52}$. Panc-02 cells were cultured in McCoy's5A medium supplemented with $10 \%$ fetal bovine serum, $2 \mathrm{mM}$ glutamine, non-essential amino acids, $1 \mathrm{mM}$ sodium pyruvate, and $100 \mathrm{U} / \mathrm{ml}$ Pen/Strep. The Panc-02 cell line expressing Dendra-2 was developed in the laboratory of Dr. Gravekamp. Briefly, Panc-02 cells were transfected with pDendra2C (ClonTech), and positive cells were selected using neomycin and FACS sorting. The 4T1 cell line was derived from a spontaneous mammary carcinoma in a $B A L B / c$ mouse ${ }^{53}$. Various $4 \mathrm{~T} 1$ sub lines have been generated with different patterns of metastases ${ }^{54}$, which is kindly provided to our lab by Dr. Fred Miller, Karmanos Institute, Wayne State University, Michigan, MI). The 4T1 cell line used in this study is highly aggressive, metastasizing predominantly to the mesenteric lymph nodes (MLN), and less frequently to the diaphragm, portal liver, spleen and kidneys (Gravekamp et al, 2008).

\section{Listeria and Listeria-TT}

In this study, an attenuated Listeria monocytogenes (Listeria) was used as the vehicle for delivery of $\mathrm{TT}_{856-1313}{ }^{55}$ to the TME and inside tumor cells. The Listeria plasmid pGG-34, expressing the non-cytolytic truncated form of Listeriolysin O (LLO) under control of the 
hemolysin promoter (Phly) and the positive regulatory factor A (prfA), with mutations to further reduce pathogenicity, have been described elsewhere ${ }^{33}$. Listeria-TT $_{856-1313}$ was developed in our laboratory (Fig. 2A). Briefly, $\mathrm{TT}_{856-1313^{55}}$ was cloned by PCR into pCR2.1 using primers containing $\mathrm{XHol}$ and $\mathrm{XMal}$ restriction sites and a myc Tag for detection of TT. (PrF5': CTC GAG TCA ACA CCA ATT CCA TTT; PrR5': CCC GGG TTA TAG ATC TTC TTC TGA AAT TAG TTT TTG TTC TGT CCA TCC TTC ATC TGT) Subsequently the pCR2.1-XHol-TT ${ }_{856-1313}-\mathrm{Myc}-\mathrm{Xmal}_{\text {and }} \mathrm{pGG} 34$ plasmids were digested

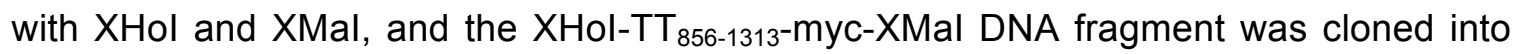
the pGG34 vector, and then electroporated into the Listeria background strain XFL7 ${ }^{33}$. The Listeria- $\mathrm{TT}_{856-1313}$ was characterized by DNA sequencing and by evaluating the secretion of $\mathrm{TT}_{856-1313}$ into the culture medium (Fig. 2A). The $\mathrm{TT}_{856-1313}$ fragment contains both mouse and human immunodominant T cell epitopes ${ }^{41,56}$.

\section{Infection of tumor cells in vitro}

The in vitro infectivity of Panc-02 tumor cells was assessed as described previously ${ }^{25}$. Briefly, $10^{6}$ cells $/ \mathrm{ml}$ were infected with $10^{7} \mathrm{CFU}$ of Listeria or Listeria -TT for $1 \mathrm{hr}$ at $37^{\circ} \mathrm{C}$ in culture medium, then incubated with gentamicin $(50 \mu \mathrm{g} / \mathrm{ml})$ for $1 \mathrm{hr}$ to kill extracellular Listeria. Finally, cells were washed with phosphate-buffered saline (PBS), lysed in water, and serial dilutions were plated onto LB agar to quantify the infection rate the next day.

\section{Evaluation of cell death}

As described previously ${ }^{25}$, tumor cell killing by Listeria or Listeria-TT was determined in vitro as follows. Panc-02 cells $\left(3 \times 10^{3}\right)$ plated in 96 well plates were infected with $10^{7}$ CFU/well of Listeria or Listeria-TT for $3 \mathrm{hrs}$ at $37^{\circ} \mathrm{C}$, then gentamicin $(50 \mu \mathrm{g} / \mathrm{ml})$ was added. Live and dead cells were counted the next day using Trypan blue staining. 


\section{Biodistribution of Listeria-TT}

C57BI/6 mice were injected with $2 \times 10^{6}$ tumor cells as described above, and 14 days later injected with a single large dose $10^{7} \mathrm{CFU}$ of Listeria-TT. Mice were euthanized at various time points after the injection, and metastases, tumors and normal tissues were dissected, weighed, and analyzed for CFU of Listeria-TT, as described previously ${ }^{26}$.

\section{Dose-limiting toxicity}

C57Bl6 mice were injected ip with various doses of Listeria-TT, and survival was monitored over the next 20 days, as described previously ${ }^{26}$.

\section{Tumor development}

Panc-02 tumor cells were injected into the mammary fat pad (peritoneal cavity model) $\left(10^{5}\right)$ or orthotopically into the pancreas $\left(10^{6}\right)$ of C57BI/6 mice. When injected into the mammary fad pat, a relatively small primary tumor develops at the place of injection (peritoneal membrane) and tumor cells metastasize via the peritoneal cavity to other organs, predominantly to the pancreas and liver, and less abundantly to mesenchymal lymph nodes along the gastrointestinal tract and the diaphragm ${ }^{22}$, but when injected into the pancreas tumor cells a primary tumor develops in the pancreas and tumor cells metastasize to the liver only ${ }^{57}$. In KPC mice, multiple primary tumors develop spontaneously in the pancreas, metastasizing to the liver and lungs ${ }^{26,31}$.

\section{Orthotopic Panc-02 model}

Orthotopic Panc-02 tumors were generated in C57BI/6 mice as described previously ${ }^{58}$. Briefly, mice were anesthetized with Ketamine/Xylazine (respectively $100 \mathrm{mg}$ and 10 $\mathrm{mg} / \mathrm{Kg}$, ip), the hair was removed at the location of the spleen, and the skin was sterilized with betadine followed by $70 \%$ alcohol. The animal was covered with gauze 
sponge surrounding the incision site. A $1 \mathrm{~cm}$ incision was made in the abdominal skin and muscle just lateral to the midline and directly above the spleen/pancreas to allow visualization. The spleen/pancreas was gently retracted and positioned to allow injection of $10^{6} \mathrm{KPC}$ tumor cells directly into the pancreas, from the tail all the way to the head of the pancreas. To prevent leakage of injected cell suspension, the injection site was tied off after tumor cell injections with dissolvable suture. The spleen/pancreas were then replaced within the abdominal cavity, and both muscle and skin layers closed with sutures. Following recovery from surgery, mice were monitored and weighed daily. A palpable tumor appeared within 2 weeks in the pancreas, and metastases in the liver began to develop within 2-4 weeks.

\section{Protocol for treatment of Panc-02 and KPC mice with Listeria-TT+GEM}

A detailed rationale for this treatment protocol and schematic view of all treatments are shown in Fig. 1B. Panc-02 mice. To generate memory T cells to TT, C57BI/6 mice were immunized twice intramuscularly with the Tetanus vaccine (the same used for childhood vaccinations, $0.3 \mu \mathrm{g} / 50 \mu \mathrm{L}) 1$ week apart. Subsequently, Panc-02 tumor cells $\left(10^{5} / 100\right.$ $\mu \mathrm{L})$ were injected into mammary fat pad. A single high dose of Listeria-TT (10 $\mathrm{CFU}$ ) was injected ip, either 3-5 days after tumor cell injection when tumors were 1-3 mm (early pancreatic cancer) or 10-14 days after tumor cell injection when tumors were 5-10 $\mathrm{mm}$ (advanced pancreatic cancer). In addition, Panc-02 tumor cells $\left(10^{6} / 50 \mu \mathrm{L}\right)$ were injected into pancreas, and 10-14 days later when tumors were 5-10 mm, a single high dose Listeria-TT (107 CFU) was injected ip. Three days later, GEM (Gemizan: Zuventus, Mombay, India) treatment was started $(1.2 \mathrm{mg} / \mathrm{mouse}$, every 3 days $)$ and continued for 14 days (six doses in total). Concomitantly, low doses of Listeria-TT were administered daily for 2 weeks (14 doses in total). All mice were euthanized 2 days after the last treatment, and visually analyzed for tumor weight and the number of metastases, as 
described previously ${ }^{22}$ KPC mice. KPC mice, age 3.5-5 months, received the same treatment described above, after verification of the presence of tumors and metastases by PET scan.

\section{Intravital multiphoton imaging (IVMI)}

Panc-02 tumor cells $\left(10^{6}\right)$ expressing Dendra-2 were injected into the pancreas of transgenic mice $[\mathrm{C} 57 \mathrm{BI} / 6 \mathrm{~N}-\mathrm{Tg}(\mathrm{Cfms}-\mathrm{gal} 4-\mathrm{vp} 16)-(\mathrm{UAS}-\mathrm{eCFP})]^{35}$ in which the macrophages were labeled with cyan fluorescent protein (CFP). Three weeks later, when a pancreatic tumor developed and on the same day as imaging, Listeria-TT was labeled ex vivo with Alexa-680 by incubation with rabbit anti-Listeria polyclonal antiserum (dilution 1:200) and anti-rabbit IgG-Alexa-680 (dilution 1:250). Listeria-TTAlexa-680 was injected ip, and four hours later, when Listeria-TT had accumulated in the TME and infected tumor cells, mice were anesthetized using isoflurane. Pancreatic tumors were externalized through a small incision $(\sim 0.7 \mathrm{~cm})$ through the skin and peritoneal wall, and stabilized for imaging using previously published protocols ${ }^{59}$. Multiphoton intravital microscopy was performed using a custom-built two-laser multiphoton microscope ${ }^{60}$. Tumors were imaged with a femtosecond laser set to $880 \mathrm{~nm}$ for excitation of CFP or the green form of Dendra-2, and an optical parametric oscillator set to $1240 \mathrm{~nm}$ for excitation of Alexa 680. Z-stacks to a depth of $45 \mu \mathrm{m}$ were acquired with a $1 \mu \mathrm{m}$ slice interval. During the course of imaging, the animal was placed in a heated chamber maintained at physiological temperature. Mice were monitored for heart rate, breathing rate, pulse distension, breath distension and oxygen saturation using a pulse oximeter (MouseSTAT, Kent Scientific). 


\section{PETscan}

Positron emission tomography (PET) was performed as described previously ${ }^{61}$. Briefly, the effect of the Listeria-TT+GEM treatment on the tumor and metastases was monitored by microPET (Siemens Imaging System) prior to and post-treatment. For this purpose, mice were injected with the positron emitter $\left[{ }^{18} \mathrm{~F}\right]$-labeled deoxyglucose. The uptake of ${ }^{18} \mathrm{~F}$-FDG by tumors and metastases was quantified by microPET as described previously $^{22}$. Increased FDG uptake reflects increased metabolic activity of cancer cells, expressed as SUVmax.

\section{Flow cytometry}

Immune cells from spleens, blood, or metastases of mice were isolated as described previously $^{50}$. Anti-CD3 and anti-CD8 antibodies were used to identify CD8 T cells, antiCD3 and anti-CD4 to identify CD4 T cells, anti-CD11b and anti-Gr1 to identify MDSC, and anti-CD11b and anti-F4/80 to identify TAM. To detect intracellular cytokine production, the cells were incubated with GolgiPlug $(1 \mu \mathrm{g} / \mathrm{ml})$ for $6 \mathrm{hrs}$, then treated with Cytofix/Cytoperm according to the manufacturer's instructions, before staining with antibodies to intracellular cytokines, IFN $\gamma$, granzyme B, perforin, IL-6, IL-10, TNFa, and other markers such as the $\mathrm{T}$ cell response inhibitor MARCO, the T cell activation marker CD69, or the costimulator CD80. Appropriate isotype controls were included for each sample. 50,000-100,000 cells were acquired by scanning using a special order LSR-II Fluorescence Activated Cell Sorter system (Beckton and Dickinson), and analyzed using FlowJo 7.6 software. Cell debris and dead cells were excluded from the analysis based on scatter signals and use of Fixable Blue or Green Live/Dead Cell Stain Kit. 


\section{ELISPOT}

Spleen cells were isolated from treated and control Panc-02 and KPC mice for ELISPOT (BD Biosciences, cat\# 551083) analysis, as described previously ${ }^{62}$. To detect $\mathrm{T}$ cell responses to TT, $10^{5}$ spleen cells were incubated with purified TT protein $(5 \mu \mathrm{g} / \mathrm{ml})$. The frequency of IFNy-producing spleen cells was measured $72 \mathrm{hrs}$ later using an ELISPOT reader (CTL Immunospot S4 analyzer). To determine the frequency of IFNy-producing CD4 and CD8 T cells, spleen cells were depleted for CD4 and CD8 T cells using magnetic bead depletion techniques according to the manufacturer's instructions. A similar protocol was used for T cells isolated from Panc-02 orthotopic tumors.

\section{Western blotting}

Expression of TT protein in tumor cells was analyzed by western blotting as described previously $^{63}$. Briefly, cells were lysed in RIPA buffer containing protease inhibitors, and proteins were separated on $4-12 \%$ gradient SDS-polyacrylamide gels, then electrotransferred to PVDF membrane. Membranes were incubated with rabbit anti-myc lgG, followed by horseradish peroxidase-conjugated goat anti-rabbit IgG. Detection was with a chemiluminescence detection kit. Antibody to $\beta$-actin was used to ensure equal loading.

\section{Immunohistochemistry (IHC)}

Tumors were dissected from pancreas and immediately fixed with buffered formalin, and the tissue was embedded in paraffin. Sections $(5 \mu \mathrm{m})$ were sliced and placed on slides, then deparaffinized at $60^{\circ} \mathrm{C}$ for $1 \mathrm{hr}$, followed by xylene, an ethanol gradient $(100-70 \%)$, water, and PBS. Slides were then incubated for $30 \mathrm{~min}$ in $3 \%$ hydrogen peroxide followed by boiling in citrate buffer for $20 \mathrm{~min}$. Once the slides were cooled, washed, and blocked with $5 \%$ goat serum, the sections were incubated with primary antibodies such 
as anti-CD4 (1:100 dilution), anti-CD8a (1:400 dilution), anti-Perforin (1:300 dilution), anti-Granzyme (1:200 dilution), anti-CD31 (1:100 dilution) or anti-TT (1:50 dilution), followed by incubation with secondary antibody (mouse anti-goat IgG-HRP), and SignalStain ${ }^{\circ}$ Boost IHC Detection Reagent (Cell Signaling Technology, cat\# 8114S). Subsequently, the slides were incubated with 3,3'-diaminobenzidine (DAB)(Vector Laboratories, cat\# SK-4100), counterstained with hematoxylin, dehydrated through an ethanol gradient $(70-100 \%)$ and xylene, and mounted with Permount. The slides were scanned with a 3D Histech P250 High Capacity Slide Scanner to acquire images and quantification data. Secondary antibodies without primary antibodies were used as negative control.

\section{RNAseq}

Sample preparation for RNA seq. Total RNA was isolated from the metastasis and tumor tissues, treated with DNase, and evaluated using the Agilent Bioanalyzer. The purified high quality total RNA was submitted to the Epigenetics Shared Facility (ESF) for assay and analysis. An RNAseq assay using $25 \mathrm{ng}$ of RNA was performed and validated by the ESF.

Whole-transcriptome library preparation and high-throughput RNA sequencing. ESF personnel performed rRNA-depletion using a Ribo-Zero rRNA Removal Kit, and reverse transcription using random hexamers and oligo(dT) to synthesize ds-cDNA. Libraries were prepared with adapters and barcodes for multiplex sequencing, and sequenced using the Illumina HiSeq 2500. Raw FASTQ files were trimmed for adapter sequences using quart. FASTQ file sequence quality was evaluated using $F a s t Q C^{64}$, and read coverage determined using the RSeQC package ${ }^{65}$.

RNAseq data analysis. We generated a total of 150 RNAseq runs. For each run we obtained at least 20 million reads, with $>70 \%$ of them aligned to the mouse genome. We 
used the Bowtie/Tophat/Cufflinks/Cuffdiff software suite ${ }^{66-68}$, applying the Tuxedo protocol.

\section{Statistics}

To statistically compare the effects of Listeria-TT+GEM on the growth of metastases and tumors or on immune responses in the mouse models, the Mann-Whitney was applied using Prism. ${ }^{*} p<0.05,{ }^{* *}<0.01,{ }^{* * *}<0.001,{ }^{* * * *}<0.0001$. Values of $p<0.05$ were considered statistically significant.

\section{REFERENCES}

1 Kulke, M. H. et al. Capecitabine plus erlotinib in gemcitabine-refractory advanced pancreatic cancer. J Clin Oncol 25, 4787-4792, doi:10.1200/JCO.2007.11.8521 (2007).

2 Maitra, A. \& Hruban, R. H. Pancreatic cancer. Annu Rev Pathol 3, 157-188, doi:10.1146/annurev.pathmechdis.3.121806.154305 (2008).

3 Moore, M. J. et al. Erlotinib plus gemcitabine compared with gemcitabine alone in patients with advanced pancreatic cancer: a phase III trial of the National Cancer Institute of Canada Clinical Trials Group. J Clin Oncol 25, 1960-1966, doi:10.1200/JCO.2006.07.9525 (2007).

4 Abbruzzese, J. L. et al. A phase I clinical, plasma, and cellular pharmacology study of gemcitabine. J Clin Oncol 9, 491-498 (1991).

5 Von Hoff, D. D. et al. Gemcitabine plus nab-paclitaxel is an active regimen in patients with advanced pancreatic cancer: a phase I/II trial. J Clin Oncol 29, 4548-4554, doi:10.1200/JCO.2011.36.5742 (2011). 
6 Valsecchi, M. E., Diaz-Canton, E., de la Vega, M. \& Littman, S. J. Recent treatment advances and novel therapies in pancreas cancer: a review. $J$ Gastrointest Cancer 45, 190-201, doi:10.1007/s12029-013-9561-z (2014).

7 Thind, K., Padrnos, L. J., Ramanathan, R. K. \& Borad, M. J. Immunotherapy in pancreatic cancer treatment: a new frontier. Therap Adv Gastroenterol 10, 168194, doi:10.1177/1756283X16667909 (2017).

8 Schumacher, T. N. \& Schreiber, R. D. Neoantigens in cancer immunotherapy. Science 348, 69-74, doi:10.1126/science.aaa4971 (2015).

9 Balachandran, V. P. et al. Identification of unique neoantigen qualities in longterm survivors of pancreatic cancer. Nature 551, 512-516, doi:10.1038/nature24462 (2017).

10 Chandra, D., Jahangir, A., Quispe-Tintaya, W., Einstein, M. H. \& Gravekamp, C. Myeloid-derived suppressor cells have a central role in attenuated Listeria monocytogenes-based immunotherapy against metastatic breast cancer in young and old mice. British journal of cancer 108, 2281-2290, doi:10.1038/bjc.2013.206 (2013).

11 Ostrand-Rosenberg, S. \& Sinha, P. Myeloid-derived suppressor cells: linking inflammation and cancer. Journal of immunology 182, 4499-4506, doi:10.4049/jimmunol.0802740 (2009).

12 Gabrilovich, D. I. \& Nagaraj, S. Myeloid-derived suppressor cells as regulators of the immune system. Nature reviews. Immunology 9, 162-174, doi:10.1038/nri2506 (2009).

13 Xia, H. et al. Suppression of FIP200 and autophagy by tumor-derived lactate promotes naive $\mathrm{T}$ cell apoptosis and affects tumor immunity. Sci Immunol 2, doi:10.1126/sciimmunol.aan4631 (2017). 
14 Jahangir, A. et al. Immunotherapy with Listeria reduces metastatic breast cancer in young and old mice through different mechanisms. Oncoimmunology $\mathbf{6}$, e1342025, doi:10.1080/2162402X.2017.1342025 (2017).

$15 \mathrm{Kim}, \mathrm{S}$. H. et al. Mage-b vaccine delivered by recombinant Listeria monocytogenes is highly effective against breast cancer metastases. British journal of cancer 99, 741-749, doi:10.1038/sj.bjc.6604526 (2008).

16 Schmitz-Winnenthal, H. et al. Chronic pancreatitis is associated with diseasespecific regulatory T-cell responses. Gastroenterology 138, 1178-1188, doi:10.1053/j.gastro.2009.11.011 (2010).

17 Escudier, B. et al. Vaccination of metastatic melanoma patients with autologous dendritic cell $(\mathrm{DC})$ derived-exosomes: results of thefirst phase I clinical trial. $J$ Transl Med 3, 10, doi:10.1186/1479-5876-3-10 (2005).

18 Tseng, J. F. et al. Patients undergoing treatment for pancreatic adenocarcinoma can mount an effective immune response to vaccinations. Pancreatology 5, 6774, doi:10.1159/000084492 (2005).

19 Alvarez-Dominguez, C., Carrasco-Marin, E. \& Leyva-Cobian, F. Role of complement component $\mathrm{C} 1 \mathrm{q}$ in phagocytosis of Listeria monocytogenes by murine macrophage-like cell lines. Infect Immun 61, 3664-3672 (1993).

20 Croize, J., Arvieux, J., Berche, P. \& Colomb, M. G. Activation of the human complement alternative pathway by Listeria monocytogenes: evidence for direct binding and proteolysis of the C3 component on bacteria. Infect Immun 61, 51345139 (1993).

21 Drevets, D. A., Sawyer, R. T., Potter, T. A. \& Campbell, P. A. Listeria monocytogenes infects human endothelial cells by two distinct mechanisms. Infect Immun 63, 4268-4276 (1995). 
22 Quispe-Tintaya, W. et al. Nontoxic radioactive Listeria(at) is a highly effective therapy against metastatic pancreatic cancer. Proc Natl Acad Sci U S A 110, 8668-8673, doi:10.1073/pnas.1211287110 (2013).

23 Bayne, L. J. et al. Tumor-derived granulocyte-macrophage colony-stimulating factor regulates myeloid inflammation and $\mathrm{T}$ cell immunity in pancreatic cancer. Cancer cell 21, 822-835, doi:10.1016/j.ccr.2012.04.025 (2012).

24 Portnoy, D. A., Auerbuch, V. \& Glomski, I. J. The cell biology of Listeria monocytogenes infection: the intersection of bacterial pathogenesis and cellmediated immunity. The Journal of cell biology 158, 409-414, doi:10.1083/jcb.200205009 (2002).

25 Kim, S. H., Castro, F., Paterson, Y. \& Gravekamp, C. High efficacy of a Listeriabased vaccine against metastatic breast cancer reveals a dual mode of action. Cancer research 69, 5860-5866, doi:10.1158/0008-5472.CAN-08-4855 (2009).

26 Chandra, D. et al. 32-Phosphorus selectively delivered by listeria to pancreatic cancer demonstrates a strong therapeutic effect. Oncotarget 8, 20729-20740, doi:10.18632/oncotarget.15117 (2017).

27 Zhou, S., Gravekamp, C., Bermudes, D. \& Liu, K. Tumour-targeting bacteria engineered to fight cancer. Nat Rev Cancer, doi:10.1038/s41568-018-0070-z (2018).

28 Singh, M. et al. Direct incorporation of the NKT-cell activator alphagalactosylceramide into a recombinant Listeria monocytogenes improves breast cancer vaccine efficacy. Br J Cancer 111, 1945-1954, doi:10.1038/bjc.2014.486 (2014).

29 Forbes, N. S. et al. White paper on microbial anti-cancer therapy and prevention. J Immunother Cancer 6, 78, doi:10.1186/s40425-018-0381-3 (2018). 
30 Zorde Khvalevsky, E. et al. Mutant KRAS is a druggable target for pancreatic cancer. Proc Natl Acad Sci U S A 110, 20723-20728, doi:10.1073/pnas.1314307110 (2013).

31 Hingorani, S. R. et al. Trp53R172H and KrasG12D cooperate to promote chromosomal instability and widely metastatic pancreatic ductal adenocarcinoma in mice. Cancer cell 7, 469-483, doi:10.1016/j.ccr.2005.04.023 (2005).

32 Qiu, W. et al. Disruption of p16 and activation of Kras in pancreas increase ductal adenocarcinoma formation and metastasis in vivo. Oncotarget 2, 862-873, doi:10.18632/oncotarget.357 (2011).

33 Gunn, G. R. et al. Two Listeria monocytogenes vaccine vectors that express different molecular forms of human papilloma virus-16 (HPV-16) E7 induce qualitatively different $\mathrm{T}$ cell immunity that correlates with their ability to induce regression of established tumors immortalized by HPV-16. Journal of immunology 167, 6471-6479 (2001).

34 Pamer, E. G. Immune responses to Listeria monocytogenes. Nat Rev Immunol 4, 812-823, doi:10.1038/nri1461 (2004).

35 Ovchinnikov, D. A. et al. Expression of Gal4-dependent transgenes in cells of the mononuclear phagocyte system labeled with enhanced cyan fluorescent protein using Csf1r-Gal4VP16/UAS-ECFP double-transgenic mice. J Leukoc Biol 83, 430-433, doi:10.1189/jlb.0807585 (2008).

36 Groom, J. R. \& Luster, A. D. CXCR3 in T cell function. Exp Cell Res 317, 620631, doi:10.1016/j.yexcr.2010.12.017 (2011).

37 Slaney, C. Y., Kershaw, M. H. \& Darcy, P. K. Trafficking of T cells into tumors. Cancer Res 74, 7168-7174, doi:10.1158/0008-5472.CAN-14-2458 (2014). 
38 Elgueta, R. et al. Molecular mechanism and function of CD40/CD40L engagement in the immune system. Immunol Rev 229, 152-172, doi:10.1111/j.1600-065X.2009.00782.x (2009).

39 Anagnostou, V. et al. Evolution of Neoantigen Landscape during Immune Checkpoint Blockade in Non-Small Cell Lung Cancer. Cancer Discov 7, 264-276, doi:10.1158/2159-8290.CD-16-0828 (2017).

40 Efremova, M., Finotello, F., Rieder, D. \& Trajanoski, Z. Neoantigens Generated by Individual Mutations and Their Role in Cancer Immunity and Immunotherapy. Front Immunol 8, 1679, doi:10.3389/fimmu.2017.01679 (2017).

41 Reece, J. C., Geysen, H. M. \& Rodda, S. J. Mapping the major human T helper epitopes of tetanus toxin. The emerging picture. $J$ Immunol 151, 6175-6184 (1993).

42 Stromnes, I. M., Hulbert, A., Pierce, R. H., Greenberg, P. D. \& Hingorani, S. R. Tcell Localization, Activation, and Clonal Expansion in Human Pancreatic Ductal Adenocarcinoma. Cancer Immunol Res 5, 978-991, doi:10.1158/2326-6066.CIR16-0322 (2017).

43 Fink, D. M., Steele, M. M. \& Hollingsworth, M. A. The lymphatic system and pancreatic cancer. Cancer letters 381, 217-236, doi:10.1016/j.canlet.2015.11.048 (2016).

44 Keenan, B. P. et al. A Listeria vaccine and depletion of T-regulatory cells activate immunity against early stage pancreatic intraepithelial neoplasms and prolong survival of mice. Gastroenterology 146, 1784-1794 e1786, doi:10.1053/j.gastro.2014.02.055 (2014).

45 Deng, W. et al. Recombinant Listeria promotes tumor rejection by CD8(+) T celldependent remodeling of the tumor microenvironment. Proc Natl Acad Sci U S A 115, 8179-8184, doi:10.1073/pnas.1801910115 (2018). 
46 Toussaint, B., Chauchet, X., Wang, Y., Polack, B. \& Le Gouellec, A. Liveattenuated bacteria as a cancer vaccine vector. Expert Rev Vaccines 12, 11391154, doi:10.1586/14760584.2013.836914 (2013).

47 McElhaney, J. E., Meneilly, G. S., Lechelt, K. E. \& Bleackley, R. C. Split-virus influenza vaccines: do they provide adequate immunity in the elderly? Journal of gerontology 49, M37-43 (1994).

48 Effros, R. B. Role of T lymphocyte replicative senescence in vaccine efficacy. Vaccine 25, 599-604, doi:10.1016/j.vaccine.2006.08.032 (2007).

49 Gravekamp, C. The impact of aging on cancer vaccination. Current opinion in immunology 23, 555-560, doi:10.1016/j.coi.2011.05.003 (2011).

50 Castro, F. et al. Vaccination with Mage-b DNA induces CD8 T-cell responses at young but not old age in mice with metastatic breast cancer. British journal of cancer 101, 1329-1337, doi:10.1038/sj.bjc.6605329 (2009).

51 Utsuyama, M. et al. Differential age-change in the numbers of CD4+CD45RA+ and CD4+CD29+ T cell subsets in human peripheral blood. Mechanisms of ageing and development 63, 57-68 (1992).

52 Corbett, T. H. et al. Induction and chemotherapeutic response of two transplantable ductal adenocarcinomas of the pancreas in C57BL/6 mice. Cancer Res 44, 717-726 (1984).

53 Aslakson, C. J. \& Miller, F. R. Selective events in the metastatic process defined by analysis of the sequential dissemination of subpopulations of a mouse mammary tumor. Cancer research 52, 1399-1405 (1992).

54 Lelekakis, M. et al. A novel orthotopic model of breast cancer metastasis to bone. Clin Exp Metastasis 17, 163-170, doi:10.1023/a:1006689719505 (1999). 
55 Medaglini, D. et al. Immunization with recombinant Streptococcus gordonii expressing tetanus toxin fragment $\mathrm{C}$ confers protection from lethal challenge in mice. Vaccine 19, 1931-1939, doi:10.1016/s0264-410x(00)00434-5 (2001).

56 Rice, J., Buchan, S. \& Stevenson, F. K. Critical components of a DNA fusion vaccine able to induce protective cytotoxic $T$ cells against a single epitope of a tumor antigen. Journal of immunology 169, 3908-3913 (2002).

57 Partecke, L. I. et al. A syngeneic orthotopic murine model of pancreatic adenocarcinoma in the C57/BL6 mouse using the Panc02 and 6606PDA cell lines. Eur Surg Res 47, 98-107, doi:10.1159/000329413 (2011).

58 Qiu, W. \& Su, G. H. Development of orthotopic pancreatic tumor mouse models. Methods Mol Biol 980, 215-223, doi:10.1007/978-1-62703-287-2_11 (2013).

59 Entenberg, D. et al. Time-lapsed, large-volume, high-resolution intravital imaging for tissue-wide analysis of single cell dynamics. Methods 128, 65-77, doi:10.1016/j.ymeth.2017.07.019 (2017).

60 Entenberg, D. et al. Setup and use of a two-laser multiphoton microscope for multichannel intravital fluorescence imaging. Nat Protoc 6, 1500-1520, doi:10.1038/nprot.2011.376 (2011).

61 Yamamoto, T. et al. Over-expression of facilitative glucose transporter genes in human cancer. Biochem Biophys Res Commun 170, 223-230 (1990).

62 Kim, S. H. et al. Mage-b vaccine delivered by recombinant Listeria monocytogenes is highly effective against breast cancer metastases. $\mathrm{Br} J$ Cancer 99, 741-749, doi:10.1038/sj.bjc.6604526 (2008).

63 Chandra, D. et al. STING ligand c-di-GMP improves cancer vaccination against metastatic breast cancer. Cancer Immunol Res 2, 901-910, doi:10.1158/23266066.CIR-13-0123 (2014). 
64 Smallwood, S. A. et al. Single-cell genome-wide bisulfite sequencing for assessing epigenetic heterogeneity. Nat Methods 11, 817-820, doi:10.1038/nmeth.3035 (2014).

65 Wang, L., Wang, S. \& Li, W. RSeQC: quality control of RNA-seq experiments. Bioinformatics 28, 2184-2185, doi:10.1093/bioinformatics/bts356 (2012).

66 Trapnell, C. et al. Transcript assembly and quantification by RNA-Seq reveals unannotated transcripts and isoform switching during cell differentiation. Nat Biotechnol 28, 511-515, doi:10.1038/nbt.1621 (2010).

67 Lien, W. H. et al. Genome-wide maps of histone modifications unwind in vivo chromatin states of the hair follicle lineage. Cell Stem Cell 9, 219-232, doi:10.1016/j.stem.2011.07.015 (2011).

68 Trapnell, C. et al. Differential gene and transcript expression analysis of RNA-seq experiments with TopHat and Cufflinks. Nat Protoc 7, 562-578, doi:10.1038/nprot.2012.016 (2012).

Acknowledgements: We greatly thank Ms. Hong Zhang, Department of Pathology, and Dr. Vera DeMarais, Director of Light Microscopy and Image Analysis, Department of Structural and Cell Biology, Einstein for providing outstanding training and support regarding the $\mathrm{IHC}$ and image analysis. Funding: This work was supported by the Pancreatic Cancer Action Network (PCAN) 422247, a private donation of Janet and Marty Spatz, NCl Administrative Supplement 3P30CA013330-44S3, and NCl cancer center support P30CA013330 (Flow Cytometry Core, Pathology Core, MicroPET Core, Genetics Core). Authors contribution: Conception, study design, and study supervision; development of methodology; administrative, technical, or material support (i.e., reporting or organizing data, constructing data bases); writing, review, and/or 
revision of the manuscript: B.C. Selvanesan, D. Chandra, W. Quispe-Tintaya, Z. Yuan, S.K. Libutti, C. Gravekamp. Acquisition of data (provided animals, developed Listeria-TT construct, acquired immunological and efficacy data, provided facilities, etc.): B.C. Selvanesan, D. Chandra, W. Quispe-Tintaya, A. Jahangir, A. Patel, K. Meena, R. Alves Da Silva, J. Li, S. Siddiqui, A. Beck, L. Tesfa, W. Koba, Z. Yuan, S.K. Libutti, C. Gravekamp. Analysis and interpretation of data (statistical analysis, biostatistics, computational analysis): B.C. Selvanesan, D. Chandra, W. Quispe-Tintaya, A. Jahangir, A. Patel, K. Meena, R. Alves Da Silva, A. Beck, L. Tesfa, W. Koba, J. Chuy, Z. Yuan, S.K. Libutti, C. Gravekamp. Competing interests: Dr. Gravekamp has ownership interest in a patent application filed for the Listeria-recall antigen concept (96700/2230). No other competing interests were disclosed by the authors. Data and materials availability: All data associated with this study are available in the paper or the Supplementary Materials.

\section{Figure Captions}

Fig. 1. (A) Mechanistic view of the Listeria-recall antigen concept. Tetanus vaccine will be used to generate memory $\mathrm{T}$ cells to recall antigen TT in mice prior to tumor development. Antigen-presenting cells (DC) take up and present TT protein to naïve T cells. Upon repeated exposures to TT, naïve T cells differentiate into memory $\mathrm{T}$ cells, which circulating in the blood for life. These memory cells are to be reactivated after appearance of the primary tumor and metastases, as follows. To deliver TT into tumor cells, mice receive a high dose of Listeria-TT bacteria, whose replication will lead to more TT protein in the tumor cells. Subsequently, frequent low dose immunizations with Listeria-TT reactivate TT-specific memory T cells. Finally, TT-specific memory T cells migrate to the tumor and kill tumor cells presenting TT epitopes. Since attenuated Listeria bacteria colonize the TME, they will also infect MDSC and macrophages (not 
depicted). (B) Protocol for treatment of Panc-02 and KPC mice with ListeriaTT+GEM. In the Panc-02 model, mice were immunized twice with Tetanus vaccine (TTvac) to generate memory T cells. Subsequently, Panc-02 tumor cells were injected and tumors allowed to develop to the early stage of pancreatic cancer $(1-3 \mathrm{~mm})$ or advanced stage $(5-10 \mathrm{~mm})$. After an initial high ip dose of Listeria-TT (10 $\mathrm{CFU})$, it accumulated and multiplied in the TME for 3 days. Low doses of GEM $(1.2 \mathrm{mg} / \mathrm{dose})$ were then given every 3 days for 14 days in order to eliminate MDSC and TAM. At this point, MDSC are no longer required to bring Listeria-TT to the TME. Instead, reducing MDSC and TAM populations by GEM serves to improve $T$ cell responses. Concomitantly, daily low doses of Listeria-TT $\left(10^{4} \mathrm{CFU}\right)$ reactivate TT-specific memory T cells, improved by GEM. Mice were euthanized two days after the last treatment. Panc02 mice were analyzed for tumor weight and the number of metastases.

In the KPC model, the presence of tumors and/or metastases were first verified by PET scan before mice received the same treatments described above. The metabolic activities (SUVmax) of tumors and metastases in KPC mice were measured by PET scan. Comparisons of SUVmax pre- and post-treatment provide a measure of the growth of tumors and metastases. LM-TT = Listeria-TT.

Fig. 2. Development and characterization of the Listeria-TT vaccine. (A) Listeria-TT construct. $\mathrm{TT}_{856-1313}$, a non-toxic fragment of the C-terminus of TT cDNA (aa position 856-1313, $52 \mathrm{kDa}$ ) was cloned as a fusion protein with a truncated non-cytolytic Listeriolysin O (LLO, $48 \mathrm{kDa}$ ) into the Listeria plasmid pGG34, under the control of the LLO promoter (P). A myc tag was included for detection of the TT protein. (B) Western blot detection of TT protein secretion using anti-myc. Lane 1: negative control (growth medium); Lane 2: supernatant of Listeria-TT culture; Lane 3: pellet of Listeria-TT culture. (C) Detection of TT protein in tumor cells. Lane 1: Panc-02 tumor cells; Lane 2: 
Panc-02 tumor cells infected with Listeria alone; Lane 3: Panc-02 tumor cells infected with Listeria-TT. (D) Panc-02 tumor cells infected with Listeria-TT. Average of 2 independent experiments, 3 wells per group. (E) Panc-02 tumor cell killing by ListeriaTT. Averages of 3 independent experiments; 3 wells per group. (F) Listeria-TT accumulation in tumors and metastases, but not in normal tissues. A single high dose of Listeria-TT, $10^{7} \mathrm{CFU} / 200 \mu \mathrm{L}$, was injected ip into Panc-02 mice, and Listeria-TT CFU were measured in tumor, metastatic, and normal tissues at different time points. Averages of a single experiment; $n=3$ mice per timepoint, $n=3$ tissues per organ/tumor/metastases. In (D-F), error bars represent SEM. (G) Listeria-TT infecting tumor cells and macrophages (MФ) in Panc-02-dendra-2 tumors of live mice, by intravital imaging. Tumor cells are green, macrophages blue, and Listeria-TT red. (H) Immunohistochemical detection of TT protein using polyclonal anti-TT antibody in tumors of KPC mice that received Listeria-TT+GEM or Listeria-TT treatment. (I) Effect of GEM on Listeria in vitro. Average of one experiment; $n=3$ wells per concentration, 3 fields per well. (J) Effect of GEM on Listeria in vivo. Average of 2 independent experiments; $n=3$ mice per group. (K) ELISPOT analysis of CD45+ IFNY-producing immune cells isolated from orthotopic Panc-02 tumors in mice treated with Listeria-TT+GEM. (L) Flow cytometry of IFNy-producing CD4+ T cells in the CD45+ fraction, isolated from orthotopic Panc-02 tumors. In each group tumors of 5 mice were pooled. Mann-Whitney ${ }^{*} p<0.05$, ${ }^{* *} p<0.01,{ }^{* * *} p<0.001,{ }^{* * *} p<0.0001$. LM-TT $=$ Listeria-TT.

Fig. 3. Generation and recall of memory CD4 and CD8 T cell responses to TT. (A) Generation of CD4 and CD8 memory T cells to TT by immunization of Panc-02 or KPC mice with Tetanus vaccine (TTvac), prior to tumor development. (B) Reactivation of TTspecific memory CD4 and CD8 T cells in Panc-02 mice post tumor development through the Listeria-TT+GEM treatment cycle described in Fig 1B. (C) Reactivation of TT-specific 
memory T cells in KPC mice post tumor development by the Listeria-TT+GEM treatment cycle. In (A-C), T cells producing IFNy were analyzed in a restimulation assay with TT protein by ELISPOT. Representative results of 2 experiments are shown; $n=3$ mice per group (pooled), 6 wells per group. Statistical significance by Mann-Whitney test: ${ }^{*} p<0.05$, ${ }^{* * *} p<0.001$ and ${ }^{* * * *} p<0.0001$. (D) RNAseq analysis of immune responses and tumor cell death pathways in pancreatic tumors of KPC mice in response to Listeria-TT+GEM treatment. The heatmap was generated by unbiased hieratical clustering at the following statistical parameters. Statistical parameters for the paired-wise comparison: $p<0.05$. The signature contains 25 important genes. m1=mouse 1, and m2=mouse 2. (E) Flow cytometric analysis of changes in MDSC $(\mathrm{CD} 11 \mathrm{~b}+\mathrm{Gr} 1+)$ in blood and tumors, and TAM $(\mathrm{CD} 11 \mathrm{~b}+\mathrm{F} 4 / 80+)$ in tumors of Panc-02 mice in response to the Listeria-TT+GEM treatment cycle. Average of a single experiment of MDSC in blood with $n=3$ mice per group, and the average of 2 independent experiments of MDSC and TAM in tumors with $\mathrm{n}=3$ mice per group. LM-TT $=$ Listeria-TT.

Fig. 4. Tetanus protein attracts CD4 memory $T$ cells to the TME. KPC mice were treated with saline, GEM, Listeria-TT, or Listeria-TT+GEM as outlined in Fig 1B. Three days after the last treatment, the pancreas with tumors including lymph node like structures (LNS) were excised and processed for CD4 and CD8 staining by IHC. (A) CD4 T cells in the KPC tumors and the presence of LNS were analyzed in all treatment groups. (B) Isolation and flow cytometry analysis of CD4 and CD8 T cells in a LNS of a mouse that received Listeria-TT. The CD45+ cells were gated, followed by CD3CD4 or CD3CD8 gating, followed by gating of CD3CD4 and CD3CD8 $T$ cells producing intracellular IFN $\gamma$, followed by staining to identify $\mathrm{T}$ cells with memory phenotype (CD44+CD62L-). (C) Production of perforin and granzyme B in KPC tumors, by IHC. (d) (D) Production of perforin and granzyme B in KPC LNS, by IHC. (E) Quantification of 
CD4 T cells in KPC tumors and the production of perforin and granzyme $B$ in the KPC tumors and LNS. CD4 T cell numbers were counted in the tumor areas of all treatment groups. Also, the number of perforin and granzyme B-producing cells were counted in the tumor areas and LNS of all treatment groups. In each group, four-ten fields were measured, and the number of cells per $1 \mathrm{~mm}^{2}$ was calculated. Results of three mice per group were averaged. Mann-Whitney ${ }^{*} p<0.05,{ }^{* *} p<0.01,{ }^{* * *} p<0.001$. LM-TT $=$ ListeriaTT. Scale bars $=100 \mu \mathrm{m}$.

Fig. 5. Listeria-TT+GEM robustly reduces advanced pancreatic cancer in KPC mice. KPC mice received the combined treatment as outlined in Fig 1B. (A) Effect of treatment on advanced pancreatic cancer in KPC mice. Averages are shown for a single experiment with 5 mice in the Listeria-TT+GEM group, and 2 mice in each other treatment group. Listeria-TT+GEM was started at age 3-5.5 months, after tumors and metastases were verified through PET scan. SUVmax of tumors and metastases were measured prior to and post-treatment. (B) Examples for each treatment group of pancreatic tumors in KPC mice. LM-TT is more effective than LM against advanced pancreatic in Panc-02 (C) and KPC mice (D). Both models received LM-TT or LM as outlined in Fig 1B. The LM-TT group also received TTvac prior tumor development. (E) LM-TT combined with TTvac was significantly more effective against advanced pancreatic cancer than LM-TT without TTvac. Panc-02 mice with advanced pancreatic cancer received the LM-TT \pm TTVac as outlined in Fig 1B. The results of 2 experiments were averaged with $n=8-9$ mice per group, and analyzed by Mann-Whitney test ${ }^{*} p<0.05$, ${ }^{* *} p<0.01,{ }^{* * *} p<0.001$. Error bars represent SEM. LM-TT $=$ Listeria-TT. 


\section{Table Captions}

Table 1A: Listeria-TT and GEM increases CD4 and CD8 T cell responses in vivo in

Panc-02 mice

Table 1B: Listeria-TT and GEM increases CD4 and CD8 T cell responses in vivo in KPC mice

Table 1C: Listeria-TT and GEM reduce immune suppressive function of MDSC $(\mathrm{CD} 11 \mathrm{~b}+\mathrm{Gr} 1+)$ in metastases of Panc-02 mice

Table 1D: Listeria-TT and GEM reduce immune suppressive function of TAM $(\mathrm{CD} 11 \mathrm{~b}+\mathrm{F} 4 / 80+)$ in metastases of Panc-02 mice

\section{SUPPLEMENTAL MATERIALS}

Fig S1: Intraperitoneally but not intravenously injected Listeria colonizes tumors and metastases

Fig S2: Gating of CD4 and CD8 T cells in spleens of tumor-bearing Panc-02 mice treated with Listeria-TT and GEM, in combination or separately

Fig S3: Detail of CD4 and CD8 T cells in tumors of Listeria-TT+GEM-treated and control mice

Fig S4: Detail of lymph node-like structures associated with pancreatic tumors in mice Fig S5: Effect of LM-TT+GEM treatment on expression of genes involved in $\mathrm{T}$ cell migration, efficacy and safety

Fig S6: Flow cytometry demonstration of MDSC and TAM in metastases of tumorbearing Panc-02 mice

Table S1: Pathological examination of tissues in C57BI/6 mice 2 days after the last treatment with Listeria-TT and Gemcitabine

Table S2: The effect of Listeria-TT and Gemcitabine on liver functions in C57BI/6 mice Additional Supplementary Information 
Figure 1
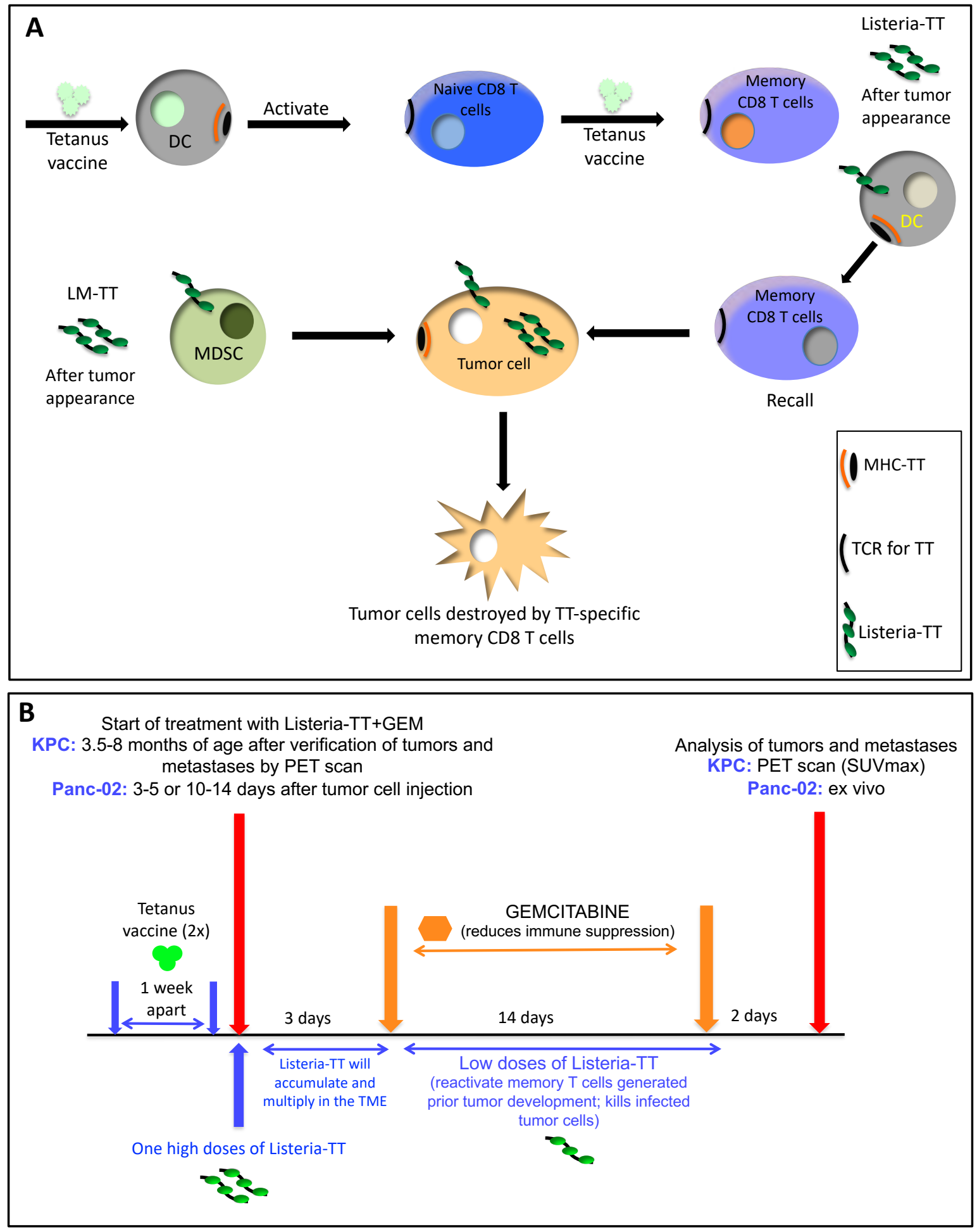
Figure 2

A

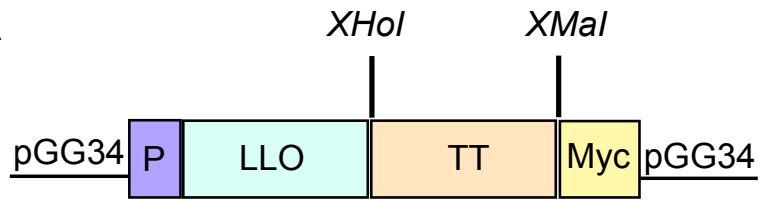

B

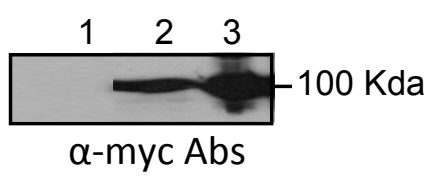

C

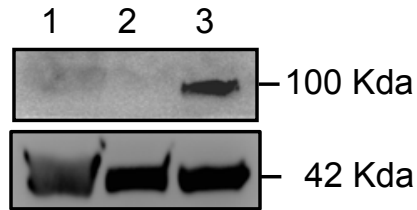

$\alpha$-myc Abs
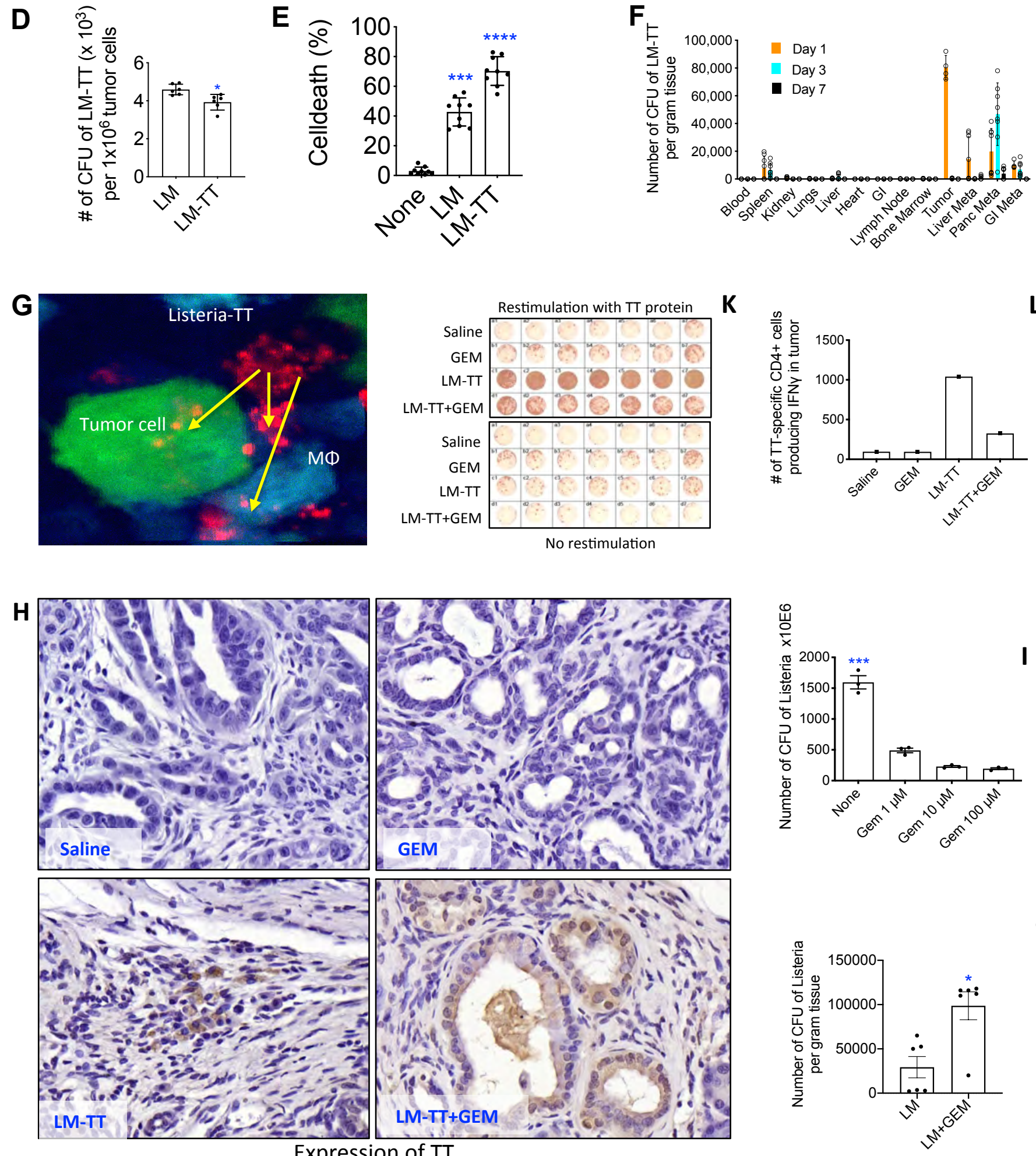


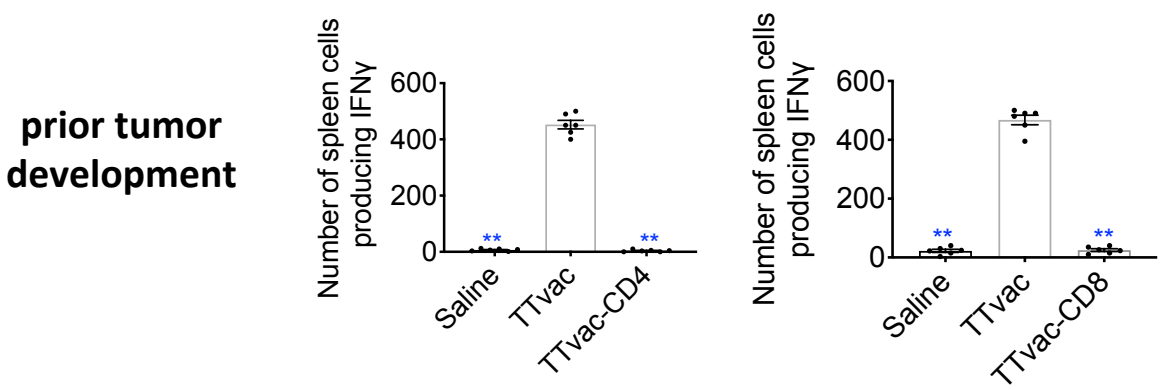

Panc-02

Reactivation of pre-existing memory T cells to TT

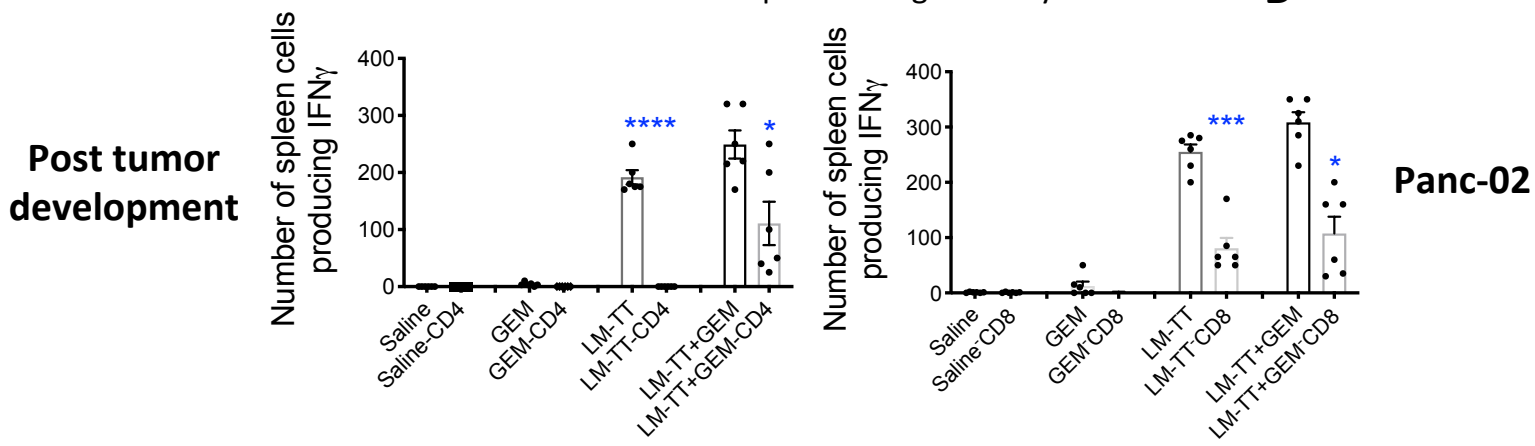

Reactivation of pre-existing memory T cells to TT
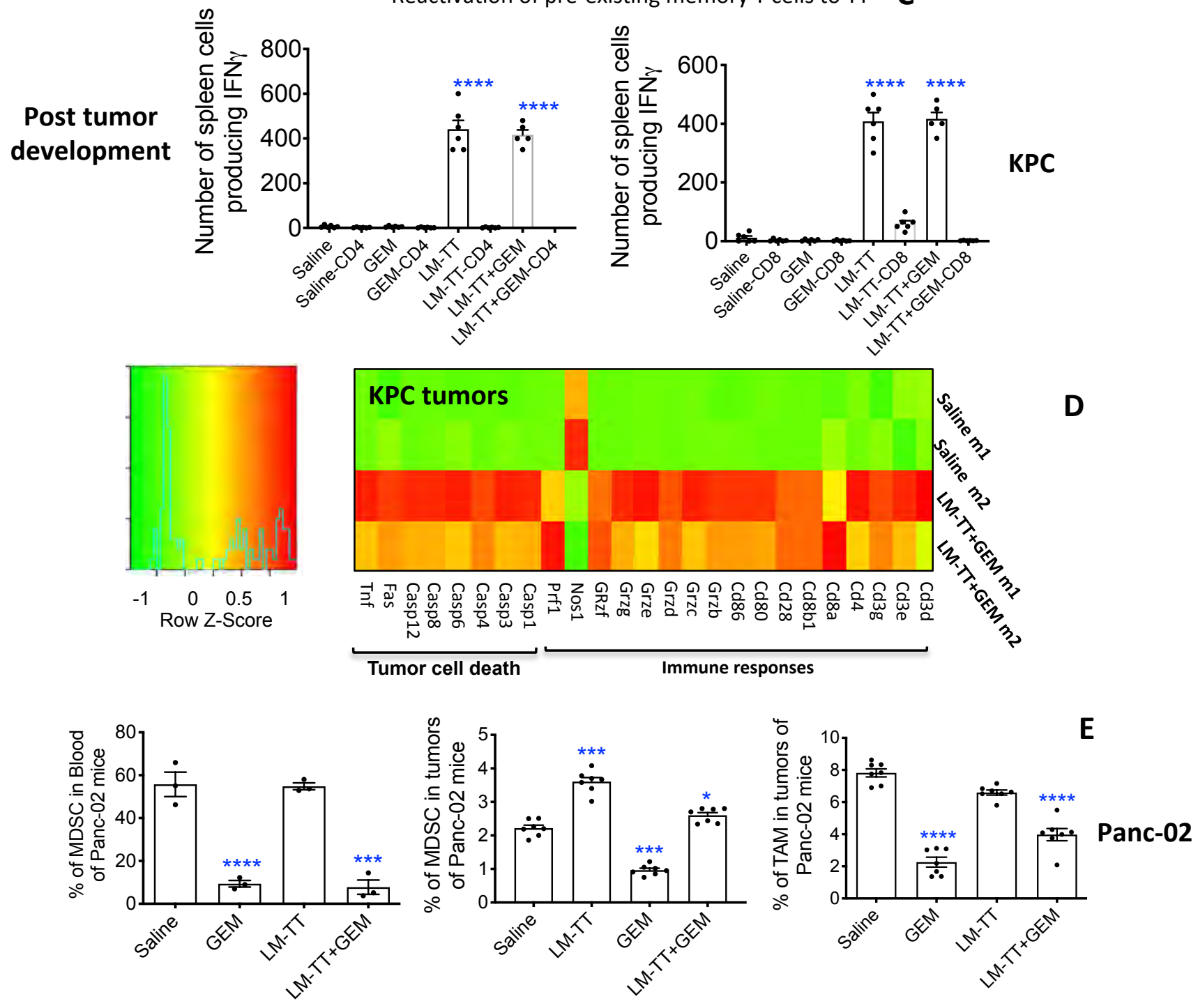

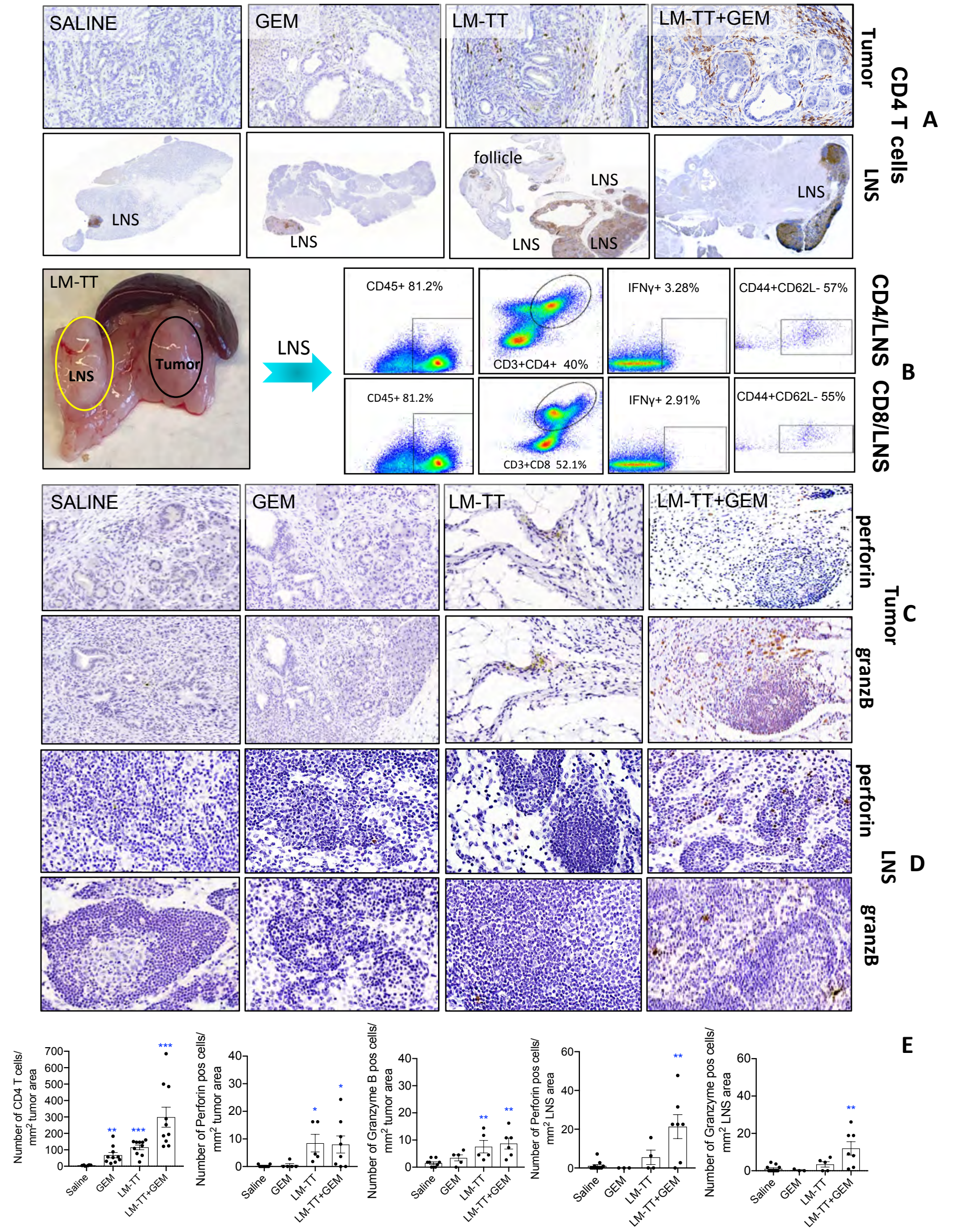
Listeria-TT+GEM robustly reduce advanced pancreatic cancer in KPC mice

A
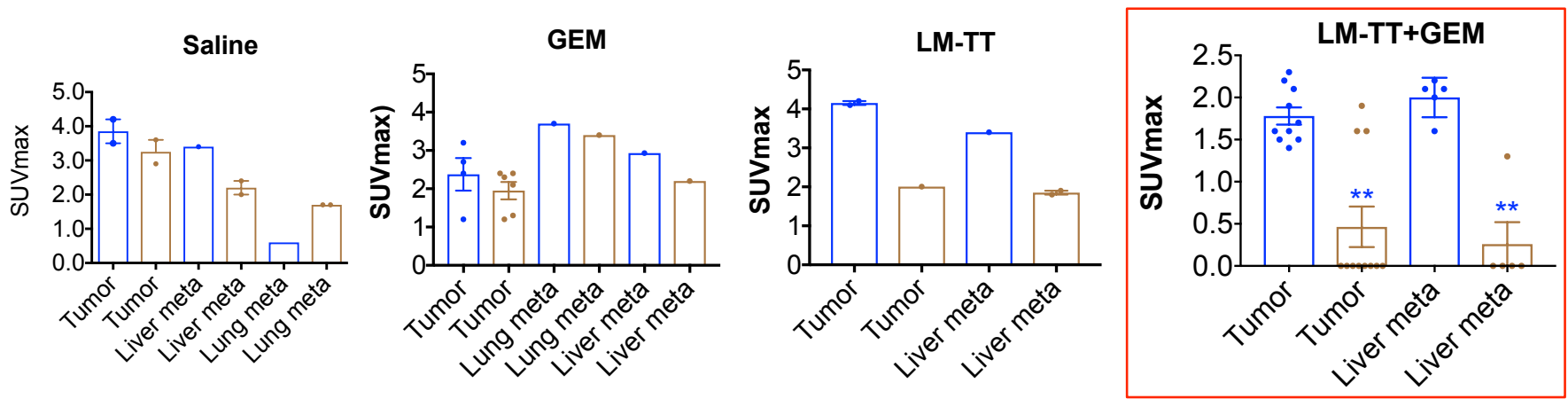

SUVmax prior treatment

SUVmax post treatment
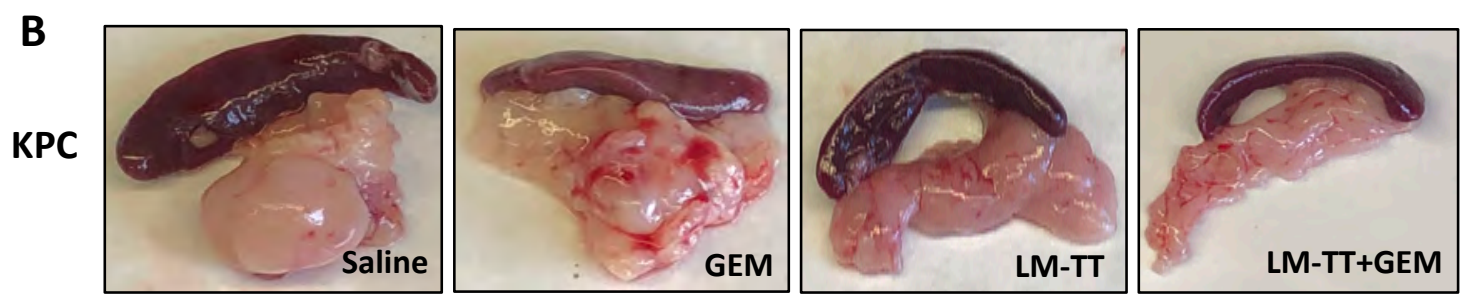

TT contributes to eradication of pancreatic cancer

LM vs LM-TT

C

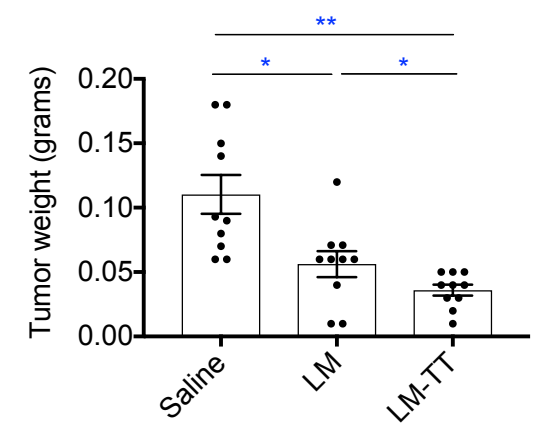

E

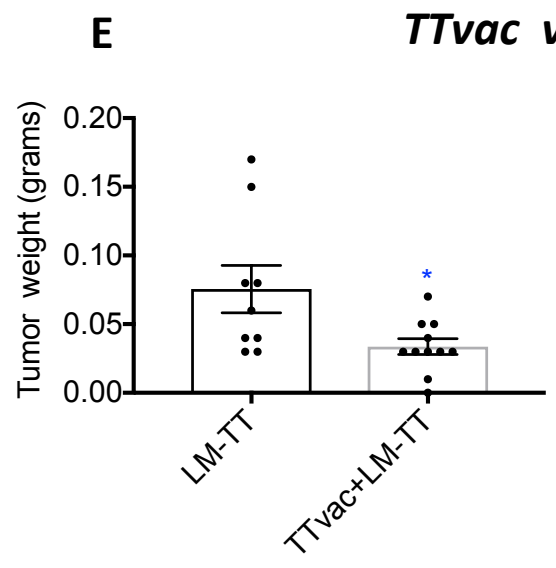

D KPC
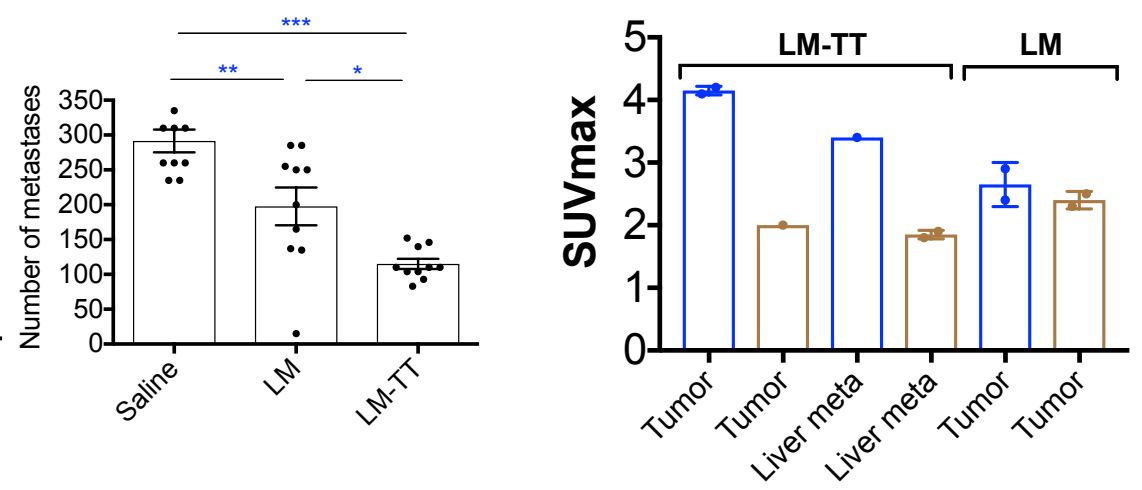

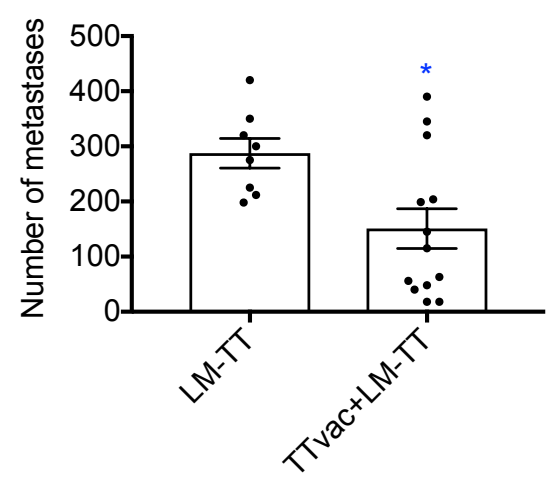

Panc-02 
Table 1A: Listeria-TT and GEM increases CD4 and CD8

$T$ cell responses in vivo in Panc-02 mice

$\begin{array}{lllll}\text { T cell responses* } & \text { Saline } & \text { GEM } & \text { LM-TT } & \text { LM-TT } \\ \text { CD3CD4CD69 } & 15.5 & 14.2 & 14.2 & 28.5 \\ \text { CD3CD8CD69 } & 16.7 & 15.5 & 15.5 & 33.2 \\ \text { CD3CD4Perforin } & 7.9 & 14.9 & 14.9 & 22.7 \\ \text { CD3CD8Perforin } & 2.1 & 4.8 & 4.9 & 6.2 \\ \text { CD3CD4Granzyme B } & 4.9 & 4.8 & 5.9 & 9.9 \\ \text { CD3CD8Granzyme B } & 1.2 & 1.1 & 1.2 & 2.4 \\ \text { CD3CD4IFNy } & 2.6 & 2.7 & 3.0 & 5.0 \\ \text { CD3CD8IFNy } & 0.5 & 0.4 & 0.4 & 0.9\end{array}$

* $T$ cell responses are provided in percentages (Flow cytometry).

An example of gating $T$ cells is shown in Fig. S2AB

All mice were treated as outlined in Fig. 1B. LM-TT = Listeria-TT

$\mathrm{n}=3$ mice per group (spleen cells were pooled). Representative of 2 experiments

Table 1B: Listeria-TT and GEM increases CD4 and CD8

$\mathrm{T}$ cell responses in vivo in KPC mice

$\begin{array}{lllll}\text { T cell responses } & \text { Saline } & \text { GEM } & \text { LM-TT } & \text { LM-TT+GEM } \\ \text { CD3CD4CD69 } & 13.5 & 10.01 & 6.59 & 17.34 \\ \text { CD3CD8CD69 } & 12.3 & 17.5 & 18.8 & 23.92 \\ \text { CD3CD4Perforin } & 0.26 & 7.90 & 8.22 & 14.27 \\ \text { CD3CD8Perforin } & 0.25 & 15.60 & 14.73 & 16.70 \\ & & & & \\ \text { CD3CD4Granzyme B } & 3.1 & 3.5 & 4.82 & 12.17 \\ \text { CD3CD8Granzyme B } & 1.6 & 9.71 & 9.82 & 12.60 \\ \text { CD3CD4IFNy } & 0.3 & 0.0 & 0.41 & 0.16 \\ \text { CD3CD8IFNy } & 0.0 & 1.7 & 1.85 & 3.33\end{array}$

${ }^{*} \mathrm{~T}$ cell responses are provided in percentages (Flow cytometry).

All mice were treated as outlined in Fig. 1B. LM-TT = Listeria-TT

$\mathrm{n}=3$ mice per group (spleen cells were pooled). Representative of 2 experiments.

Table 1C: Listeria-TT and GEM reduce immune suppressive function of MDSC $(\mathrm{CD} 11 \mathrm{~b}+\mathrm{Gr} 1+)$ in metastases of Panc-02 mice

$\begin{array}{lllll}\text { MDSC responses }^{*} & \text { Saline } & \text { LM-TT } & \text { GEM } & \text { LM-TT+GEM } \\ \text { IL-10 } & 3.46 & 2.44 & 2.76 & 1.45 \\ \text { IL-6 } & 4.25 & 4.05 & 3.59 & 1.97 \\ \text { TNFa } & 3.64 & 8.42 & 8.49 & 11.6 \\ \text { MARCO } & 3.38 & 3.70 & 3.84 & 1.79 \\ \text { CD80 } & 1.28 & 1.08 & 1.78 & 1.17\end{array}$

${ }^{*} \mathrm{MDSC}$ responses are provided in percentages (Flow cytometry).

An example of gating the MDSC is shown in Fig. S6A.

All mice were treated as outlined in Fig. 1B. LM-TT = Listeria-TT

$\mathrm{n}=3$ mice per group (CD45+ cells were pooled). This experiment was performed once.

Table 1D: Listeria-TT and GEM reduce immune suppressive function of TAM (CD11b+F4/80+) in metastases of Panc-02 mice

$\begin{array}{lllll}\text { TAM responses* }^{*} & \text { Saline } & \text { LM-TT } & \text { GEM } & \text { LM-TT+GEM } \\ \text { IL-10 } & 1.45 & 0.65 & 1.47 & 0.72 \\ \text { IL-6 } & 1.09 & 0.76 & 1.25 & 0.42 \\ \text { TNFa } & 4.78 & 8.73 & 8.85 & 8.04 \\ \text { MARCO } & 1.96 & 2.16 & 1.94 & 1.33 \\ \text { CD80 } & 1.93 & 3.07 & 4.28 & 5.26\end{array}$

*TAM responses are provided in percentages (Flow cytometry).

An example of gating TAM is shown in Fig. S6B.

All mice were treated as outlined in Fig. 1B. LM-TT = Listeria-TT

$\mathrm{n}=3$ mice per group (CD45+ cells were pooled). This experiment was performed once. 


\section{SUPPLEMENTARY INFORMATION}

Tumor-targeted delivery of childhood vaccine recall antigens by attenuated Listeria reduces pancreatic cancer

Benson Chellakkan Selvanesan ${ }^{1 \$}$, Dinesh Chandra ${ }^{1 \$}$, Wilber Quispe-Tintaya ${ }^{1 \$}$, Arthee Jahangir $^{1}$, Ankur Patel ${ }^{1}$, Kiran Meena ${ }^{1}$, Rodrigo Alves Da Silva ${ }^{1}$, Steven K Libutti ${ }^{2}$, Ziqiang Yuan ${ }^{2}$, Jenny $\mathrm{Li}^{1}$, Sarah Siddiqui1, Amanda Beck ${ }^{3}$, Lydia Tesfa ${ }^{4}$, Wade Koba ${ }^{5}$, Jennifer Chuy ${ }^{6}$, John C. McAuliffe ${ }^{7}$, Rojin Jafari ${ }^{8}$, David Entenberg ${ }^{8,9,10}$, Yarong Wang $^{8,9,10}$, John Condeelis $8,9,10,11$, and Claudia Gravekamp ${ }^{1 *}$. 
Fig. S1: Intraperitoneally but not intravenously injected Listeria colonizes tumors and metastases

Experiments conducted in three different mouse models showed that Listeria colonized the TME efficiently if injected intraperitoneally (ip), but very poorly or not at all when injected intravenously (iv). (A) Balb/C mice were injected into the mammary fat pad with 4T1 tumor cells, resulting in primary tumors in the peritoneal membrane and multiple metastases in the liver, pancreas and along the GI, as described previously ${ }^{1}$. After tumors and metastases had developed, Listeria $\left(10^{7} \mathrm{CFU}\right)$ was injected ip or iv, and the number of Listeria bacteria was determined 1, 3, or 4 days later in blood and all organs, including tumors and metastases, as done previously ${ }^{2}$. (B) A similar experiment in the Panc-02 mouse peritoneal cavity model. Panc-02 tumor cells were injected into the mammary fat pad of Panc-02 mice, resulting in a primary tumor in the peritoneal membrane and multiple metastases in the pancreas, liver and gastrointestinal tract, as described previously ${ }^{3}$. Ten days later, when primary tumor was palpable at the place of injection and metastases had developed, Listeria-TT was administered as above. CFU in the blood, tumors, metastases and normal tissue (spleen) were determined 3 days later as described previously ${ }^{3}$. (C) A similar experiment in the 4T1 model. Injection of 4T1 tumor cells into the mammary fat pad resulted in a primary mammary tumor and metastases in the lungs within 4 weeks, Listeria-TT was administered, and CFU measured 3 days later, as described previously ${ }^{4}$. In A-C, $n=3$ mice per timepoint and multiple tissues per organ/tumor/metastases have been analyzed.

Fig. S2: Gating of CD4 and CD8 T cells in spleens of tumor-bearing Panc-02 mice treated with Listeria-TT and GEM, in combination or separately

Examples of gating (A) the CD4 T cells and (B) CD8 T cells isolated from spleens of treated and control mice. CD3CD4-pos cells and CD3CD8-pos cells were gated, 
followed by gating of CD4 or CD8 T cells producing IFNy, Perforin, Granzyme B, or expressing CD69. A similar gating protocol was used to analyze CD4 and CD8 T cells in spleens of KPC mice.

$\mathrm{LM}-\mathrm{TT}=$ Listeria-TT.

Fig. S3: Detail of CD4 and CD8 T cells in tumors of Listeria-TT+GEM-treated and control mice

$\mathrm{KPC}$ mice received treatment with Listeria-TT+GEM, or control treatments, as outlined in

Fig 1B. Two days after the last treatment, tumor tissues were analyzed by IHC for the presence of CD4 (A-D) and CD8 (E-H) T cells. CD8, and particularly CD4 T cells, were predominantly observed in the tumor areas of KPC mice that received Listeria-TT or Listeria-TT+GEM.

$\mathrm{LM}-\mathrm{TT}=$ Listeria-TT.

Fig. S4: Detail of lymph node-like structures associated with pancreatic tumors in mice.

CD4 T cells (A) in tumor areas with TT (B) and CD31 (C) expression by IHC of KPC mice treated with Listeria-TT+GEM. Circles mark tumor areas. (D) Example of LNS in close proximity to a pancreatic tumor of a KPC mouse. In the overview of the lymphoid structure, there were well-developed follicular structures, many of which contained a pale germinal area at the center. CD4+ T cells were concentrated in the cortex and in the deep cortical zone/paracortex, where they were arranged in sheets rather than follicles. CD8+ T cells were concentrated within the deep cortical zone/paracortex. Below are views of the lymphoid structure at higher magnification, to visualize the density of CD4+ and CD8+ T cells. CD4+ cells were located mostly within the cortex, surrounding and within the follicles, and in the paracortex. CD8+ cells were primarily within the 
paracortex. (E) Production of Granzyme B and Perforin in LNS of KPC mice treated with saline, GEM, Listeria-TT, or Listeria-TT+GEM, detected by IHC.

$\mathrm{LM}-\mathrm{TT}=$ Listeria-TT.

Fig. S5: Effect of LM-TT+GEM treatment on expression of genes involved in T cell migration, efficacy and safety

(A) Detection of chemokines and their receptors in pancreatic tumors of Listeria TT+GEM-treated or untreated KPC mice by RNAseq. Results of 2 mice are shown in each group. Log2-fold increase in the group of Listeria-TT+GEM compared to the untreated mice. The heatmap was generated by unbiased hieratical clustering at the following statistical parameters. Statistical parameters for the paired-wise comparison: $p<0.05$. (B) LM-TT+GEM testing in the Panc-02 mouse peritoneal cavity model of early pancreatic cancer. Treatments began three days after tumor cell injection as outlined in Fig 1B. Mice were euthanized after treatment, and analyzed for tumor weight and the number of metastases. Two independent experiments with 5 mice per group were averaged. (C) LM-TT+GEM testing in the Panc-02 mouse peritoneal cavity model of advanced pancreatic cancer. Treatments began ten days after tumor cell injection as outlined in Fig 1B. Two independent experiments with 5 mice per group were averaged. (D) LM-TT+GEM testing in the orthotopic Panc-02 mouse model of advanced pancreatic cancer. Treatments were started 14 days after tumor cell injection as outlined in Fig $1 \mathrm{~B}$. Averages are shown for a single experiment with 5 mice in each group. Error bars represent standard error of the mean. Mann-Whitney ${ }^{*} p<0.05,{ }^{* * *} p<0.01$. Examples of pancreatic metastases and tumors are shown of early pancreatic cancer in the peritoneal Panc-02 model (E), advanced pancreatic cancer in the peritoneal Panc-02 model (F), and advanced pancreatic cancer in the orthotopic Panc-02 model (G). 
(H) Dose-limiting toxicity study of Listeria-TT in tumor-naive C57BI6 mice ( $\mathrm{n}=5$ mice per group).

Fig. S6: Flow cytometry demonstration of MDSC and TAM in metastases of tumorbearing Panc-02 mice.

(A) Example of gating of MDSC cells present in metastases of treated and control mice.

First, live cells were gated. Subsequently, CD11bGr1-pos cells (MDSC) were gated in the live cell population, followed by the gating of Gr1-pos cells producing IL-10, IL-6, TNFa, or expressing MARCO or CD80 as indicated in the figure. (B) Example of gating TAMs present in metastases of treated and control mice. First, CD45+ leukocytes were gated to exclude tumor cells, followed by gating of CD11bF4/80-pos cells, followed by F4/80-pos cells producing IL-10, IL-6, TNFa, or expressing MARCO or CD80.

\section{REFERENCES}

1. Kim, S.H., et al. Mage-b vaccine delivered by recombinant Listeria monocytogenes is highly effective against breast cancer metastases. British journal of cancer $99,741-749$ (2008).

2. Chandra, D., et al. 32-Phosphorus selectively delivered by listeria to pancreatic cancer demonstrates a strong therapeutic effect. Oncotarget 8, 20729-20740 (2017).

3. Quispe-Tintaya, W., et al. Nontoxic radioactive Listeria(at) is a highly effective therapy against metastatic pancreatic cancer. Proc Natl Acad Sci U S A 110, 8668-8673 (2013).

4. Chandra, D., et al. Cryoablation and Meriva have strong therapeutic effect on triple-negative breast cancer. Oncoimmunology 5, e1049802 (2016). 
iv injected Listeria

ip injected Listeria
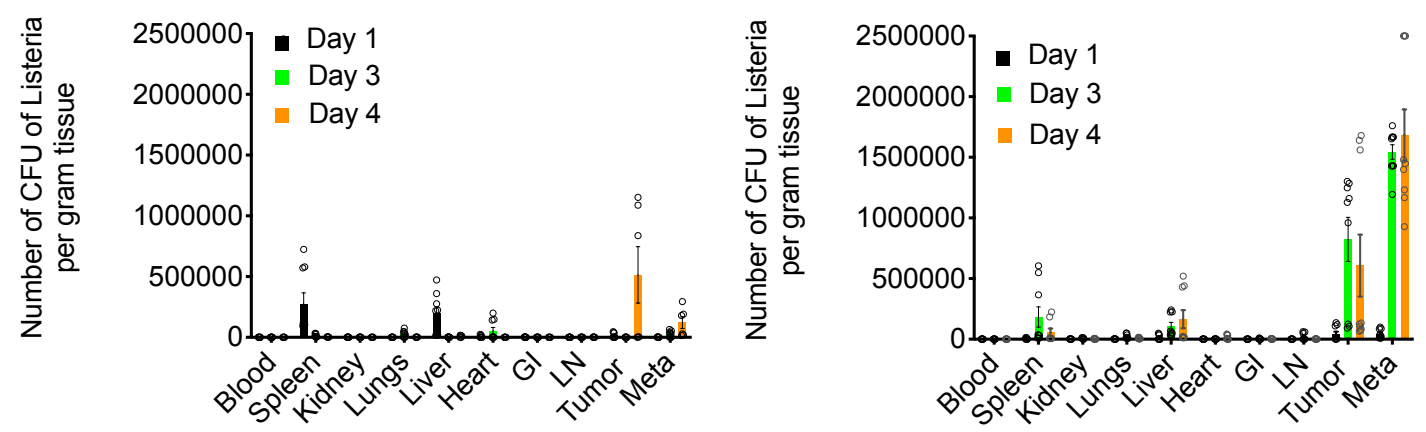

A
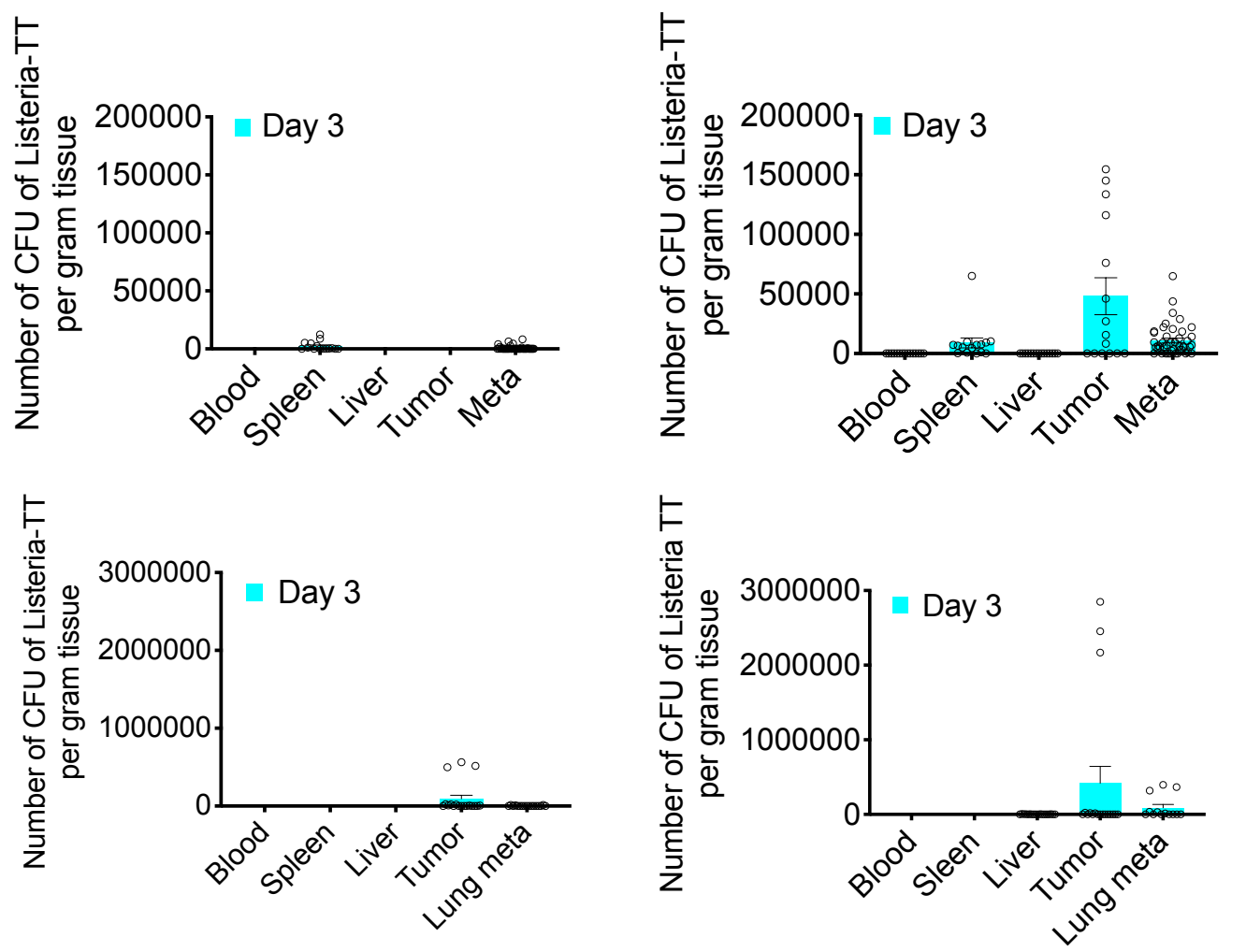

B 


\section{Saline}
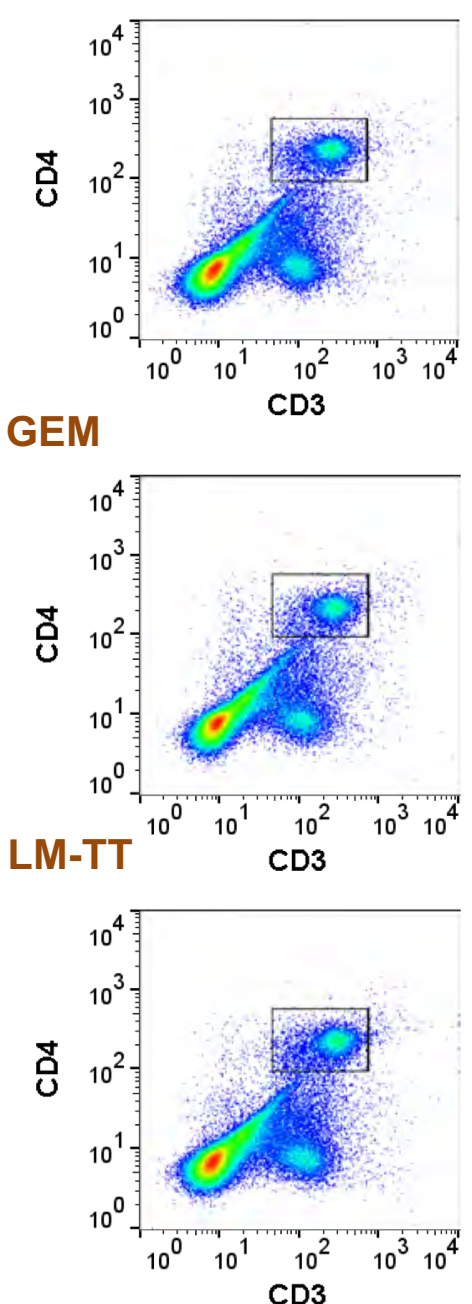

\section{LM-TT + GEM}

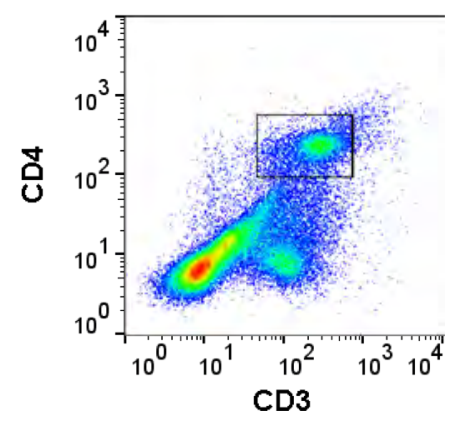

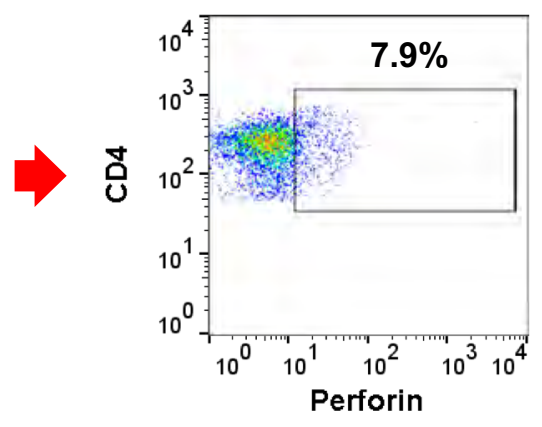
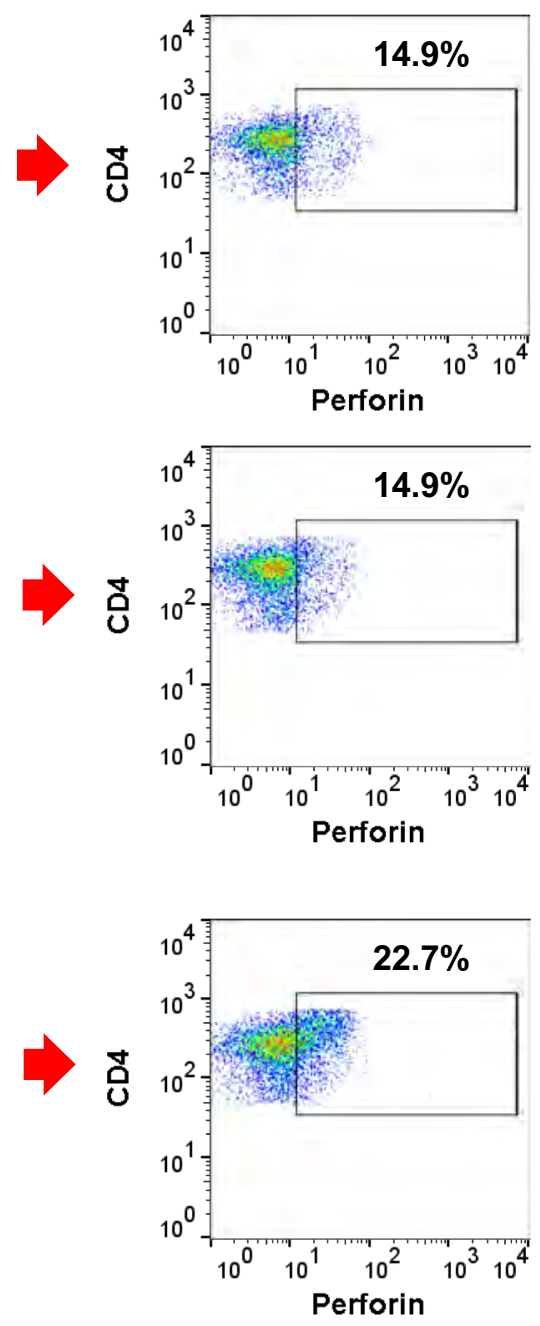
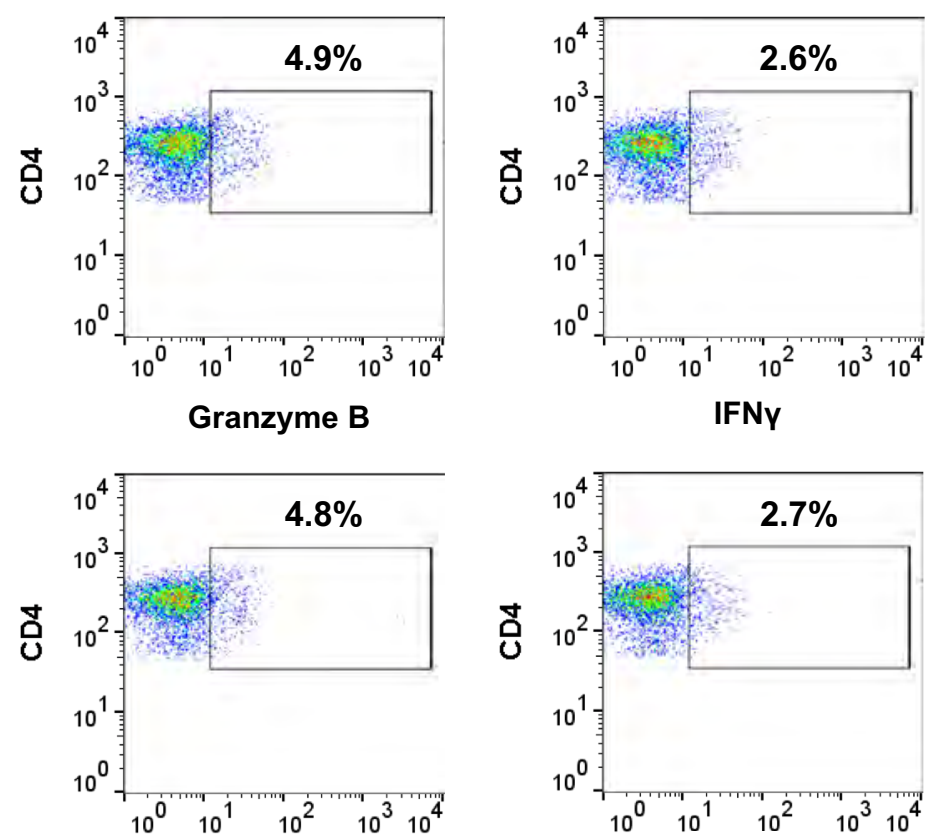

Granzyme B
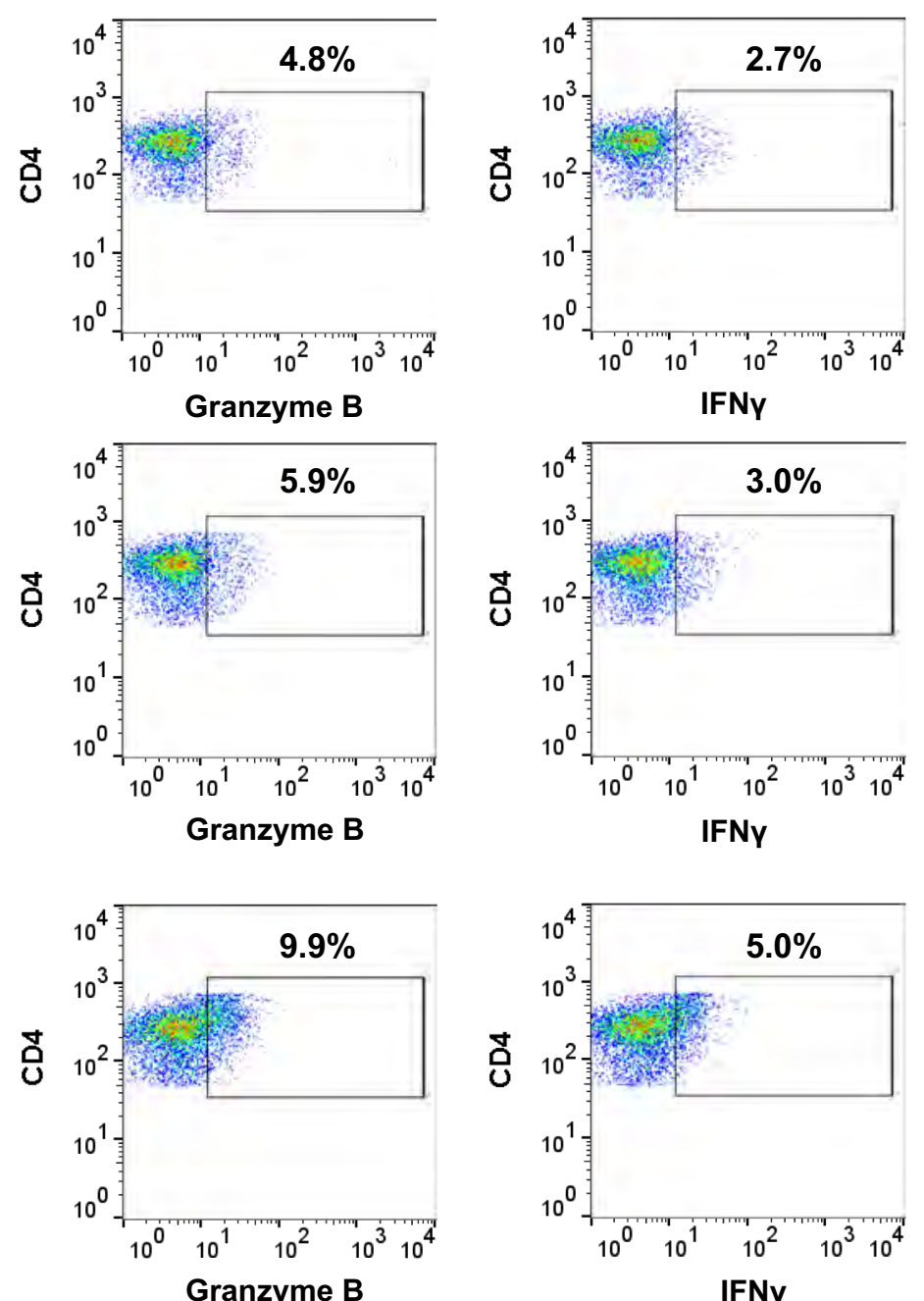

Figure S2A
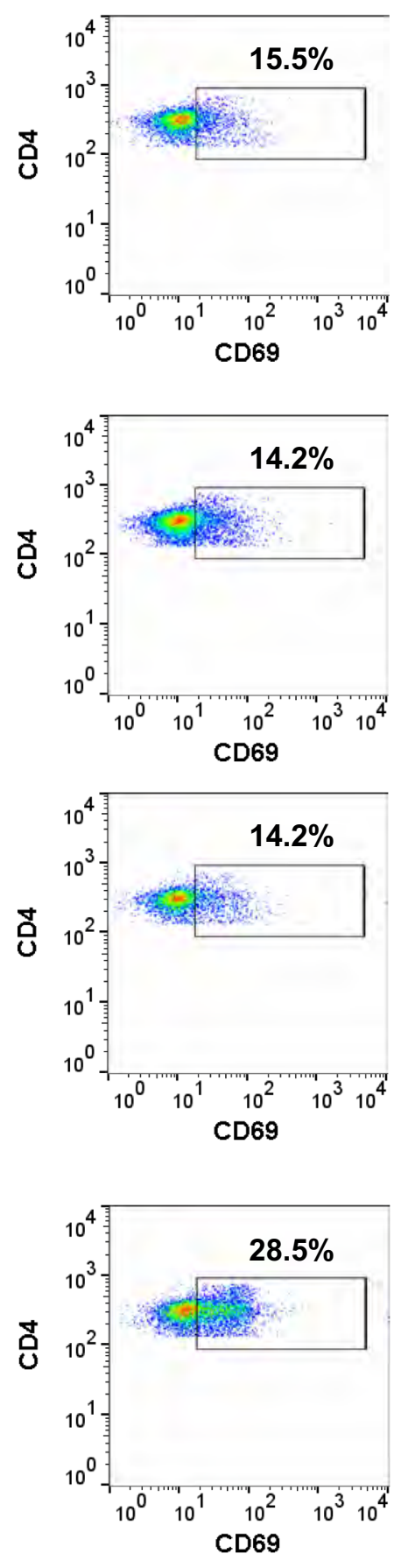


\section{Saline}

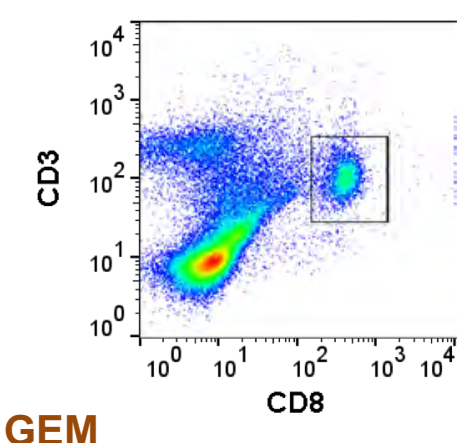

GEM
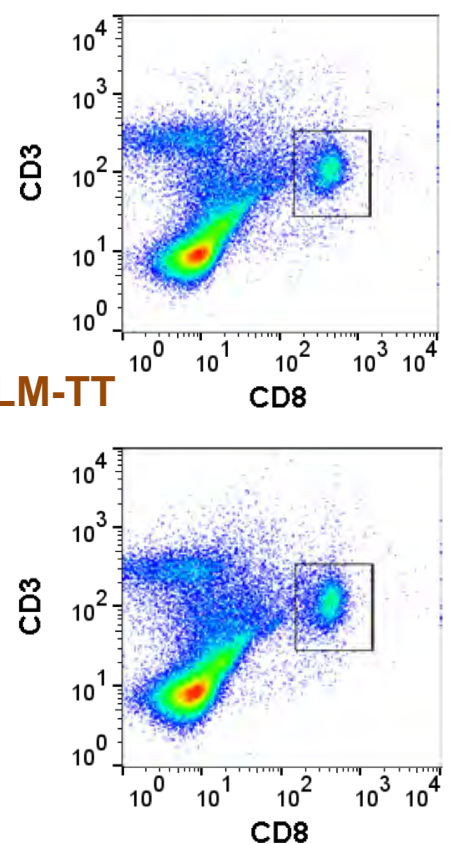

LM-TT + GEM

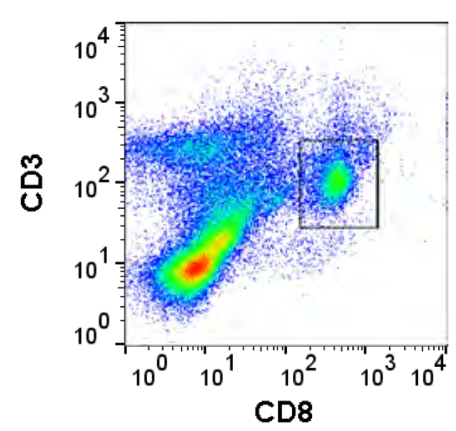

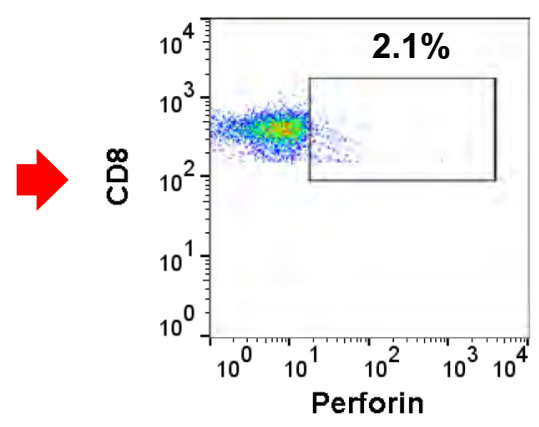
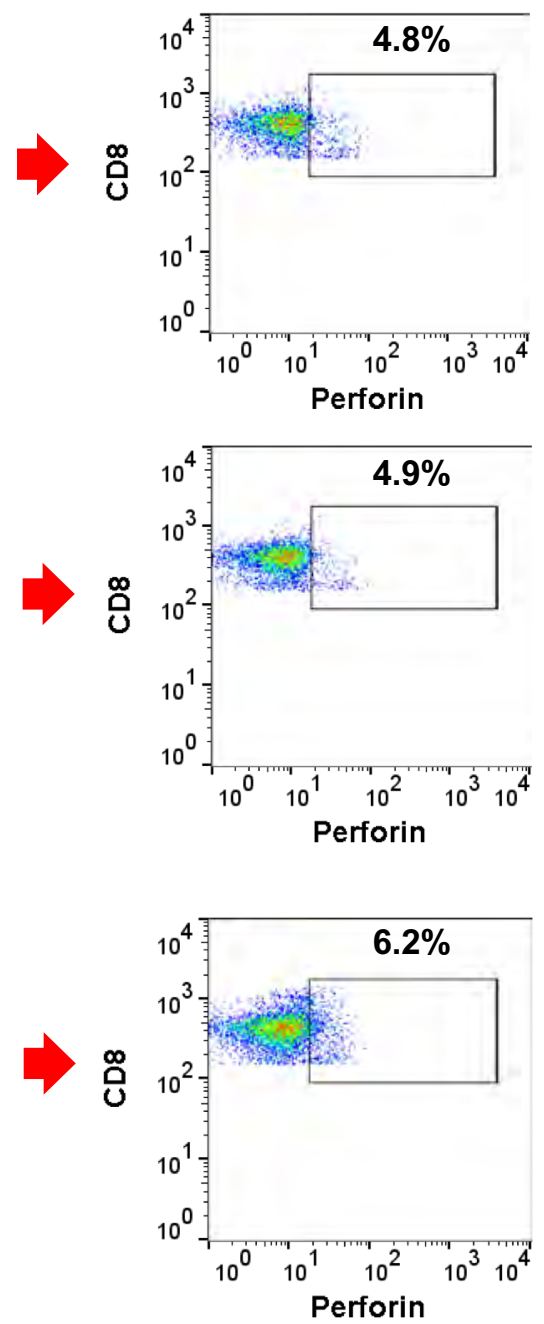
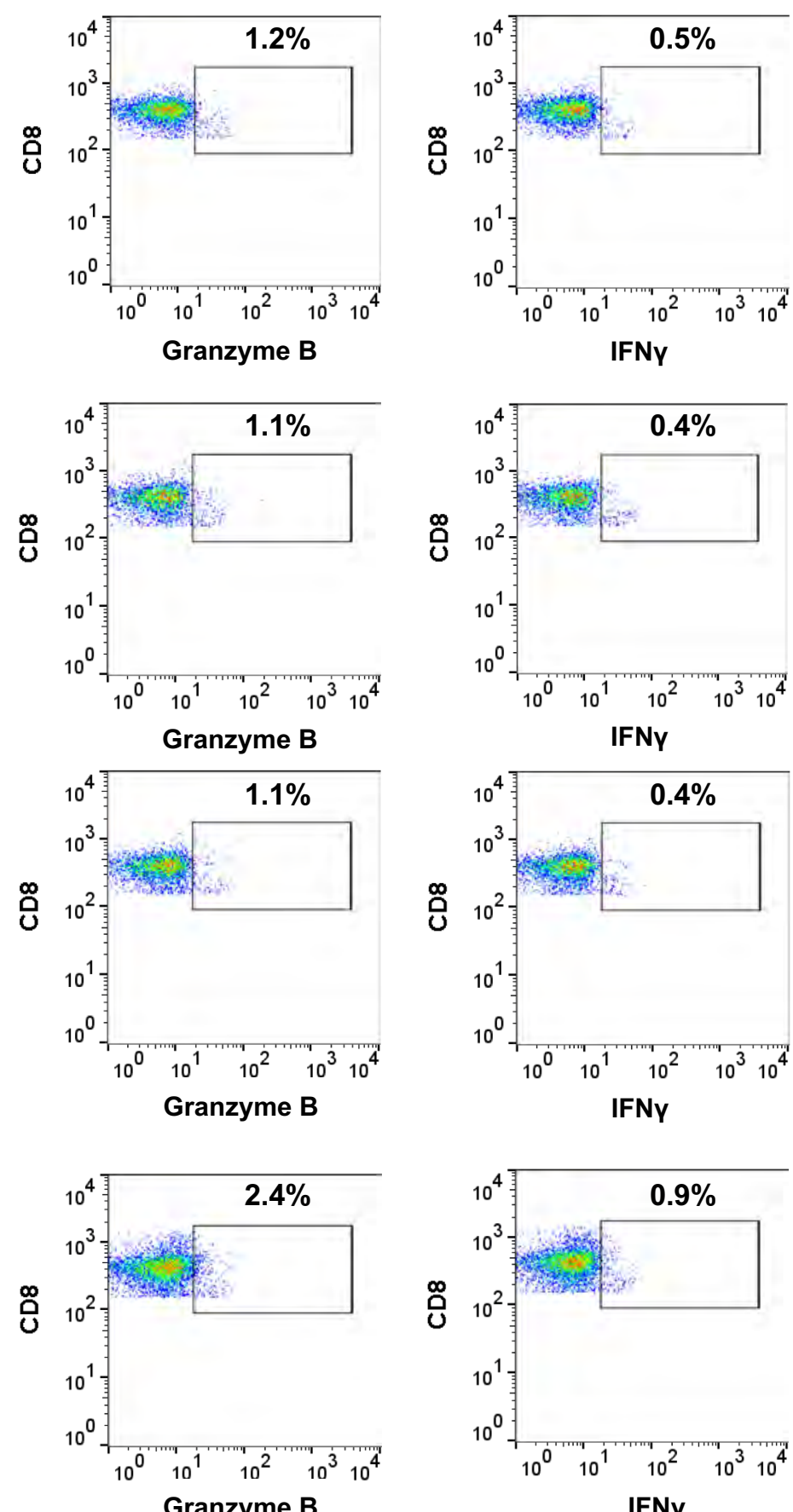

Figure S2B
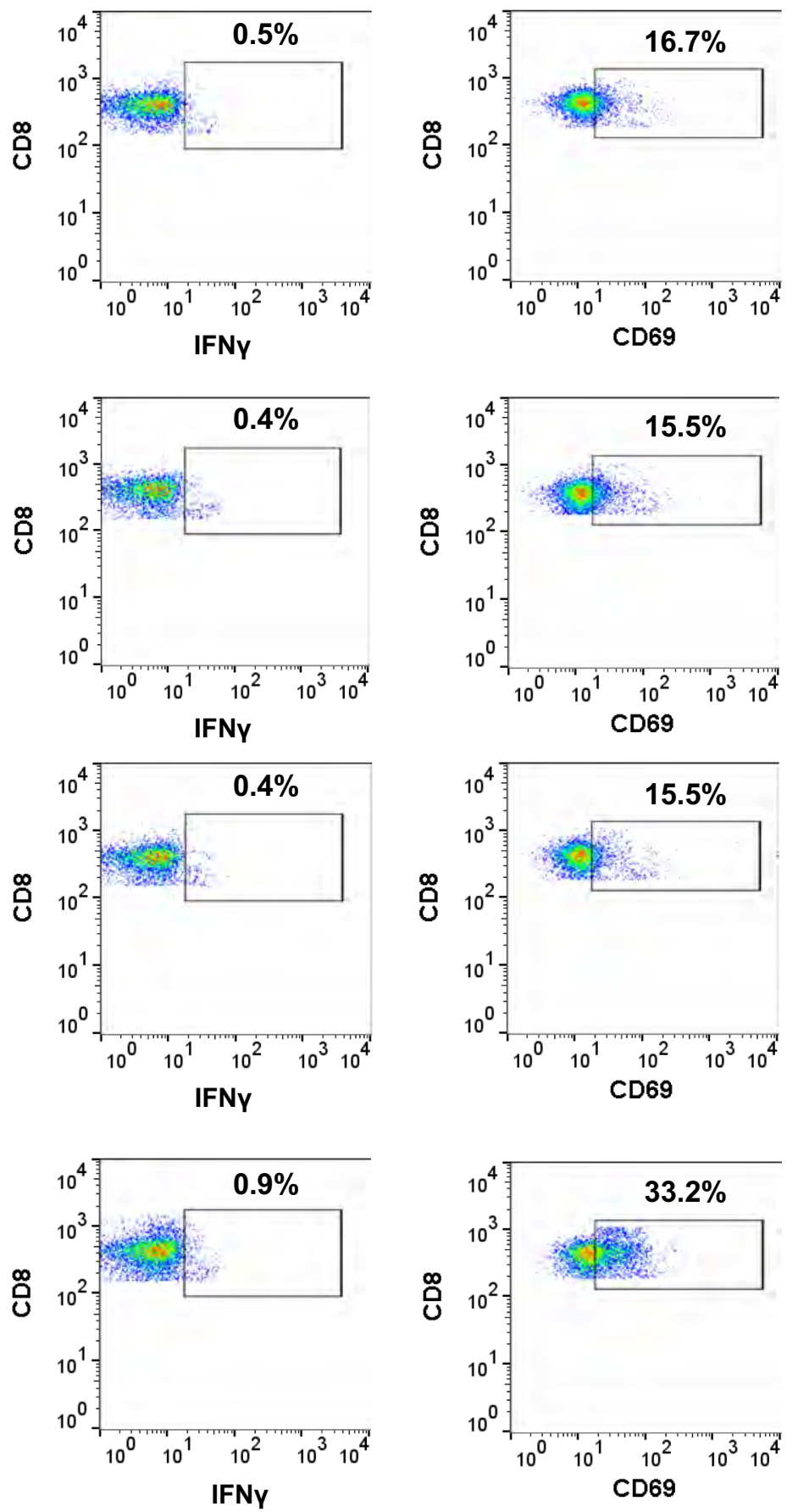


\section{Saline \\ CD4}

Figure S3A
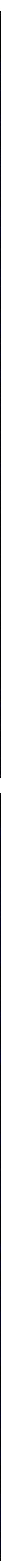


\section{GEM \\ CD4}

Figure S3B
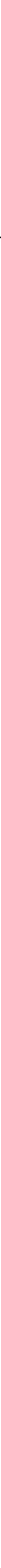

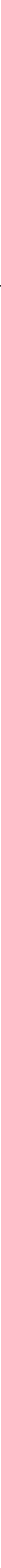


\section{LM-TT+GEM \\ CD4}

Figure S3D
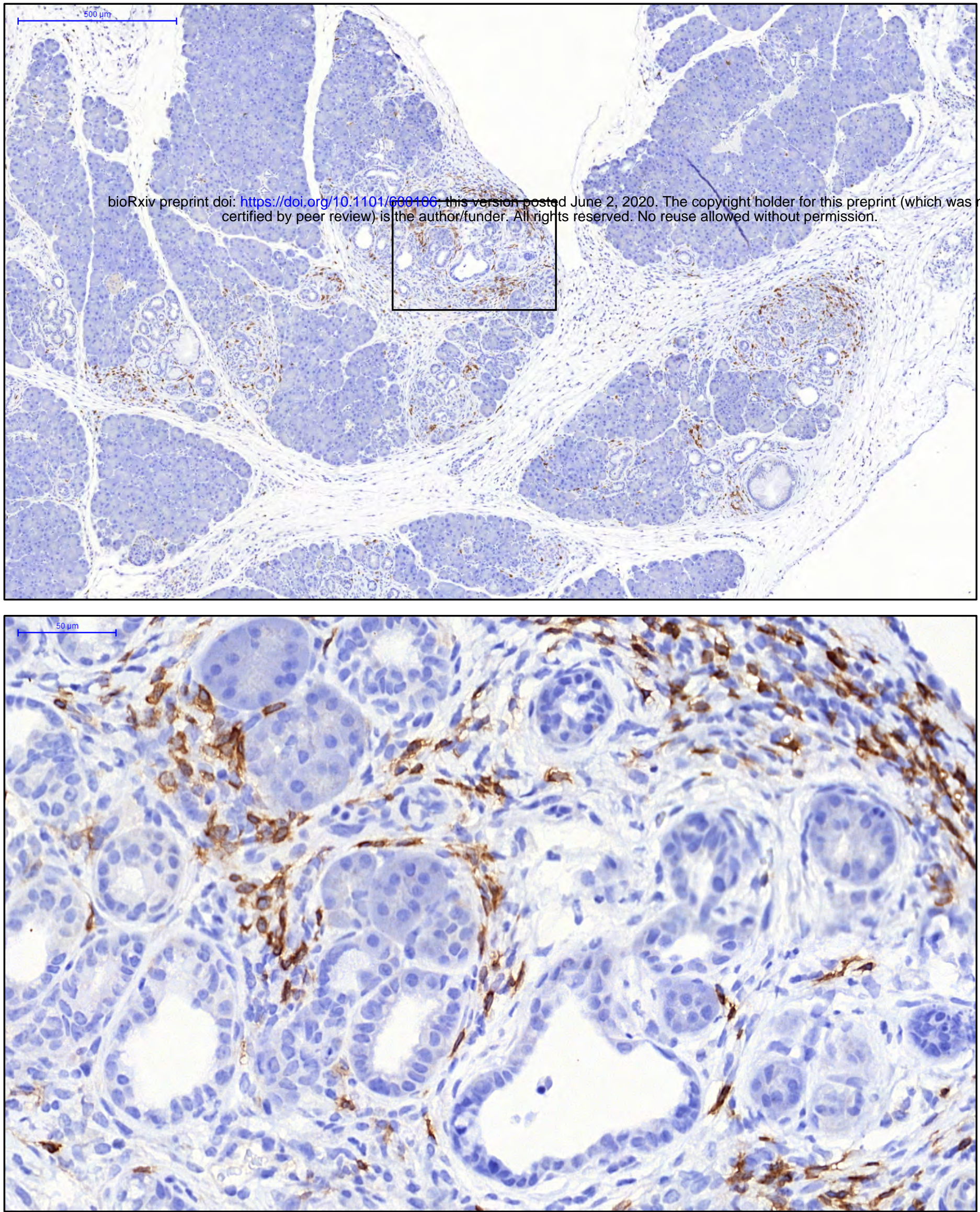


\section{Saline \\ CD8}

Figure S3E
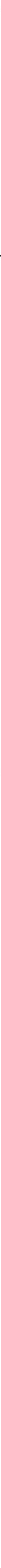


\section{GEM \\ CD8}

Figure S3F
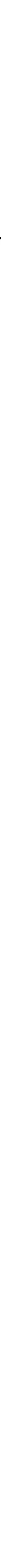


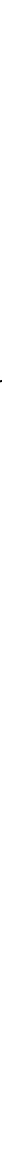

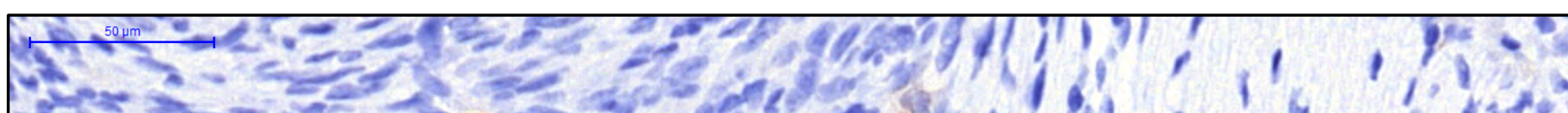

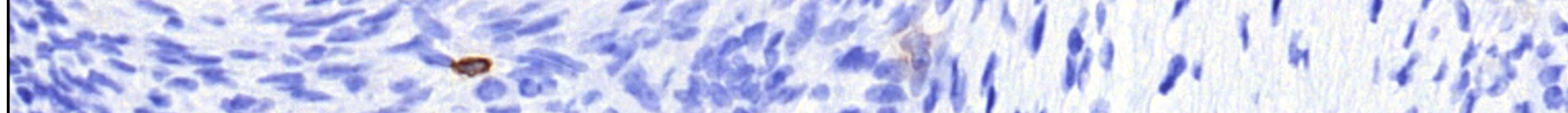

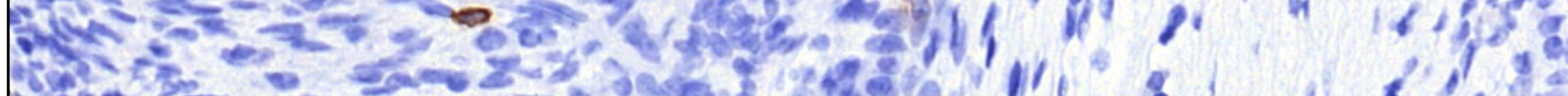
W.

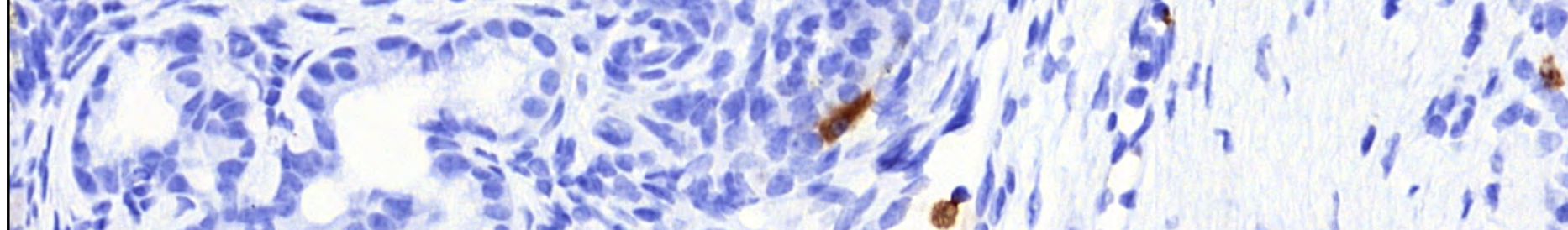

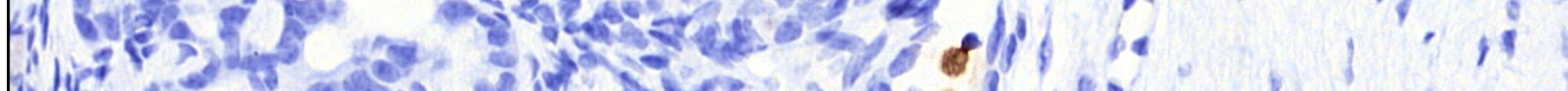
I i if

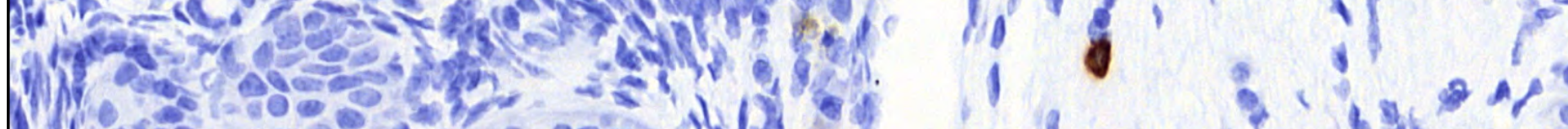

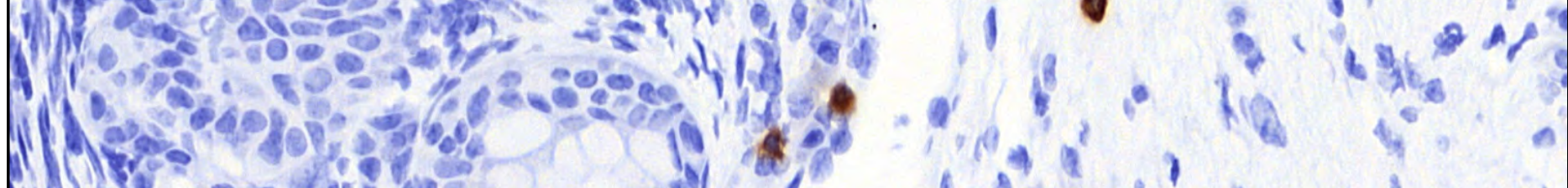
ro 40 Hot 


\section{CD8}
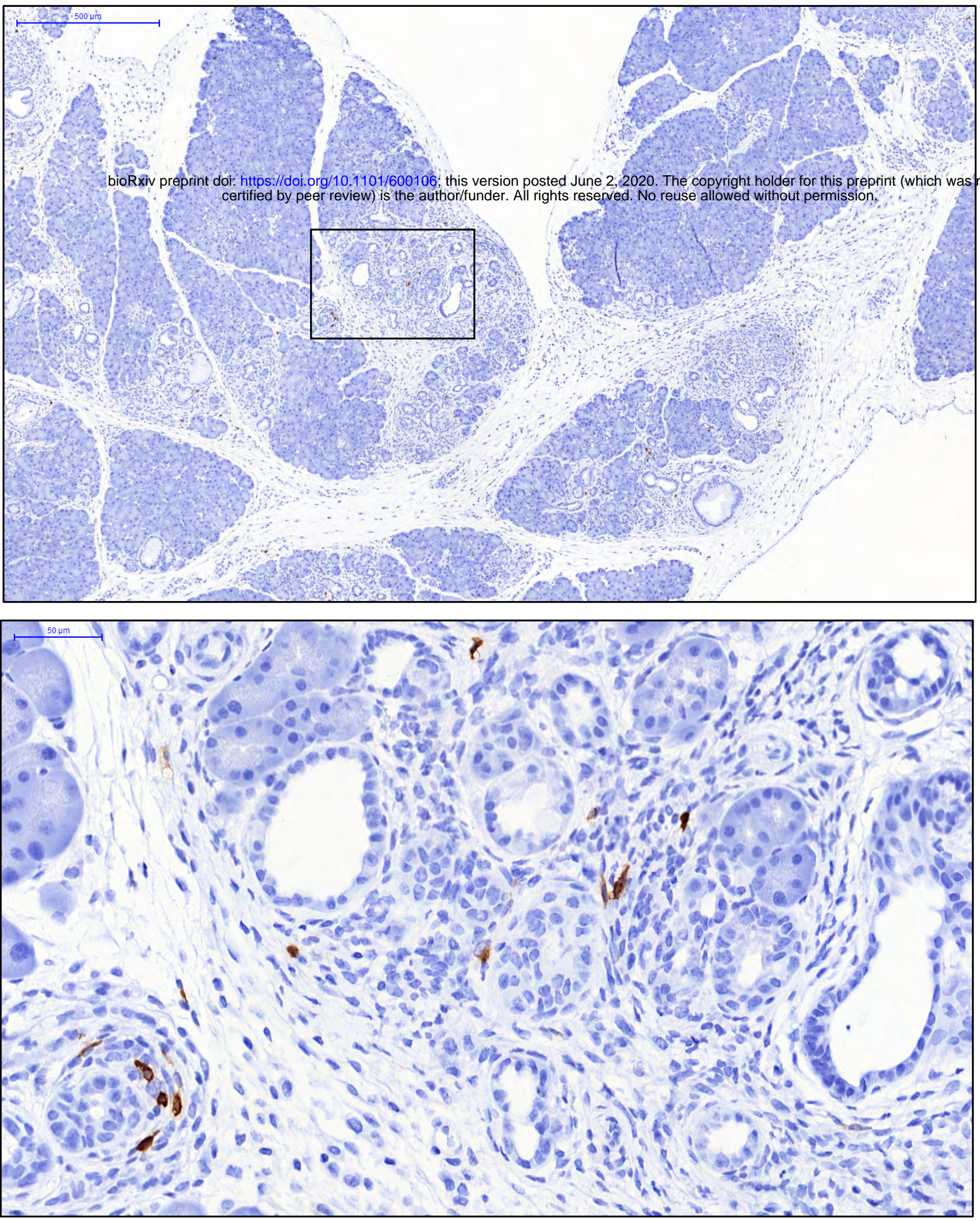

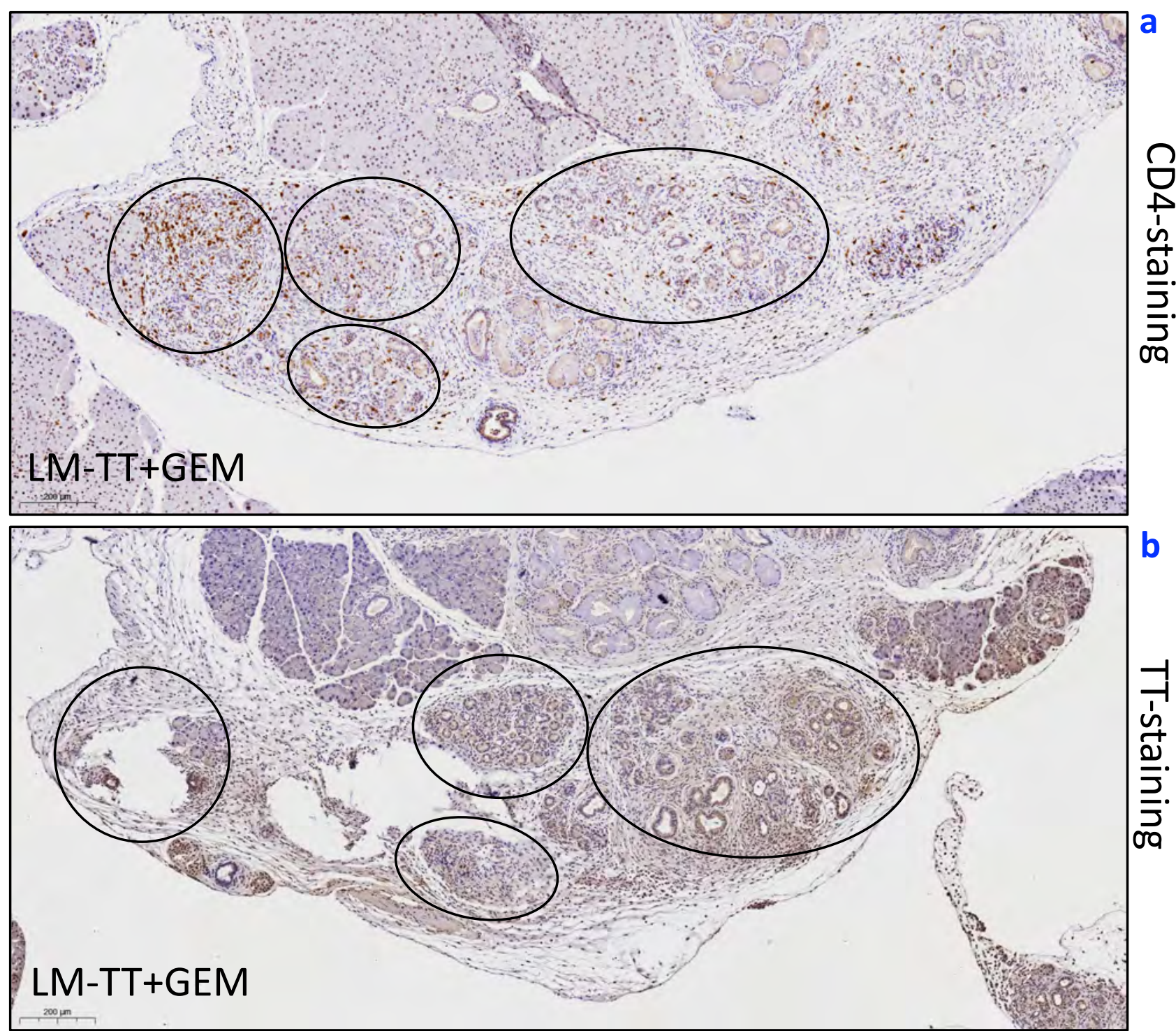

b

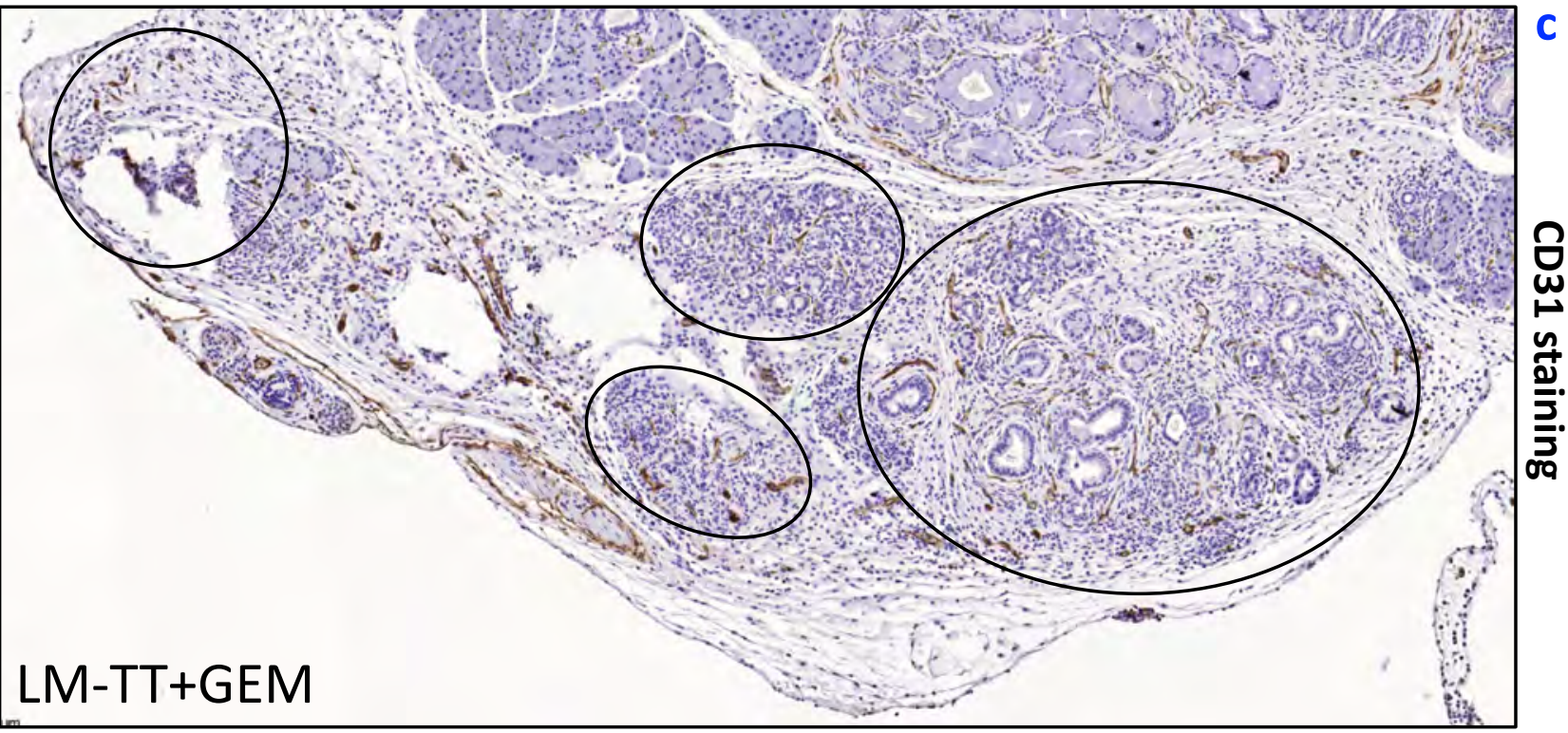



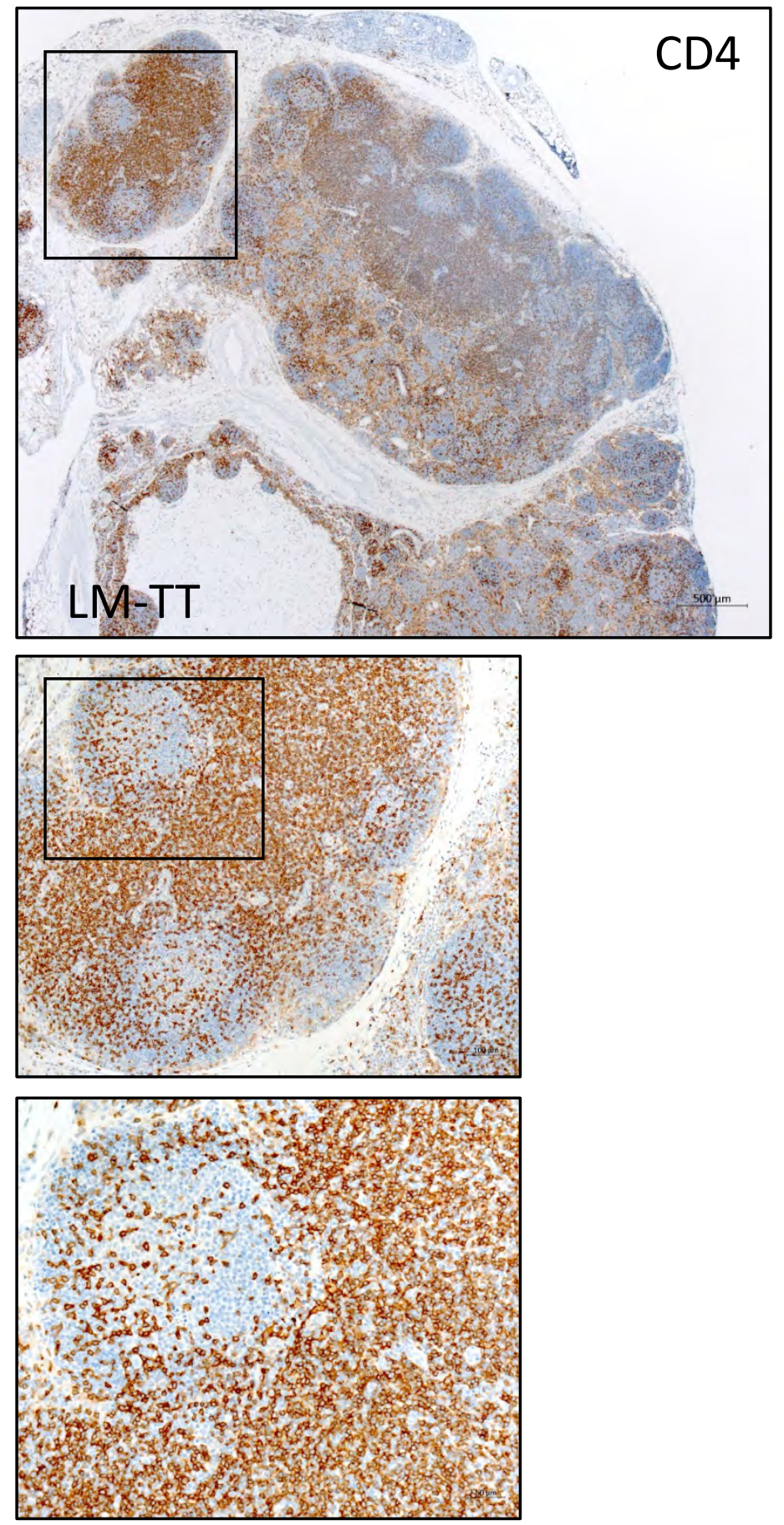
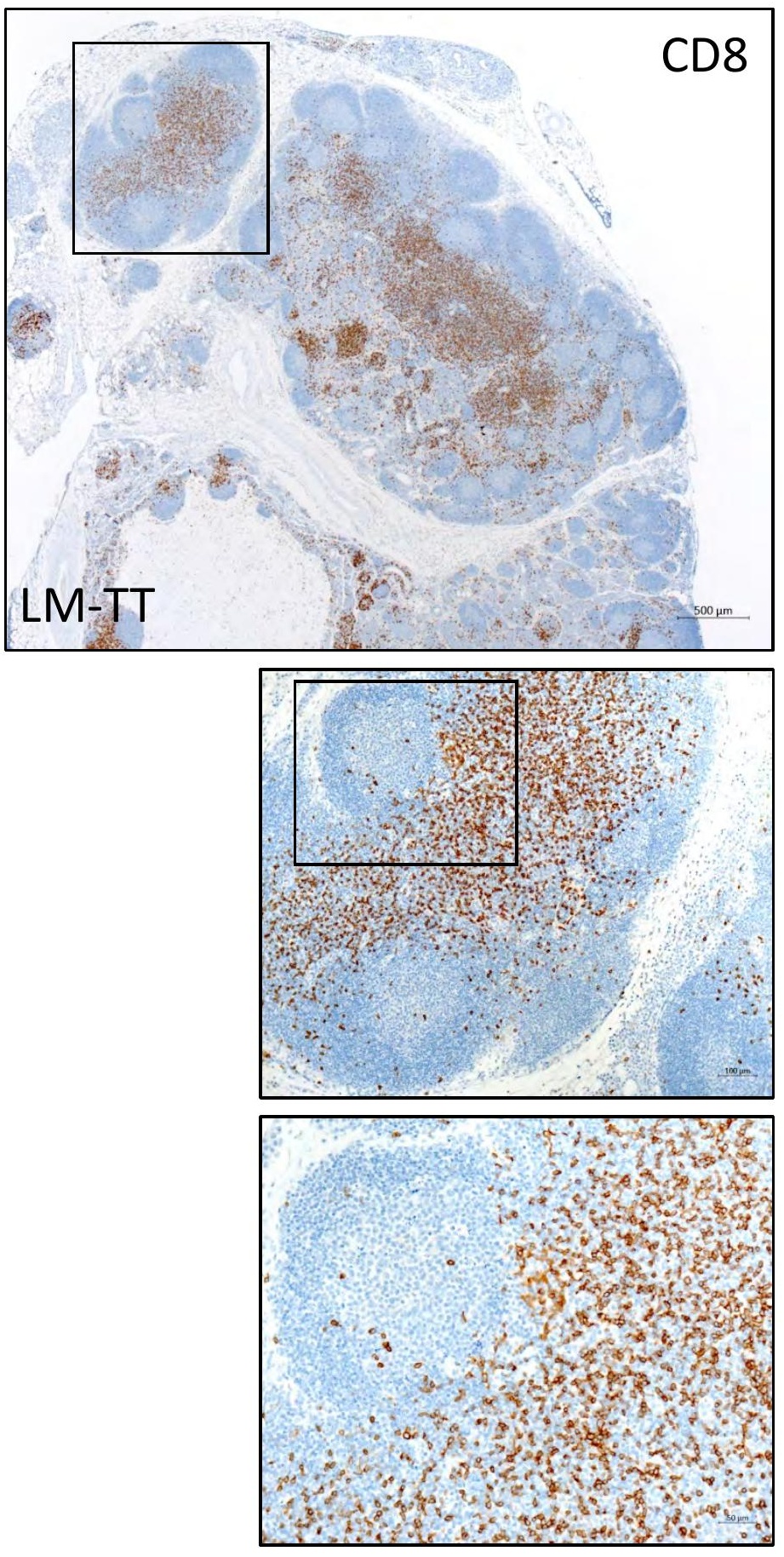


\section{Saline/Granzyme B \&}

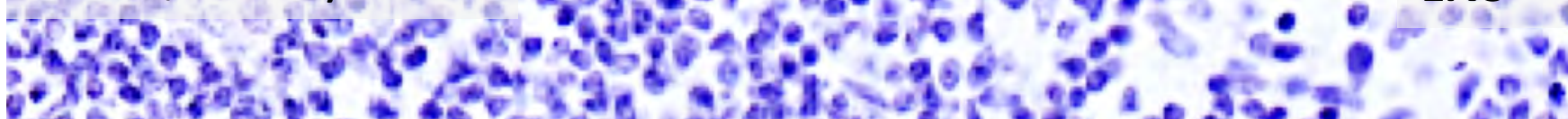

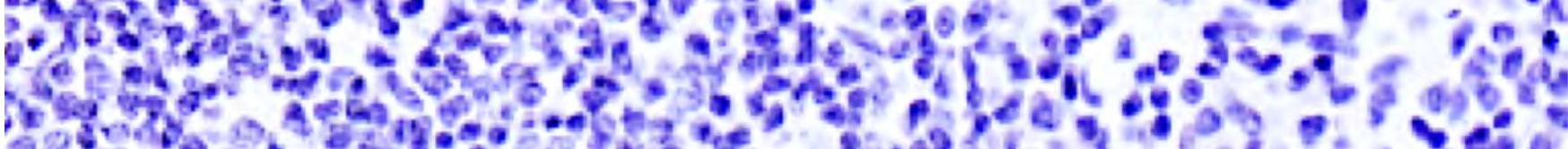

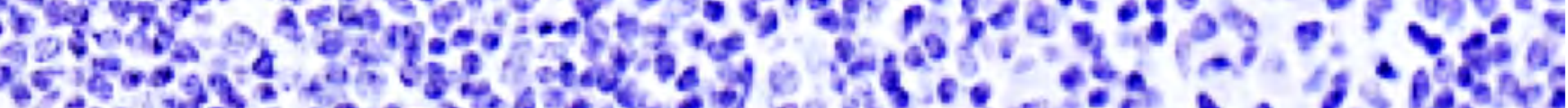

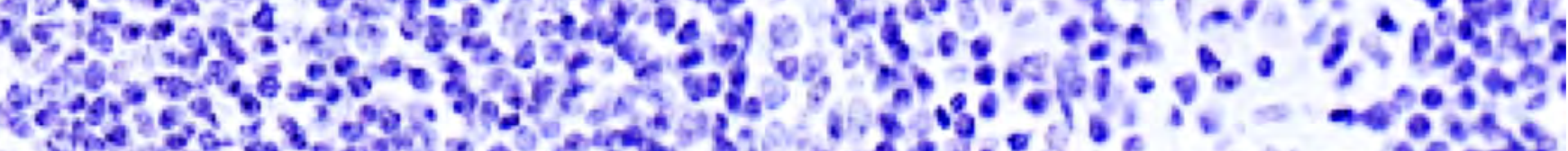

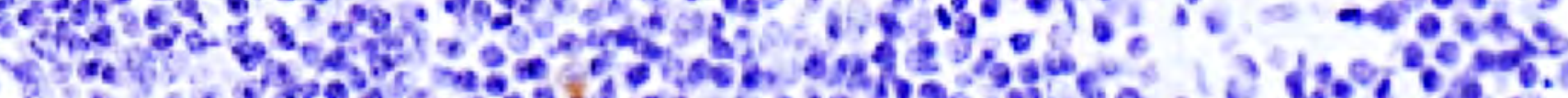

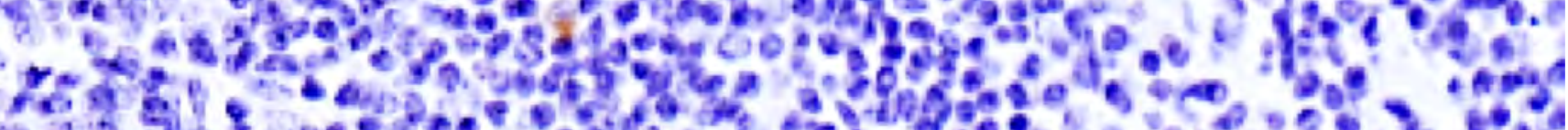

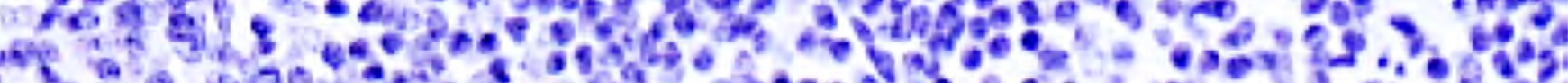

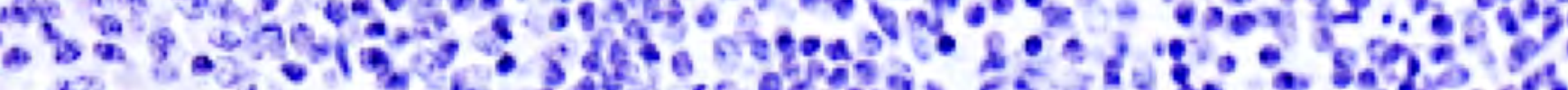

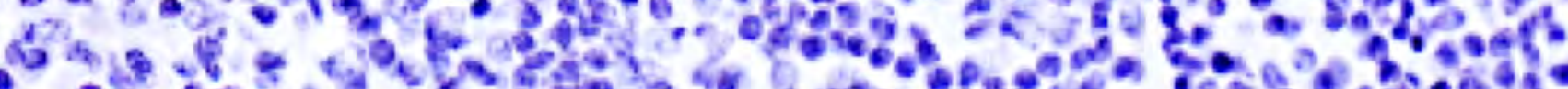

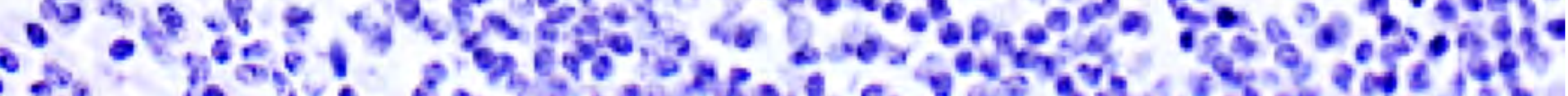

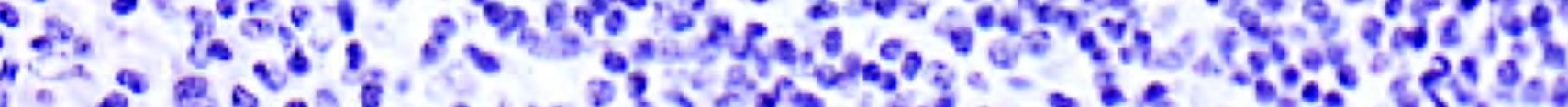

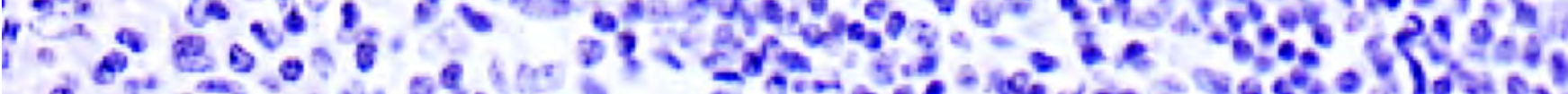

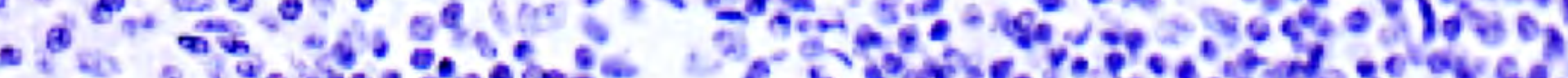

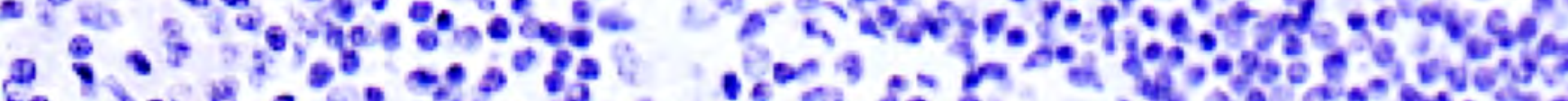

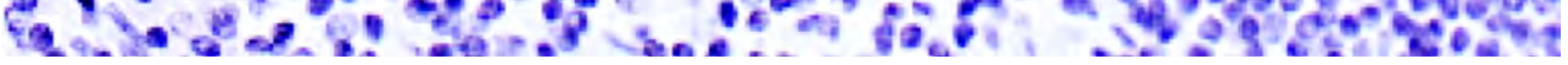

\section{GEM/Granzyme B of of of}

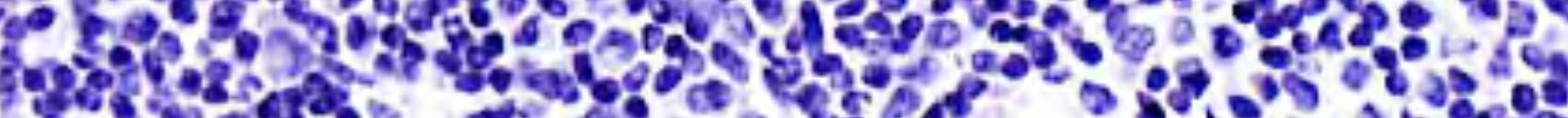

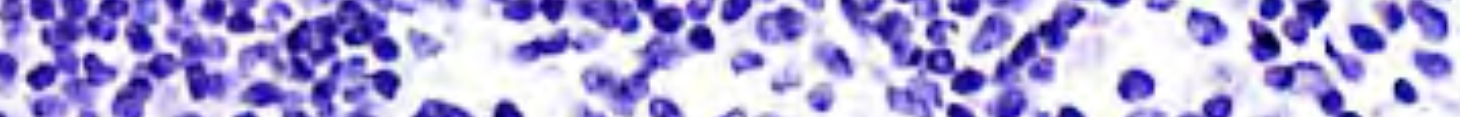

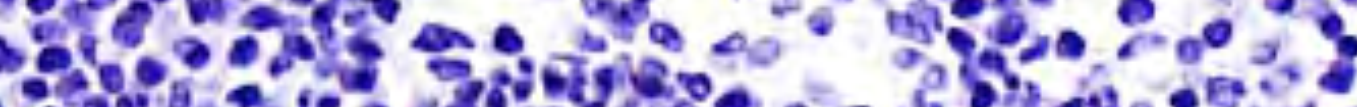

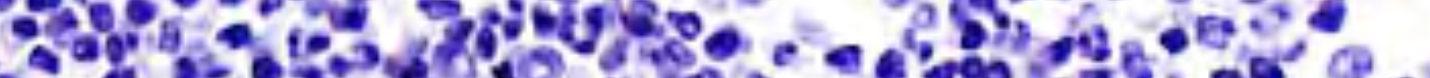

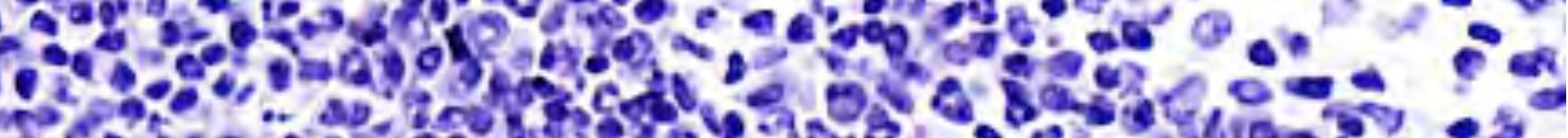

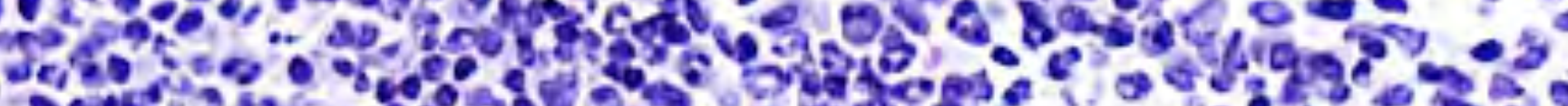

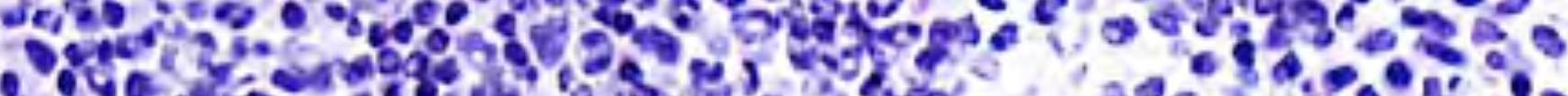

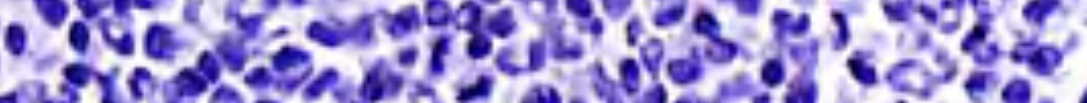

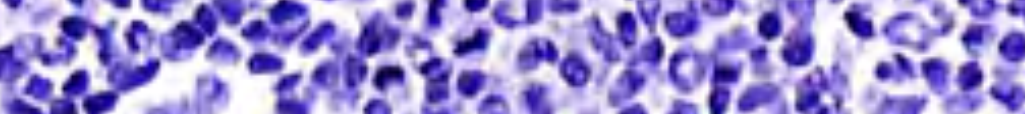

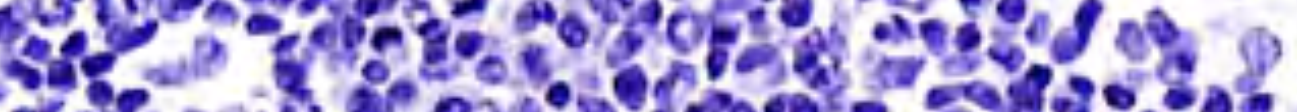

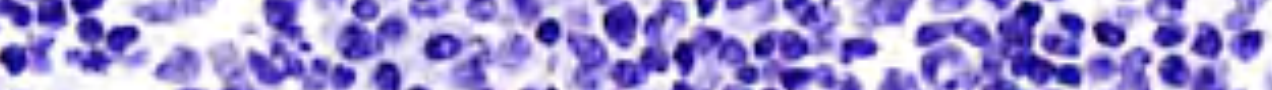

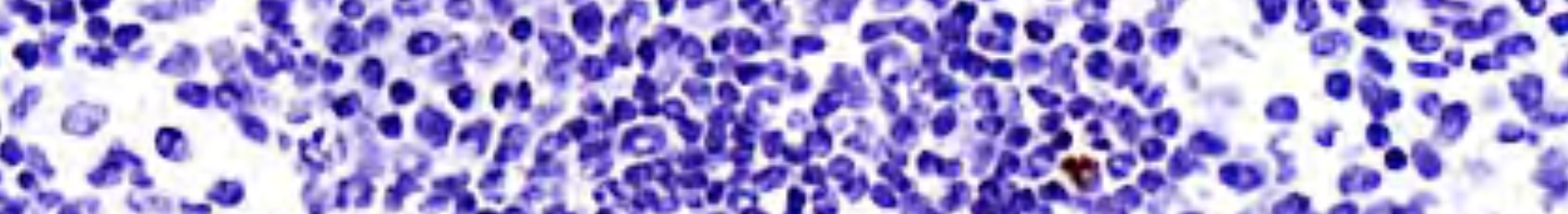

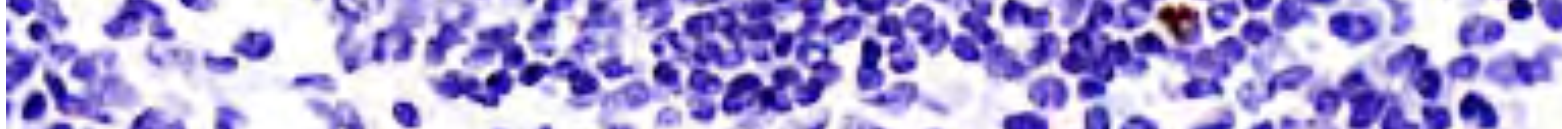

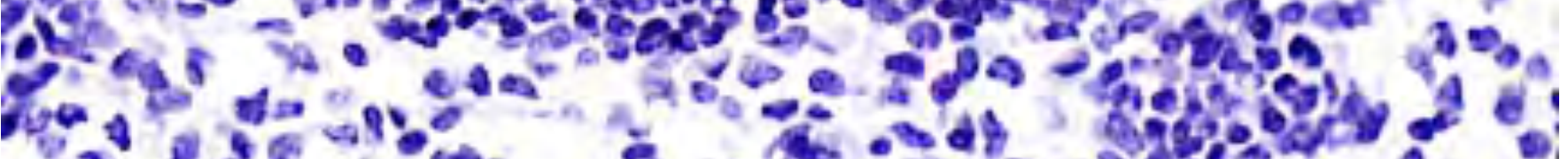

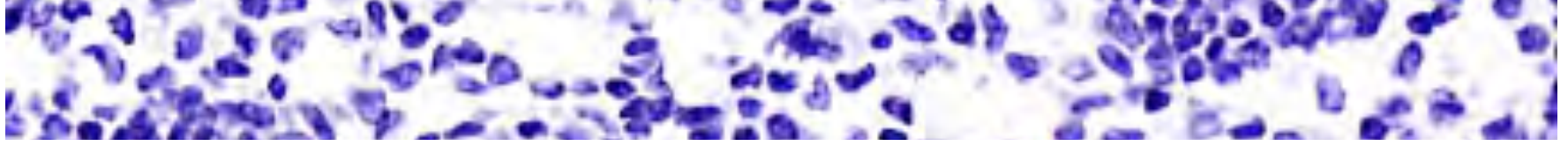


LM-TT/Granzyme B

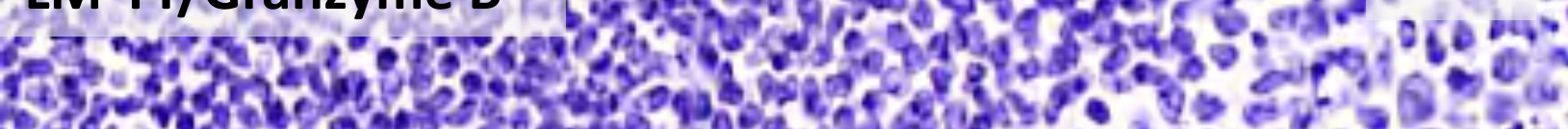

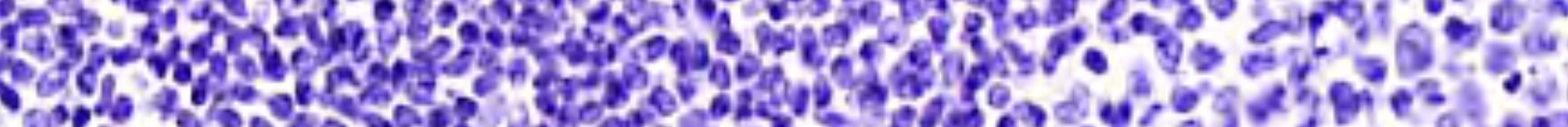

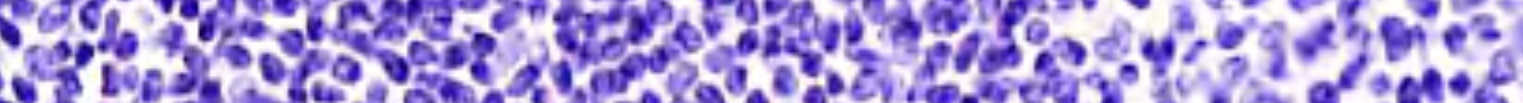

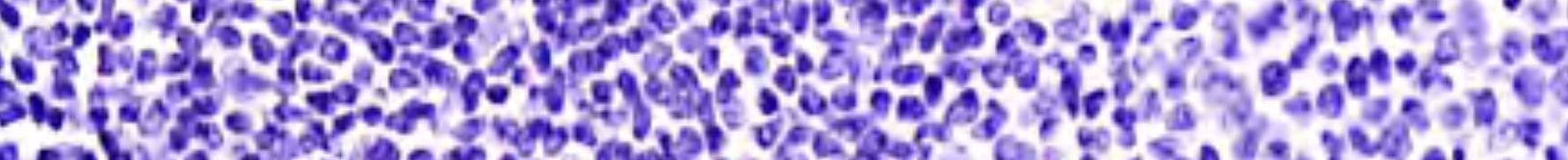
R.

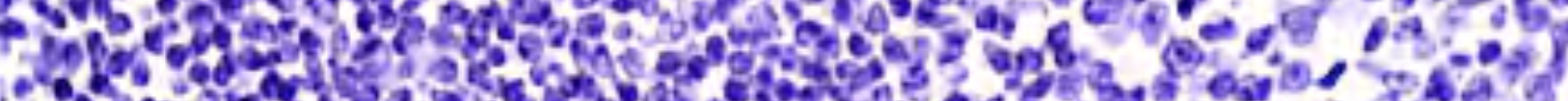

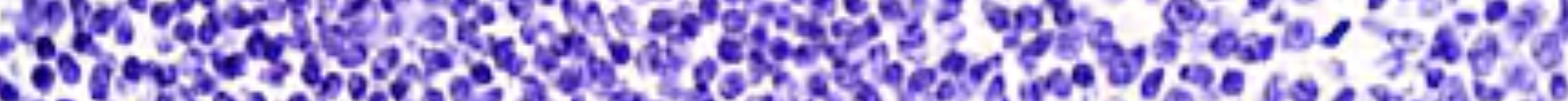
Hej -

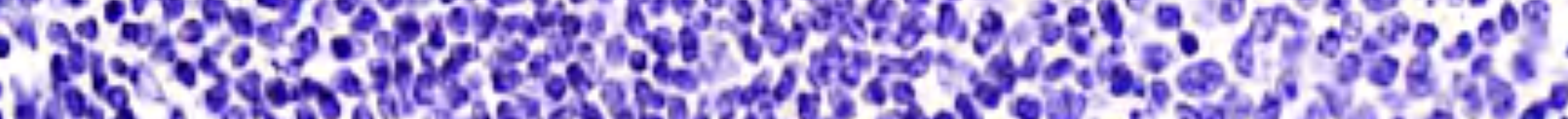

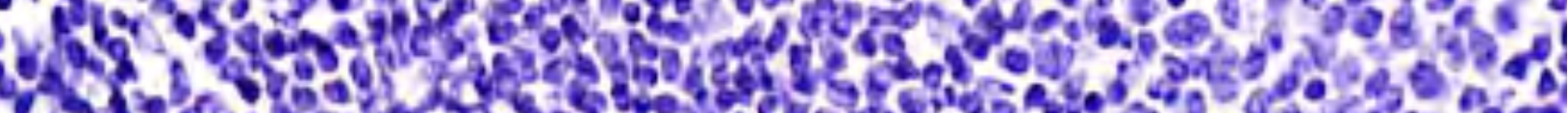
F.

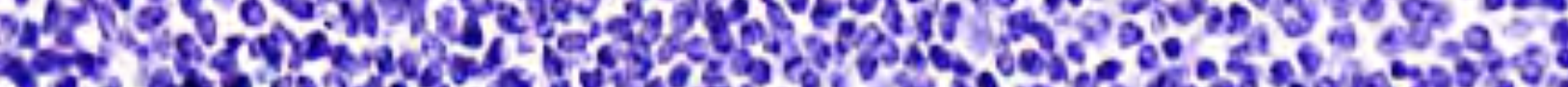

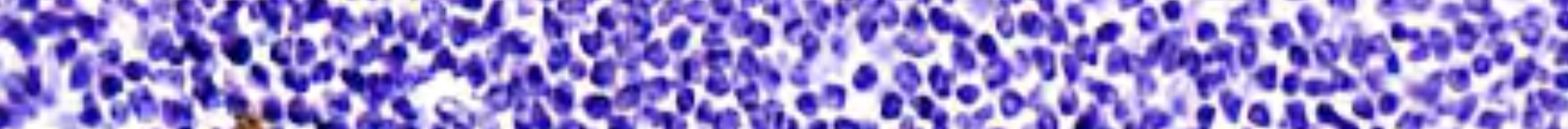

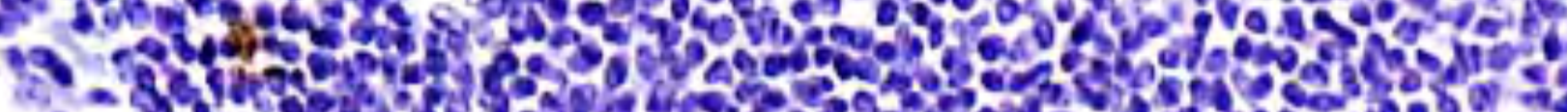

LM-TT+GEM/Granzyme B

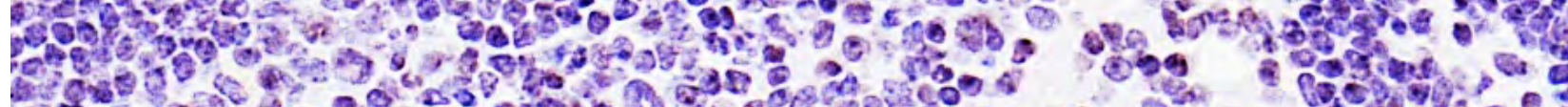

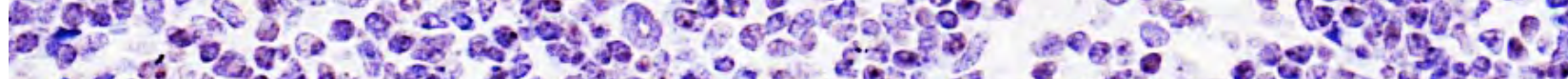

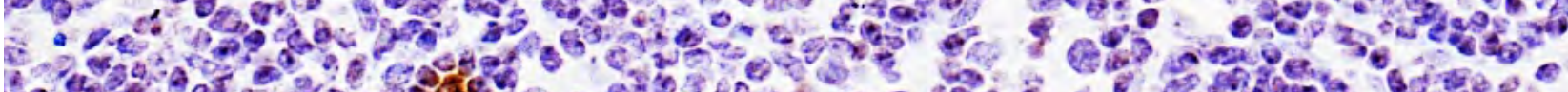

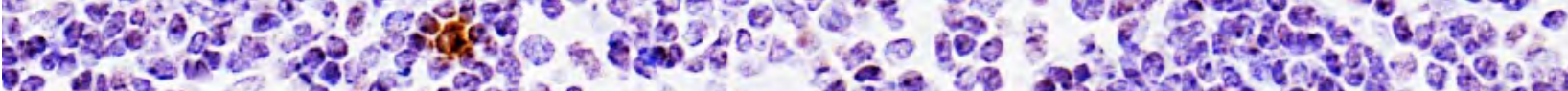

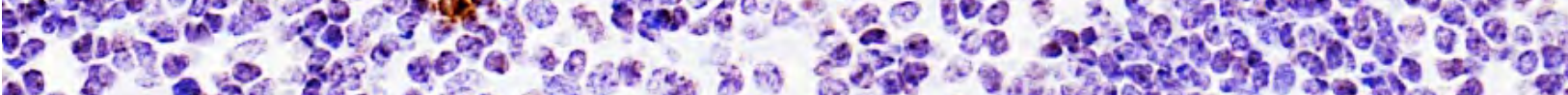

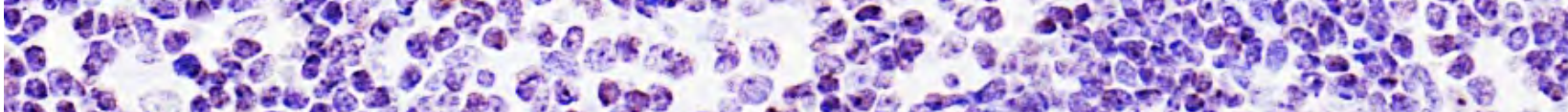

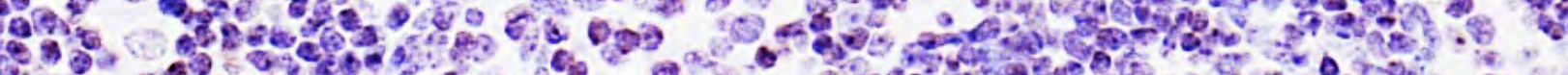

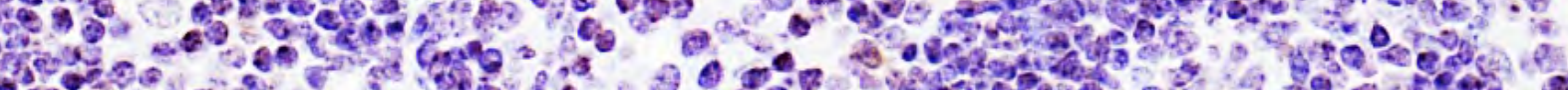

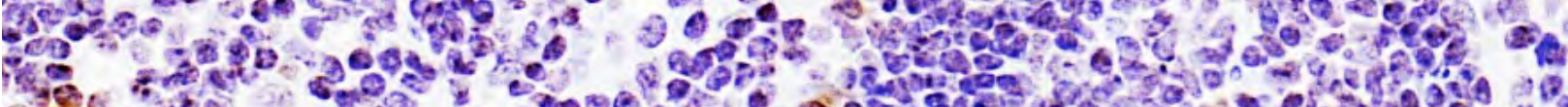

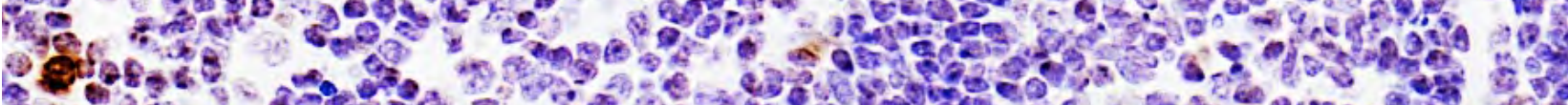

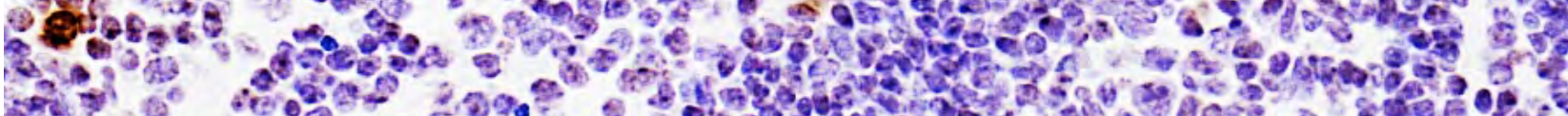

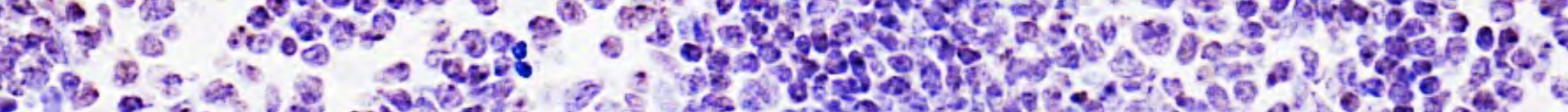

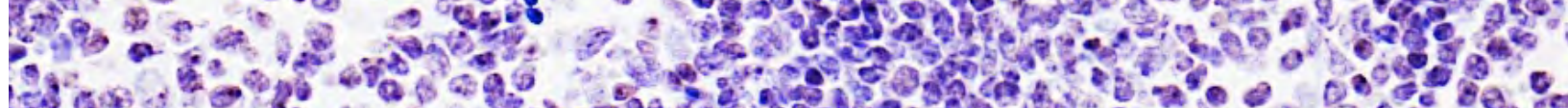

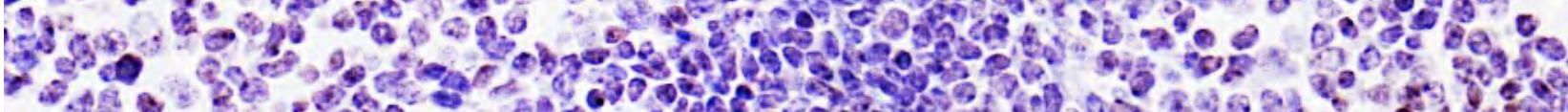

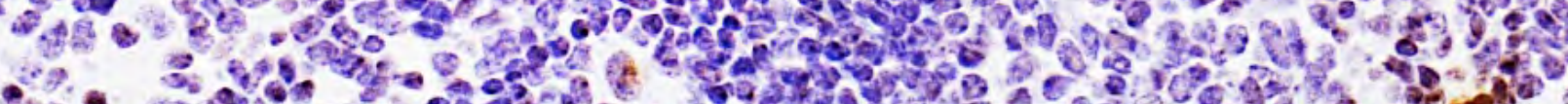

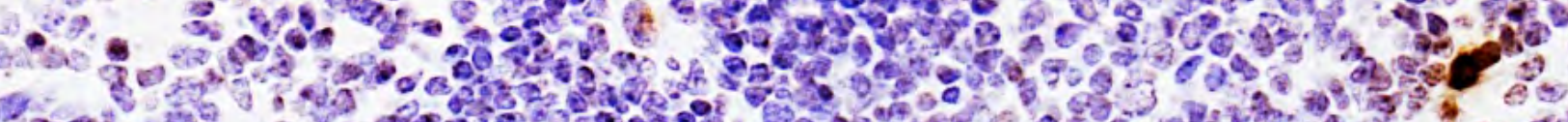

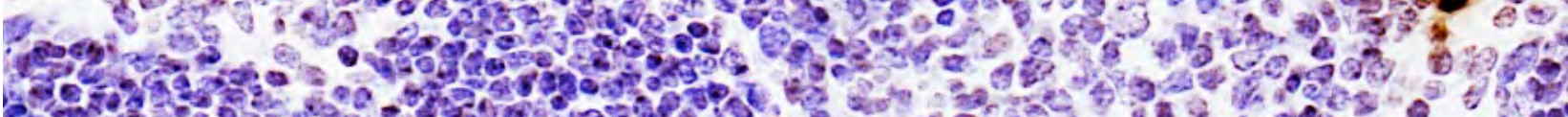

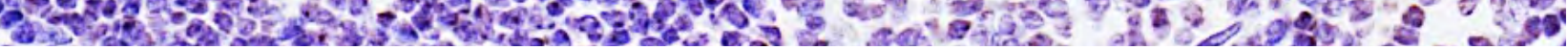


Saline/Perforin s. सम००

$\therefore$

19.8

S. Q

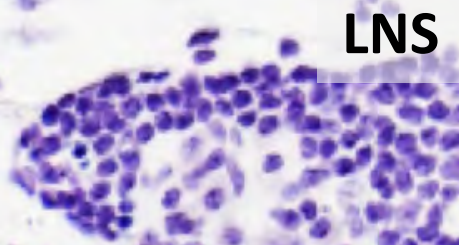

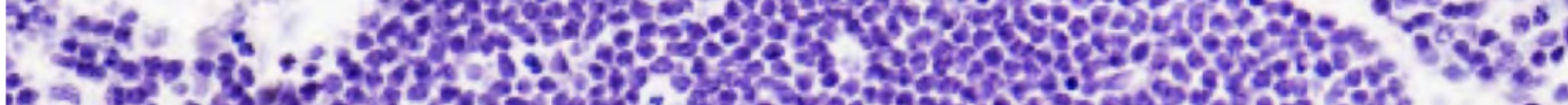

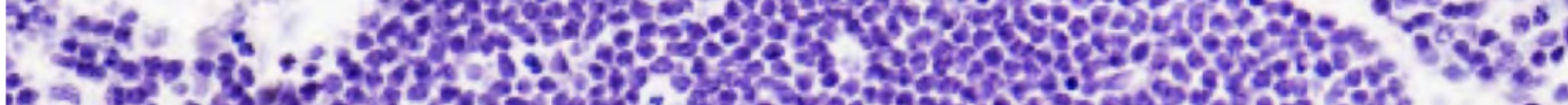

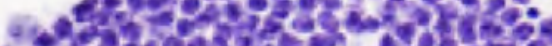

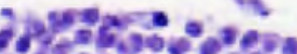

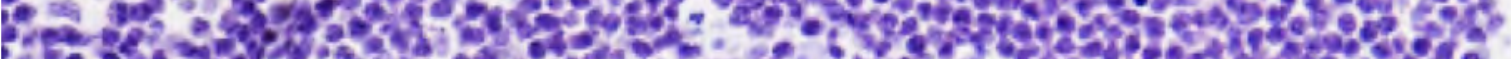
bage,

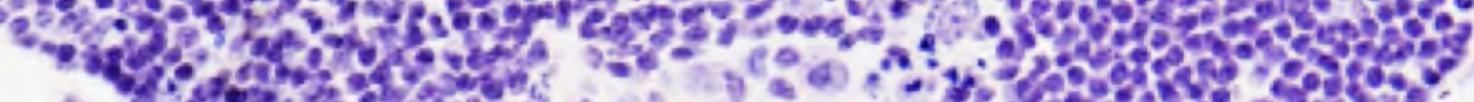

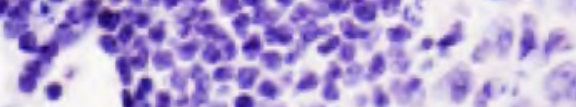

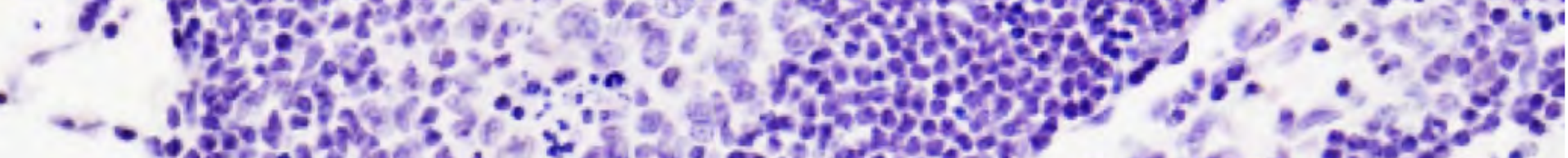

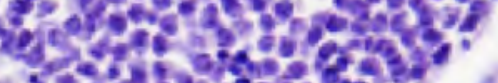

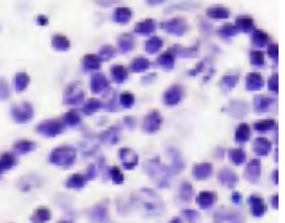
Q

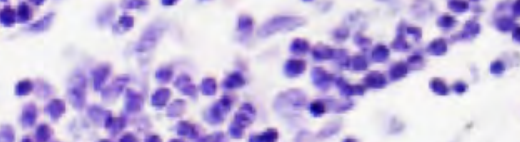

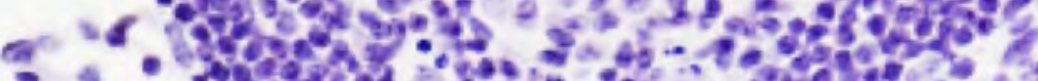

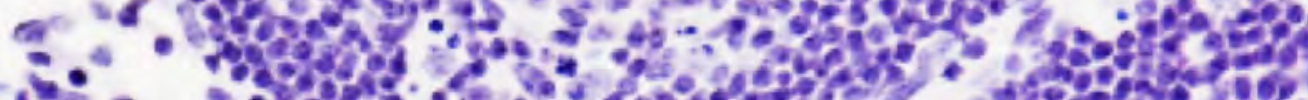

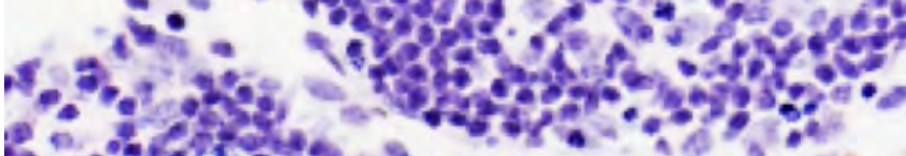

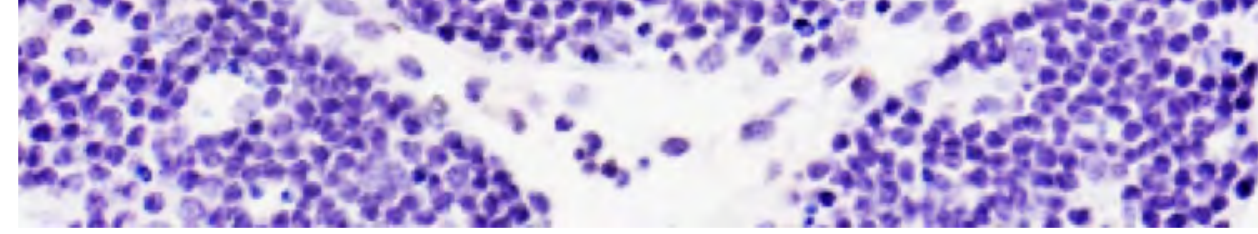

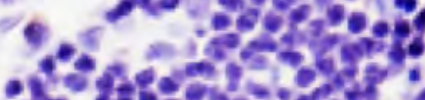 ingoting

(c)

T.8.8.

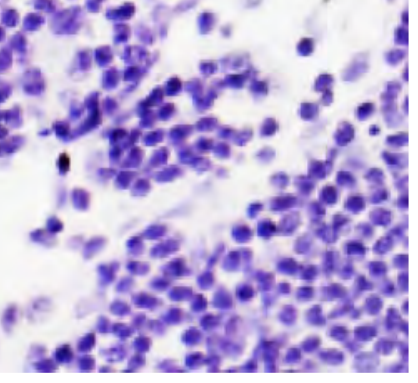

\section{- GEM/Perforin}

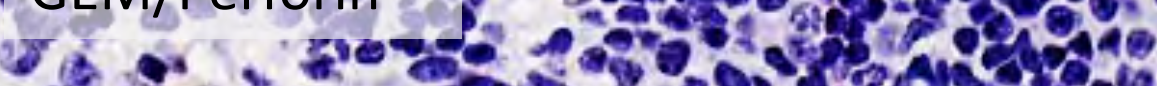

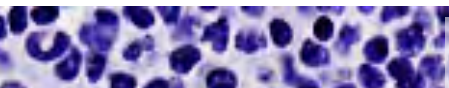

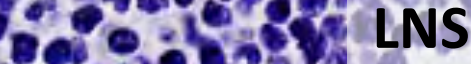

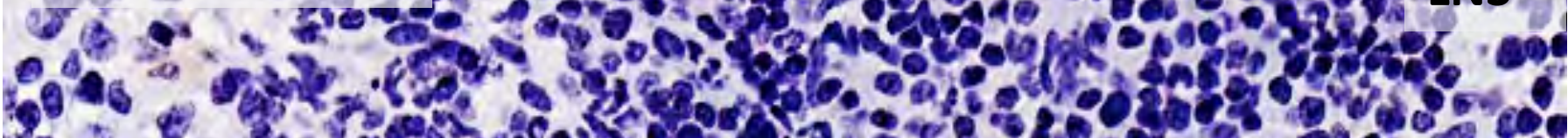

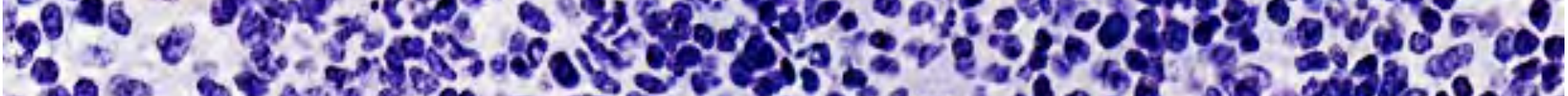

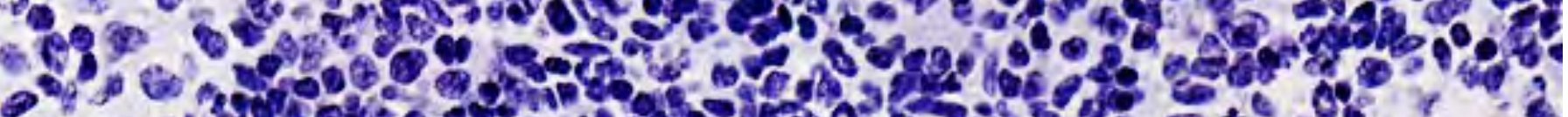

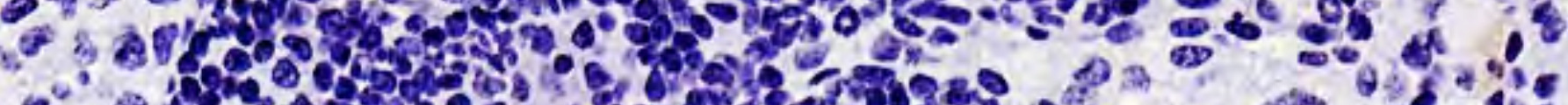

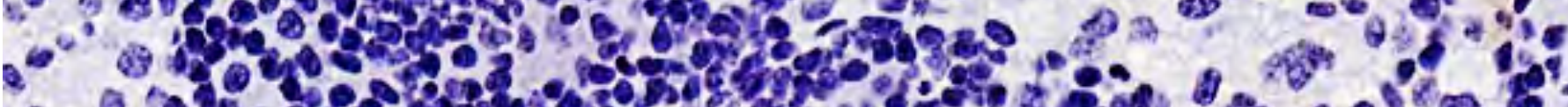

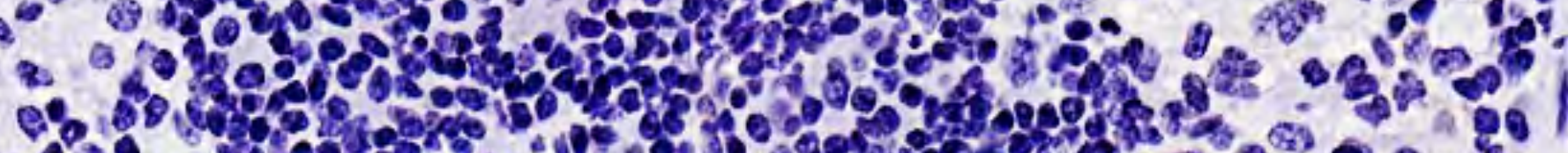

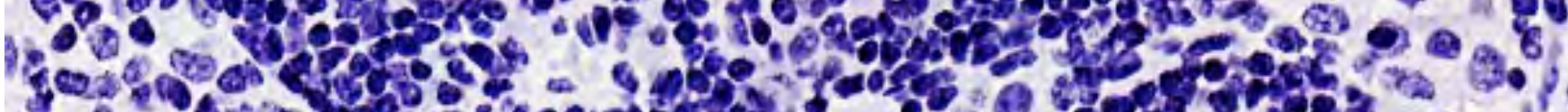

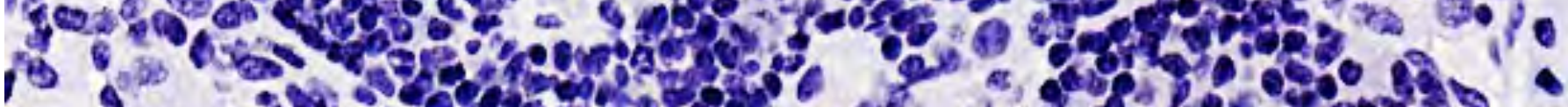

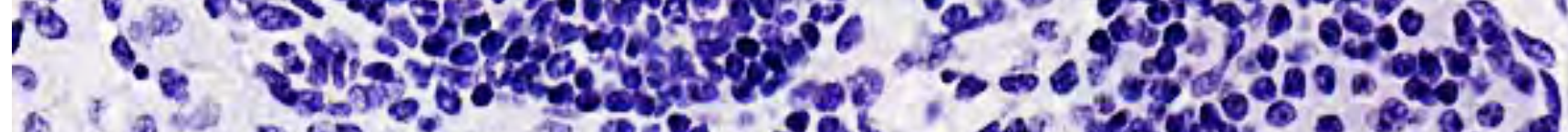

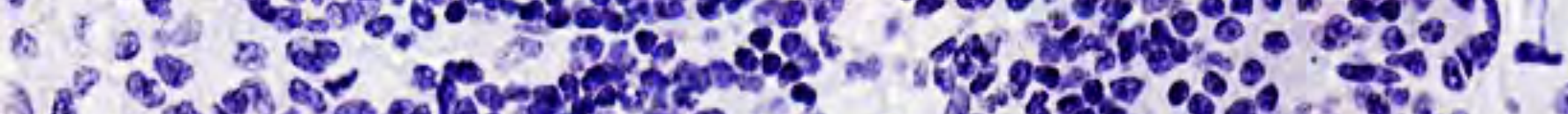

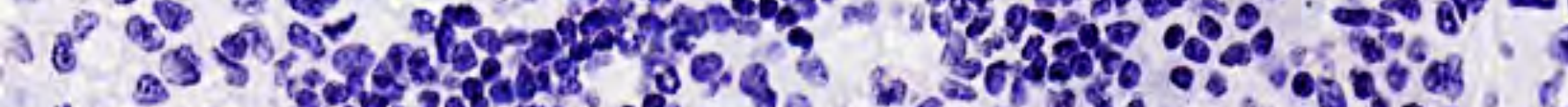

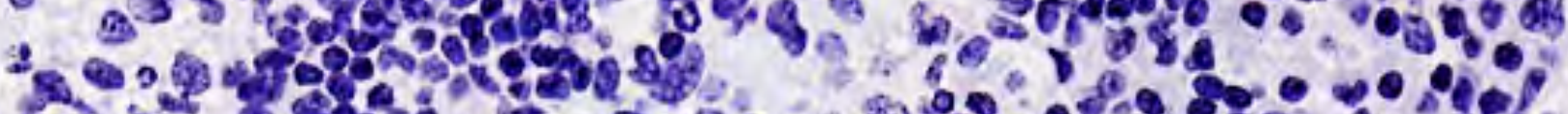

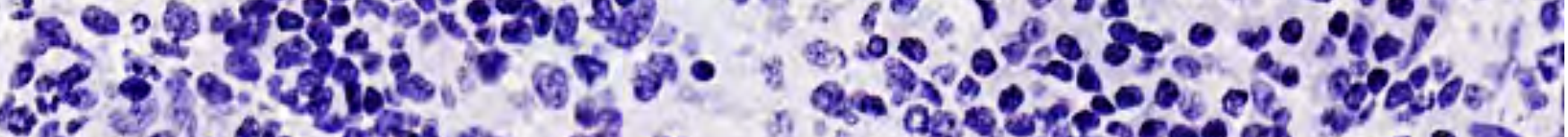

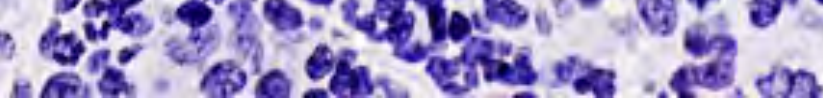

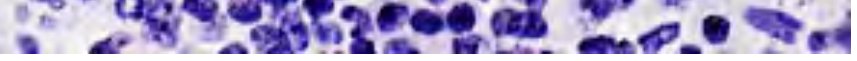




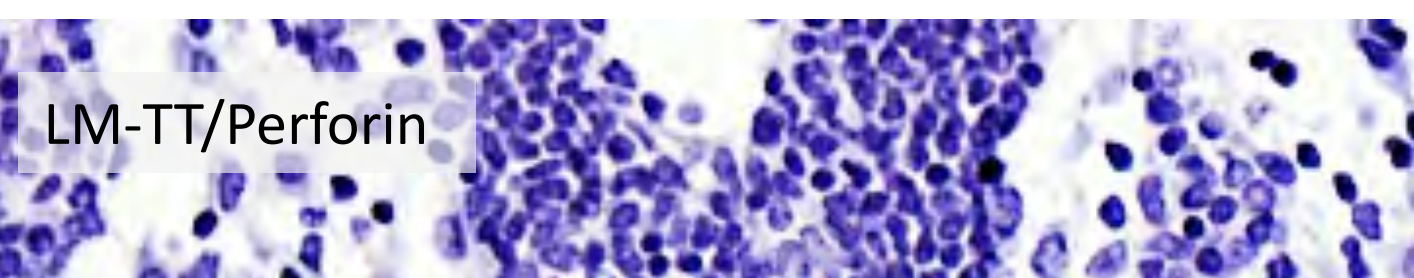

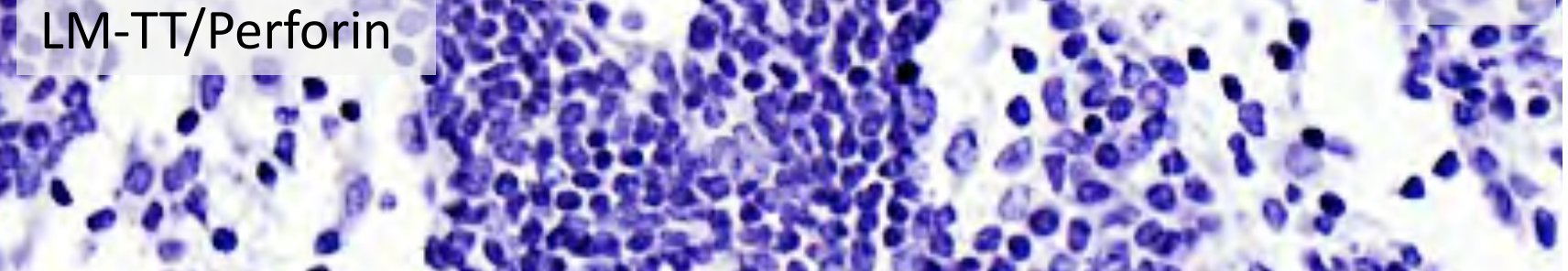

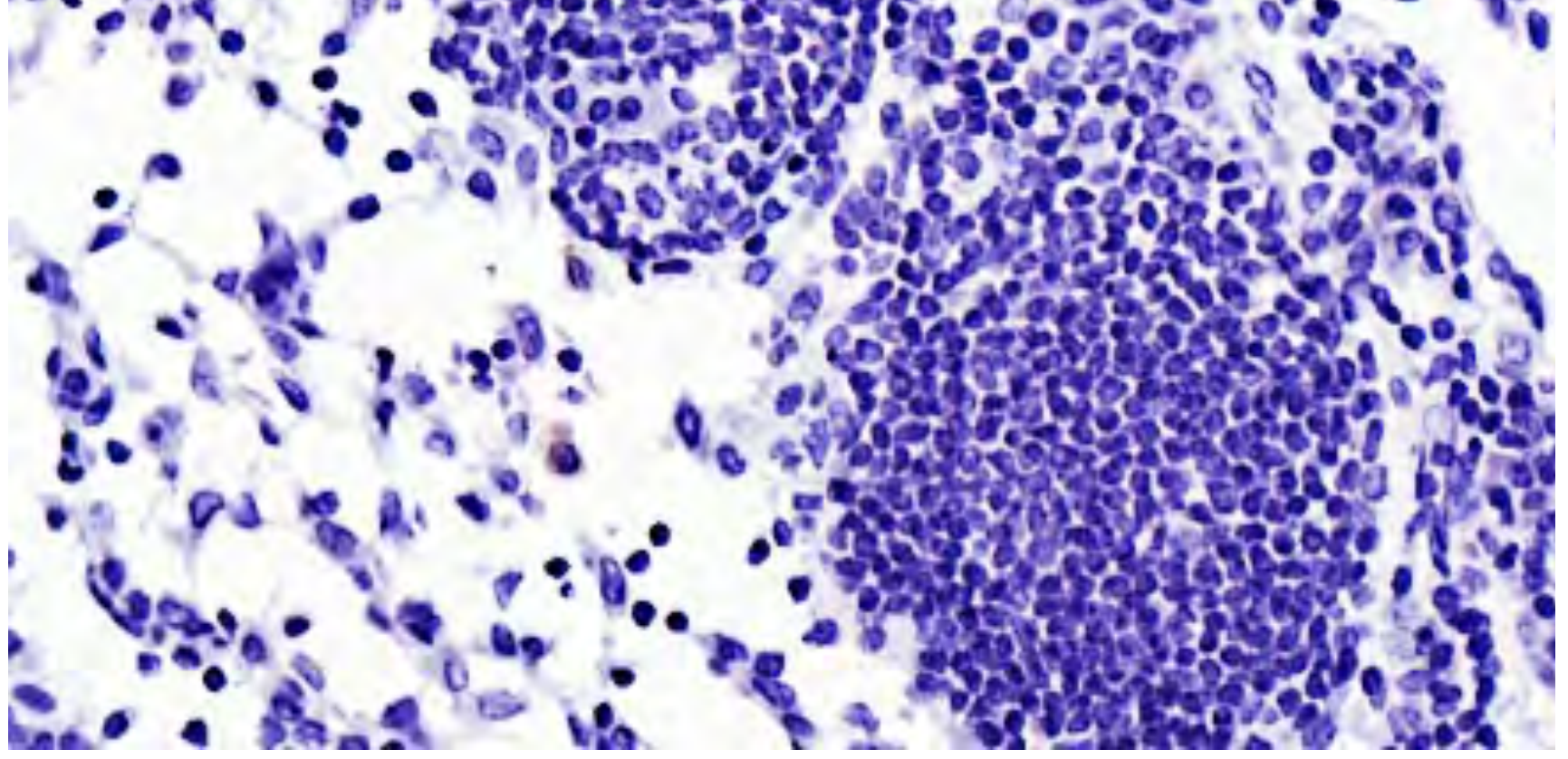

LM-TT+GEM/Perforin , "

LM-TT+GEM/Perforin

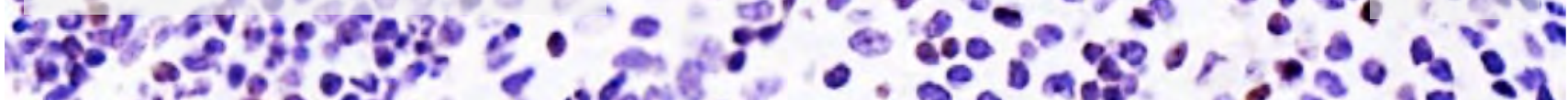
- b́

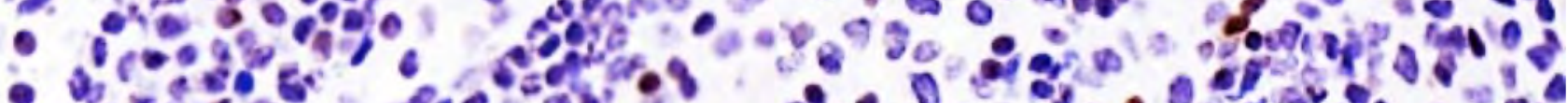

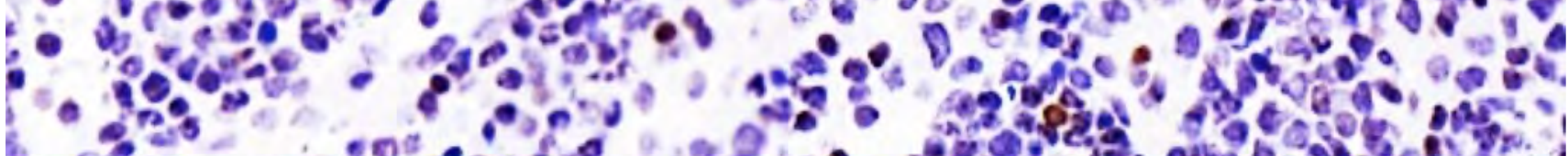

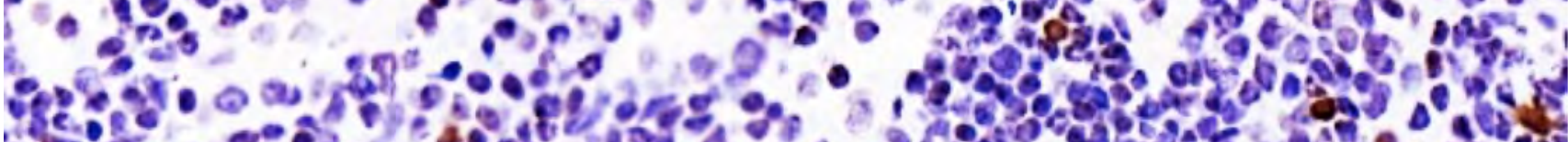

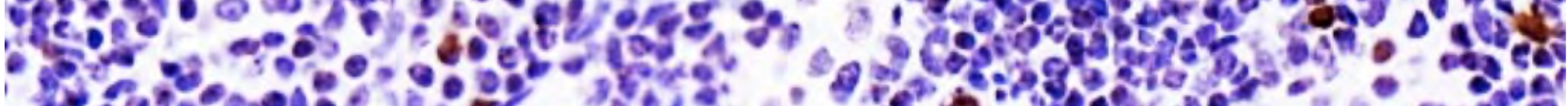

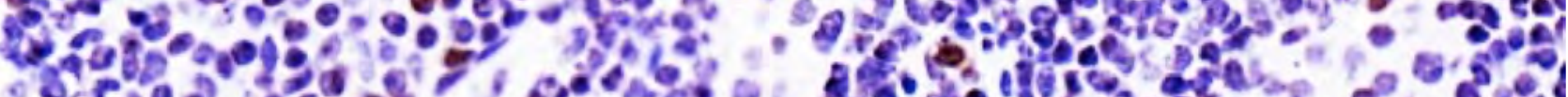

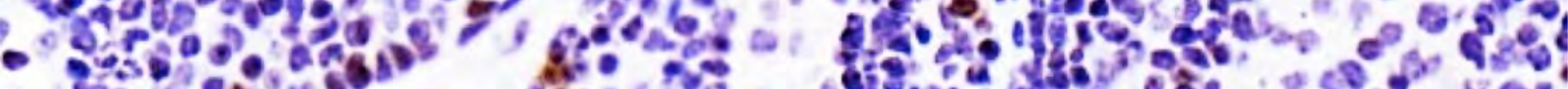

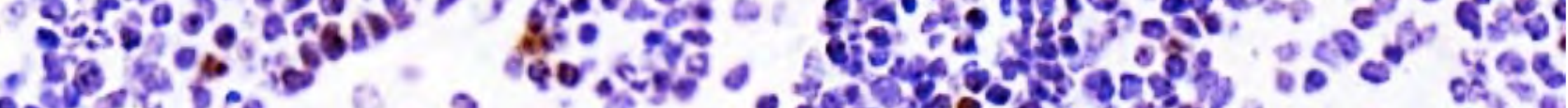

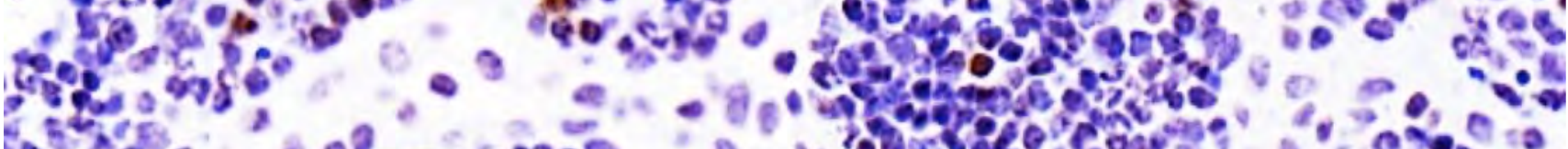

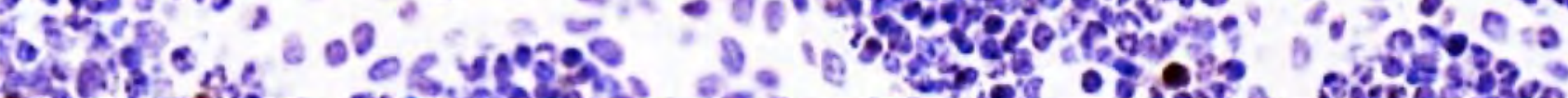

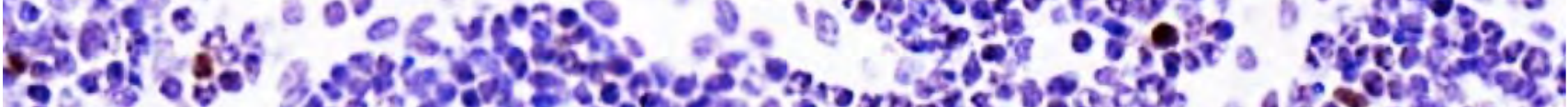

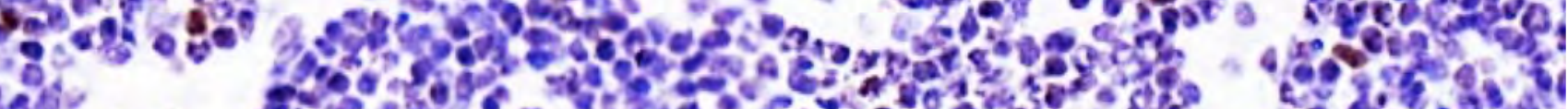

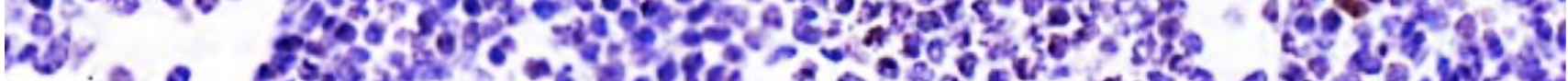

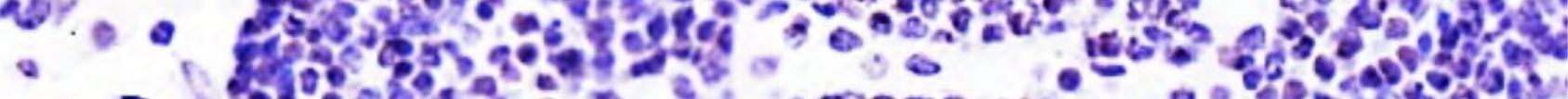

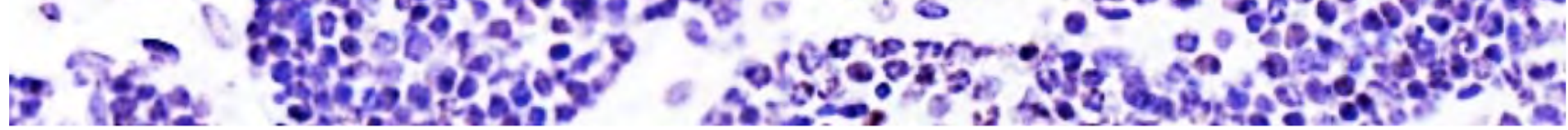




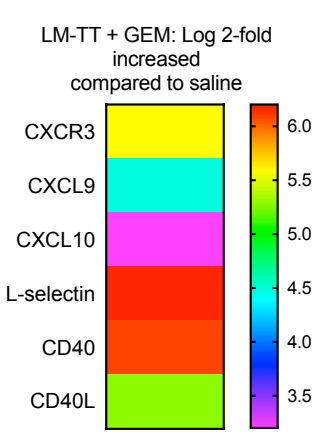

A

peritoneal model
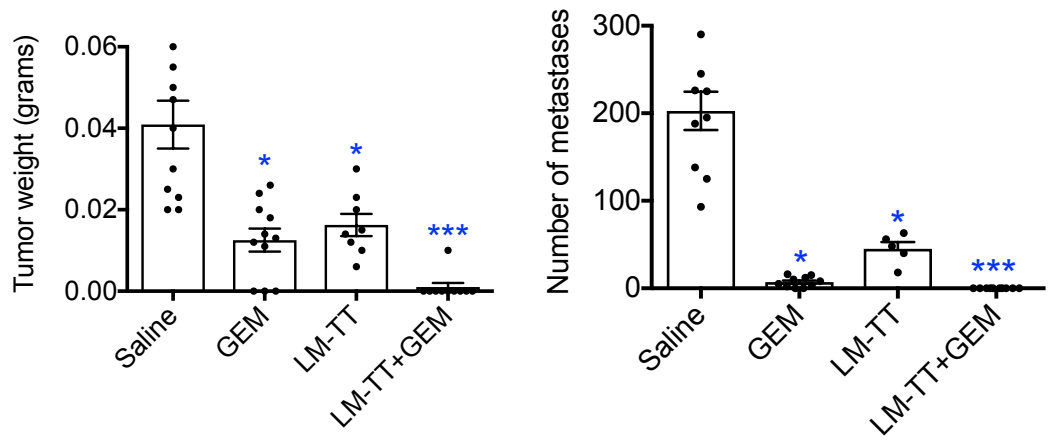

Advanced pancreatic cancer C peritoneal model

Advanced pancreatic cancer D orthotopic model
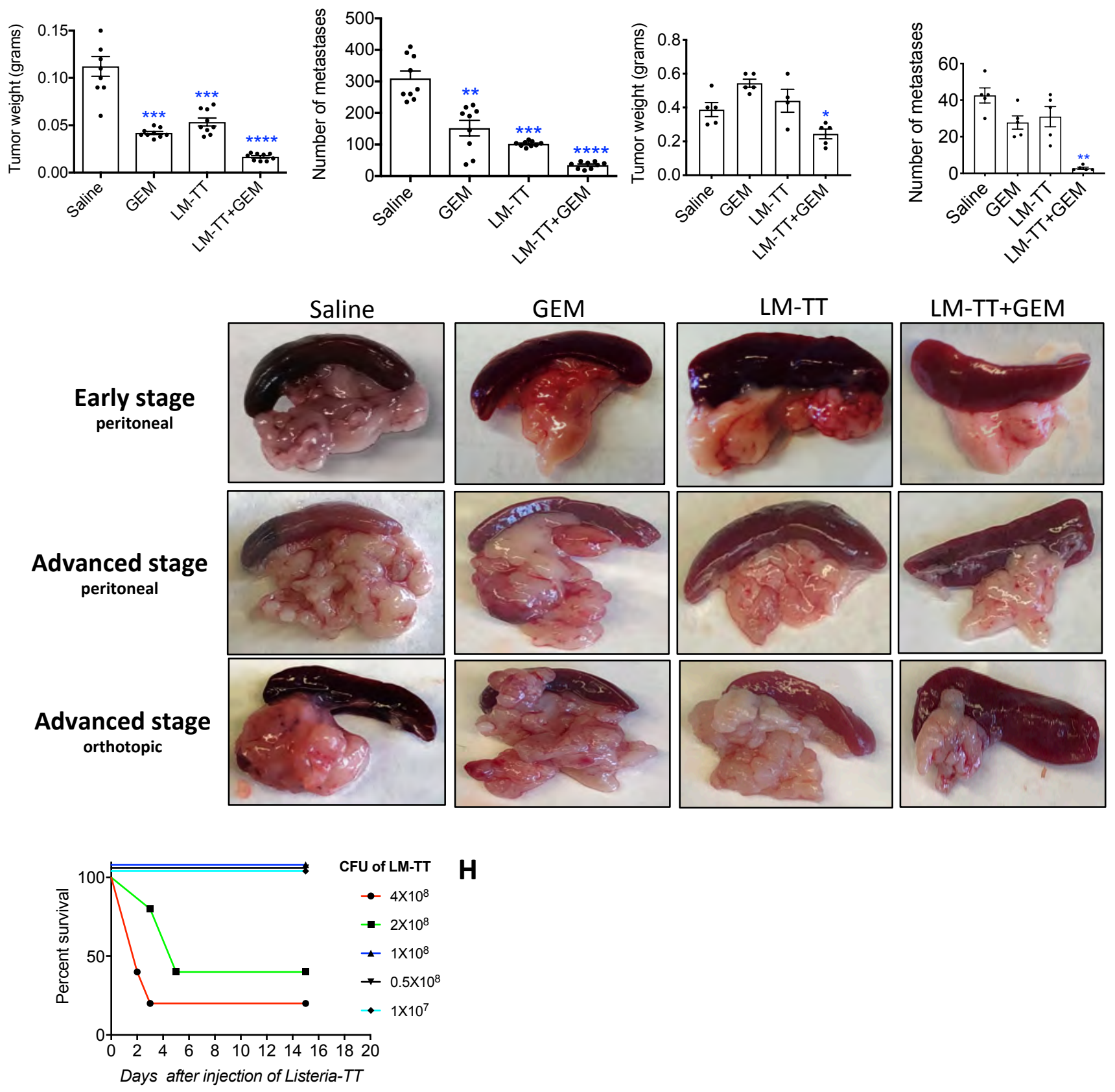

GEM
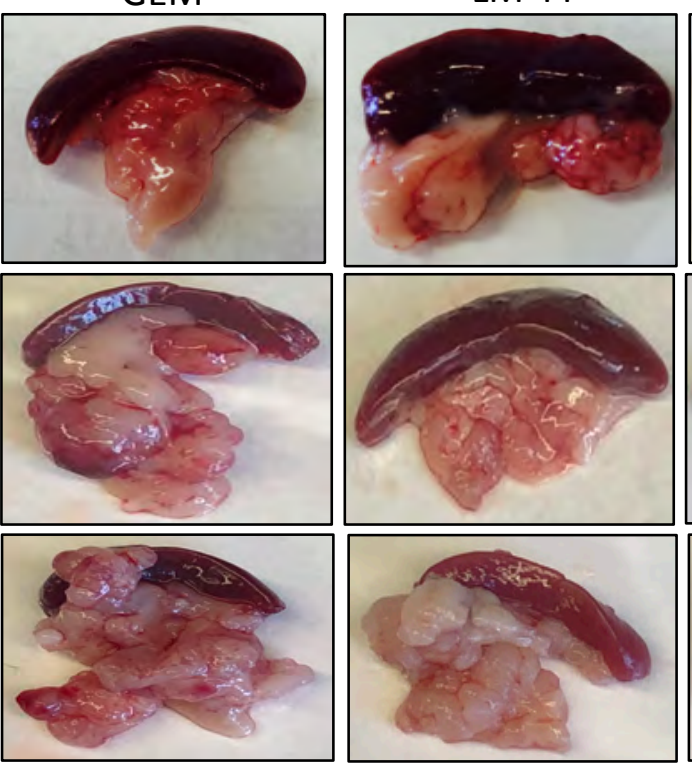

LM-TT+GEM
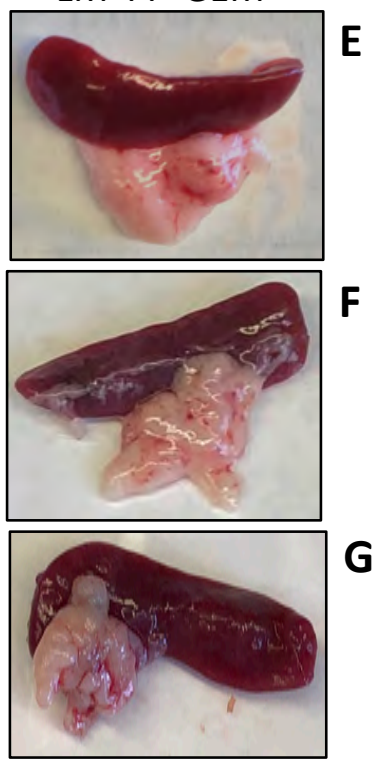
Table S1: Pathological examination of tissues in C57Bl/6 mice 2 days after the last treatment with Listeria-TT and Gemcitabine

\begin{tabular}{|c|c|c|c|c|c|c|}
\hline \multirow{2}{*}{$\begin{array}{l}\text { Treatment } \\
\text { Mouse }\end{array}$} & \multicolumn{3}{|c|}{ Saline } & \multicolumn{3}{|c|}{ Listeria-TT+Gem } \\
\hline & 1 & 2 & 3 & 1 & 2 & 3 \\
\hline \multicolumn{7}{|l|}{ Liver } \\
\hline $\begin{array}{l}\text { Random foci of mixed } \\
\text { leukocytes }\end{array}$ & 1 & 1 & 1 & 0 & 1 & 1 \\
\hline $\begin{array}{l}\text { Individual hepatocyte cell } \\
\text { death }\end{array}$ & 1 & 0 & 0 & 0 & 1 & 1 \\
\hline $\begin{array}{l}\text { Extramedullary } \\
\text { hematopoiesis }\end{array}$ & 0 & 0 & 0 & 0 & 0 & 1 \\
\hline $\begin{array}{l}\text { Hepatocellular } \\
\text { cytoplasmic vacuolation }\end{array}$ & 0 & 0 & 0 & 0 & 0 & 0 \\
\hline Foci of necrosis & 0 & 0 & 0 & 0 & 0 & 0 \\
\hline \multicolumn{7}{|l|}{ Kidney } \\
\hline Tubular ectasia, cortex & 0 & 0 & 0 & 0 & 0 & 0 \\
\hline Tubular ectasia, medulla & 0 & 0 & 0 & 0 & 0 & 1 \\
\hline $\begin{array}{l}\text { Tubular epithelial cell } \\
\text { cytoplasmic vacuolation, } \\
\text { cortex }\end{array}$ & 0 & 0 & 0 & 0 & 1 & 0 \\
\hline $\begin{array}{l}\text { Tubular epithelial cell } \\
\text { cytoplasmic vacuolation, } \\
\text { medulla }\end{array}$ & 0 & 0 & 0 & 0 & 0 & 0 \\
\hline $\begin{array}{l}\text { Regenerative tubules, } \\
\text { cortex }\end{array}$ & 0 & 0 & 0 & $1-2$ & $1-2$ & 0 \\
\hline $\begin{array}{l}\text { Regenerative tubules, } \\
\text { medulla }\end{array}$ & 0 & 0 & 0 & 0 & 0 & 0 \\
\hline $\begin{array}{l}\text { Tubular proteinosis, } \\
\text { cortex }\end{array}$ & 0 & 0 & 0 & 0 & 0 & 0 \\
\hline $\begin{array}{l}\text { Tubular proteinosis, } \\
\text { medulla }\end{array}$ & 0 & 0 & 0 & 0 & 0 & 1 \\
\hline \multicolumn{7}{|l|}{ Spleen } \\
\hline $\begin{array}{l}\text { Lymphoid hyperplasia, } \\
\text { white pulp }\end{array}$ & 2 & 2 & 2 & 0 & 0 & 0 \\
\hline $\begin{array}{l}\text { Extramedullary } \\
\text { hematopoiesis, red pulp }\end{array}$ & 0 & 2 & 2 & 3 & 3 & 3 \\
\hline \multicolumn{7}{|l|}{ Lung } \\
\hline $\begin{array}{l}\text { Increased mixed leukocytes, } \\
\text { alveolar septae }\end{array}$ & $2-3$ & $2-3$ & $2-3$ & $2-3$ & $2-3$ & $2-3$ \\
\hline $\begin{array}{l}\text { Perivascular/peribronchiolar } \\
\text { lymphocytic to } \\
\text { lymphohistiocytic infiltrates }\end{array}$ & 1 & 0 & 0 & $1-2$ & 0 & 0 \\
\hline
\end{tabular}

The samples were graded on a scale of 0-5; $0=$ no significant findings, $1=$ minimal finding, 2=mild finding, 3=moderate finding, 4=marked finding, 5=severe finding. C57BI/6 mice were treated with Listeria-TT and GEM or Saline as described in Fig. 1B of the manuscript. Two days after the last treatment mice were euthanized and analyzed for potential side effects by a Histopathological board-certified veterinary pathologist. In each group 3 mice were analyzed. 
Table S2: The effect of Listeria-TT and Gemcitabine on liver functions in $\mathrm{C} 57 \mathrm{BI} / 6$ mice

\begin{tabular}{lll}
\hline Treatment & AST (U/L) & ALT (U/L) \\
Saline & 107 & 16 \\
Listeria-TT and GEM & 137 & 15 \\
Normal values & $50-100$ & $25-60$ \\
\hline
\end{tabular}

C57BI/6 mice were treated with Listeria-TT and GEM or Saline as described in Fig. 1B of the manuscript. Two days after the last treatment mice were euthanized and analyzed for liver functions such as aspartate aminotransferase (AST) and alanine aminotransferase (ALT). In each group 3 mice were analyzed. The plasma samples were pooled in each group. 


\section{ADDITIONAL SUPPLEMENTARY INFORMATION}

\section{Software used for data collection}

1. BD CellQuest ${ }^{\mathrm{TM}}$ Pro software (BD Bioscience, version 6.1) was used to collect the flow cytometry data.

2. Panoramic Scanner software (3D Histech, version) was used to scan the IHC slides.

3. AID ELISPOT reader software (AID Autoimmun Diagnostika $\mathrm{GmbH}$, version 3.2.3) was used to scan ELISPOT plates.

4. Image lab software (Bio-Rad, version 5.2.1) was used to acquire western blot images.

5. BD FACSDiva software (BD Bioscience, version 8.0.1) was used to collect the flow cytometry data.

6. Inveon Application Workstation software (Siemens Medical Solutions, Version 2.1.272) was used to collect MicroPET data.

\section{Software used for data analysis}

1. Flowjo software (Becton Dickinson \& Company, version 10.6.1) was used to analyze flow cytometry data.

2. Flowjo software (Tree Star, Inc, version 8.7) was used to analyze flow cytometry data

3. GraphPad Prism software (GraphPad software Inc, version 8.2.0) was for statistical analysis and data presentation.

4. CaseViewer software (3DHISTECH Ltd, version 2.3.0.99276) was used to view and data presentation of IHC images.

5. Inveon Research WorkStation (Siemens Molecular Imaging, Version 4.2) was used to analyze MicroPET data.

\section{Antibodies used}

\begin{tabular}{|c|c|c|c|}
\hline Antibody & Manufacturer & Catalog \# & Dilution \\
\hline Myc-Tag & Cell Signaling Technology & 2272 & $1: 1000$ \\
\hline Clostridium tetani Tetanus toxin & Invitrogen & PA1-73168 & $1: 50$ \\
\hline $\begin{array}{l}\text { BD Difco }{ }^{\mathrm{TM}} \text { Listeria O Antiserum } \\
\text { poly serotype } 1,4\end{array}$ & BD Bioscience & 223021 & $1: 100$ \\
\hline CD4 & Cell Signaling Technology & 25229 & $1: 200$ \\
\hline CD8 & Cell Signaling Technology & 98941 & $1: 400$ \\
\hline CD31 & Cell Signaling Technology & 77699 & $1: 100$ \\
\hline
\end{tabular}




\begin{tabular}{|l|l|l|l|}
\hline Perforin & Cell Signaling Technology & 31647 & $1: 200$ \\
\hline Granzyme B & Cell Signaling Technology & 44153 & $1: 50$ \\
\hline CD45; color: FITC & BD Bioscience & 553080 & $1: 50$ \\
\hline CD3; color: PerCP-Cy5.5 & BD Bioscience & 560527 & $1: 50$ \\
\hline CD4; color: APC-Cy7 & BD Bioscience & 552051 & $1: 50$ \\
\hline CD8; color: PE-Cy7 & BD Bioscience & 552877 & $1: 50$ \\
\hline IFN- Y; color: FITC & BD Bioscience & 554411 & $1: 50$ \\
\hline CD44; color: BV421 & BD Bioscience & 563970 & $1: 50$ \\
\hline CD62L; color: PE-CF594 & BD Bioscience & 562404 & $1: 50$ \\
\hline CD69; color: AF700 & BD Bioscience & 561238 & $1: 50$ \\
\hline Perforin; color: APC & eBioscience & $17-9392-80$ & $1: 50$ \\
\hline Granzyme B; color: PE & eBioscience & $12-8898-82$ & $1: 50$ \\
\hline IL-10; color: APC & BD Bioscience & 554468 & $1: 50$ \\
\hline IL-6; color: FITC & eBioscience & $11-7061-41$ & $1: 50$ \\
\hline TNF- $\alpha ;$ color: PE-Cy7 & BioLegend & 506324 & $1: 50$ \\
\hline MARCO; color: PE & R\&D systems & FAB2956P & $1: 50$ \\
\hline CD11b; color: APC & BD Bioscience & 553312 & $1: 50$ \\
\hline Ly-6C; color: FITC & BD Bioscience & 553127 & $1: 50$ \\
\hline F4/80; color: APC & eBioscience & $17-4801-82$ & $1: 50$ \\
\hline Listeriolysin o (LLO) & Diatheva & REP0007 & $1: 1000$ \\
\hline
\end{tabular}

\section{Cell lines used}

1. Panc-02 (provided by Dr. Chandan Guha, Albert Einstein College of Medicine)

2. 4T1 (provided by Dr. Fred Miller, Karmanos Cancer Institute, Wayne state University)

\section{Laboratory animals}

1. C57BL/6 (Charles River)

2. BALB/c (Charles River)

3. KPC mice (LSL-p53R172/+; LSLKrasG12D; Pdx1-Cre)(maintained at Einstein)

a. MacBlue [C57BI/6N--Tg(Cfms--gal4--vp16)--(UAS--eCFP)] (maintained at Einstein)

All mice were housed in the animal husbandry facility at Albert Einstein College of Medicine according to the Association and Accreditation of Laboratory Animal Care guidelines, and kept under BSL-2 conditions as required for Listeria treatments. 